\title{
Role of the CtrA cell cycle regulator in the bloodborne bacterial pathogen, Bartonella quintana.
}

\section{Robert Haydn Thomson.}

A thesis submitted to the Victoria University of Wellington in fulfilment for the degree of Master of Science in Molecular Microbiology.

Victoria University of Wellington.

2018. 



\section{Abstract.}

Bartonella quintana is an important re-emerging human pathogen and the causative agent of trench fever. It utilizes a stealth invasion strategy to infect hosts and is transmitted by lice. Throughout infection it is crucial for the bacteria to maintain a tight regulation of cell division, to prevent immune detection and allow for transmission to new hosts.

CtrA is an essential master cell cycle regulatory protein found in the alpha-proteobacteria. It regulates many genes, ensuring the appropriate timing of gene expression and DNA replication. In the model organism Caulobacter crescentus, it regulates $26 \%$ of cell cycle-regulated genes. CtrA has been reported to bind two specific DNA motifs in gene promoter regions, TTAAN 7 TTAAC, and TTAACCAT. Genes regulated by CtrA encode proteins with a wide range of activities, including initiation of DNA replication, cell division, DNA methylation, polar morphogenesis, flagellar biosynthesis, and cell wall metabolism. However, the role of the CtrA homologue in Bartonella spp. has not been investigated.

In this project we aimed to make an initial characterisation of the master cell cycle regulator CtrA. This was done by identifying gene regulatory regions containing putative CtrA binding sites and testing for direct interactions via a $\beta$-galactosidase assay. It was found B. quintana CtrA shared 81 $\%$ amino acid identity with its $C$. crescentus homologue. Within the genome of B. quintana str. Toulouse we discovered 21 genes containing putative CtrA binding sites in their regulatory regions. Of these genes we demonstrated interactions between CtrA and the promoter region of $f t s E$ a cell division gene ${ }^{[1]}$, hemS, and $h b p C$, two heme regulatory genes. We also found no evidence of CtrA regulating its own expression, which was unexpected because CtrA autoregulation has been demonstrated in C. crescentus. 


\section{Acknowledgements.}

To begin I would like to thank my supervisor Dr. Joanna Mackichan. You have been such a fantastic mentor over the last two years and completing this project would not have been possible without your everlasting enthusiasm and patience. I have learnt so much and you have been a real inspiration to me. Throughout my time here you have gone beyond what was expected in helping me, and for this I am extraordinarily thankful.

Next, I have to thank everyone in the Mackichan lab group and the AM offices. During work on my masters everyone in the office provided an exceedingly friendly and welcoming environment which made my time here so enjoyable. Also thank you to the Ackerley lab group and Alistair for your expert advice and crash course in protein expression. To my lab mates Callum, and Alvey your constant positivity and advice through good times and bad was really appreciated. I'd like to give Alvey special thanks for suffering through checking my many terrible drafts, I'm sure your lifespan has become considerably shorter because of it. To my fantastic friends, thank you for being there when I needed you, and a special thanks to Maddie and Caiti for help with proof reading this thesis.

Finally, and most importantly I would like to thank my family. Without your constant support and encouragement during this project none of this would have been possible, it means a lot to me. 


\section{Table of Contents.}

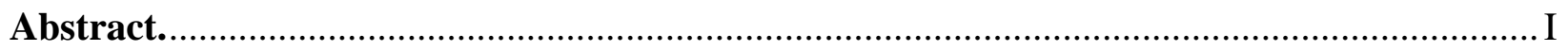

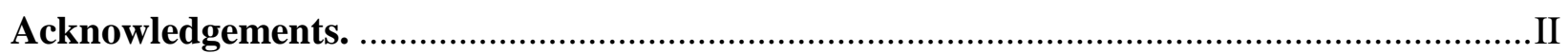

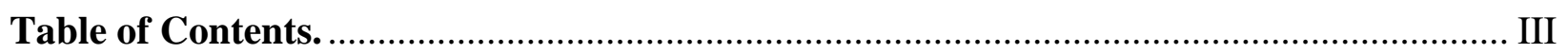

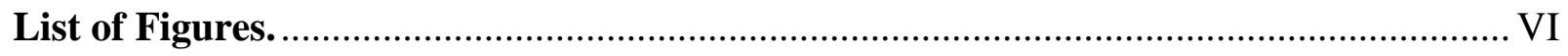

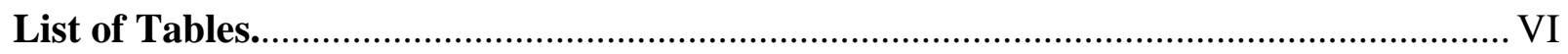

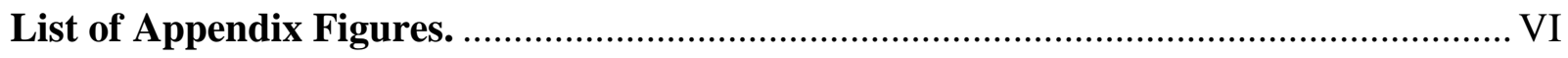

Abbreviations. ............................................................................................................. VIII

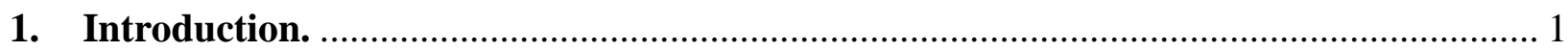

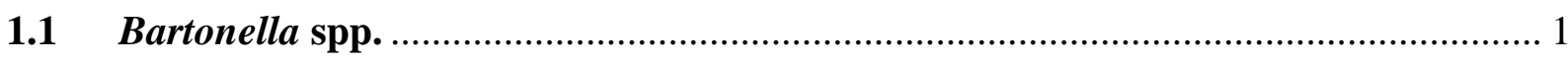

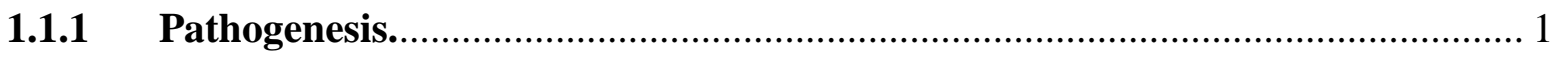

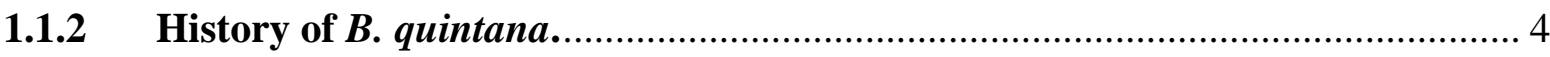

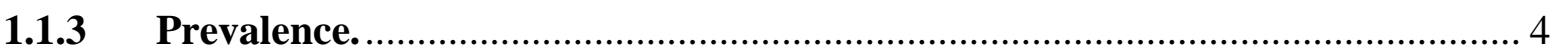

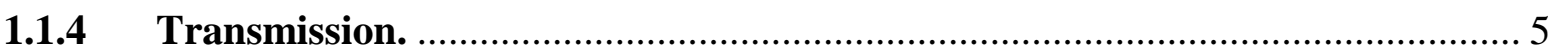

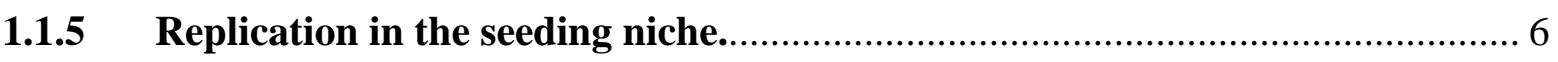

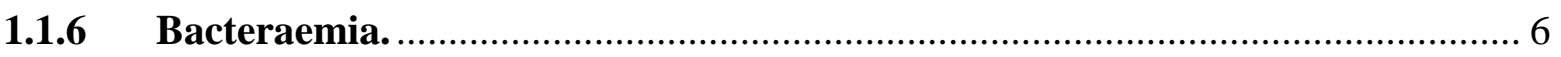

1.1.7 Environmental stresses................................................................... 7

1.2 Bacterial Cell Cycle Control.......................................................................... 8

1.2.1 Cell Cycle Regulation in Alpha-Proteobacteria............................................. 8

1.2.2 CtrA

1.2.3 CtrA Activation and Regulation................................................................ 9

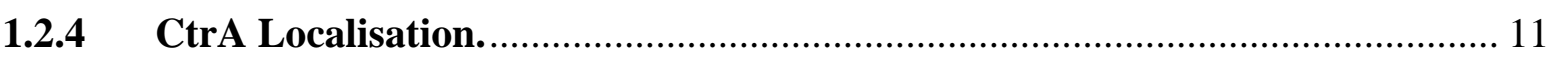

1.2.5 Multiple Cell Cycle Regulators coordinate the $\boldsymbol{C}$. crescentus cell cycle.......... 12

1.2.6 CtrA, DnaA, and GcrA Coordinate an Oscillating Cell Cycle. ...................... 14

1.2.7 CtrA in other alpha-proteobacteria. ........................................................ 15

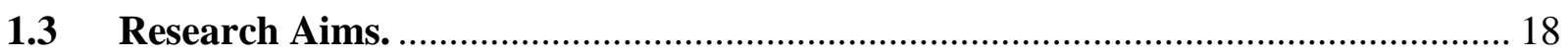

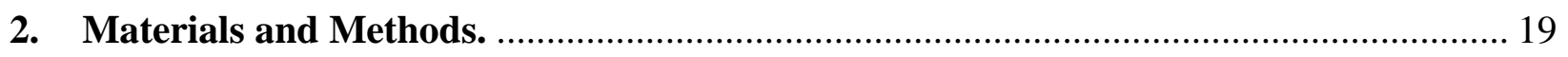

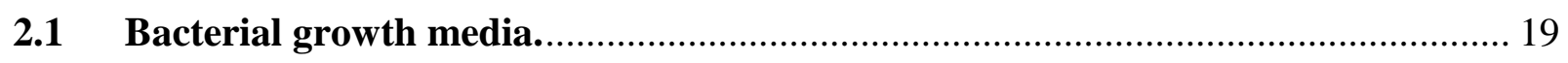

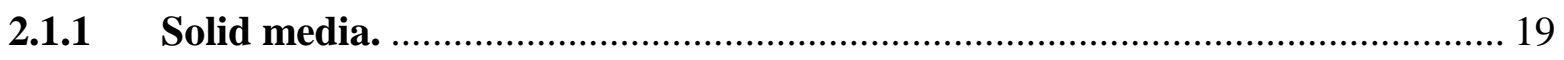

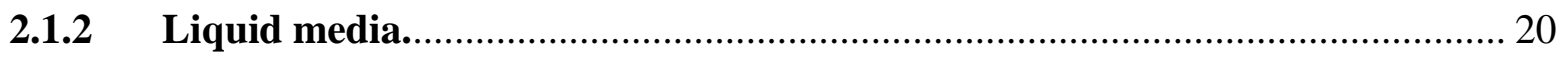

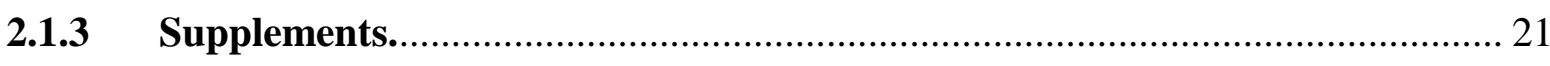

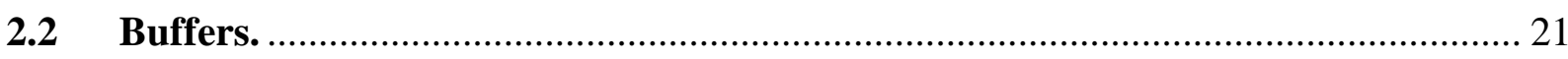

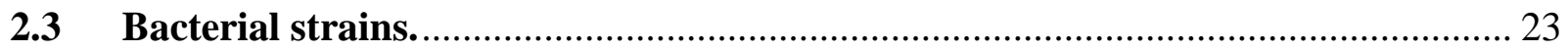




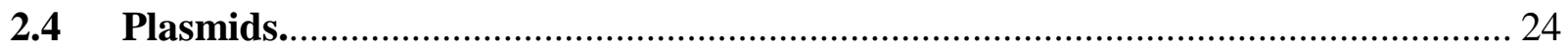

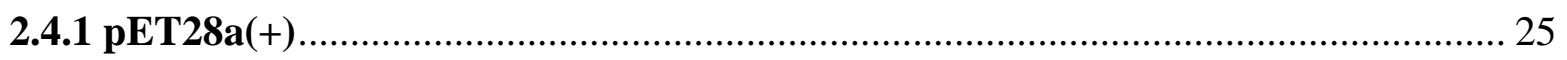

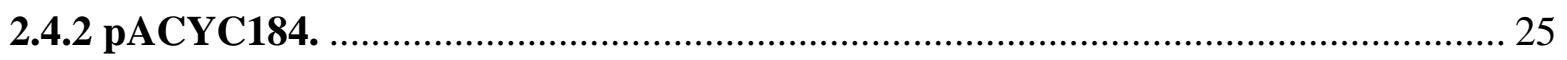

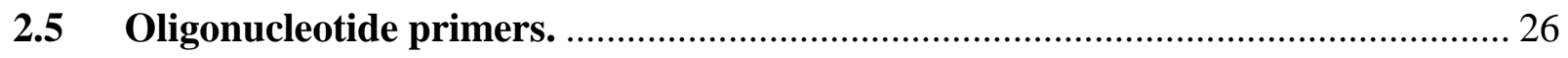

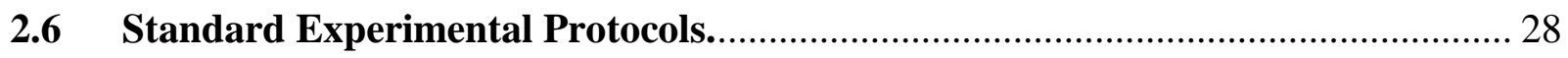

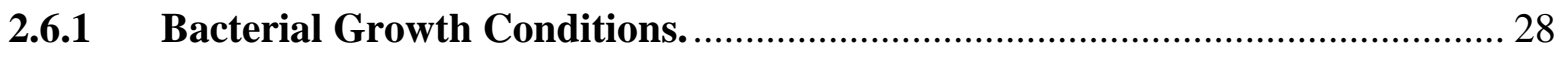

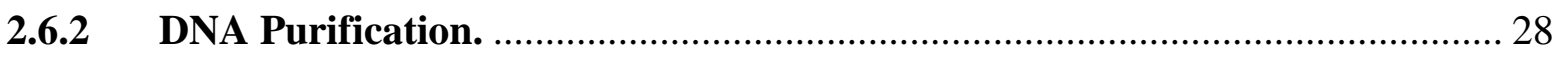

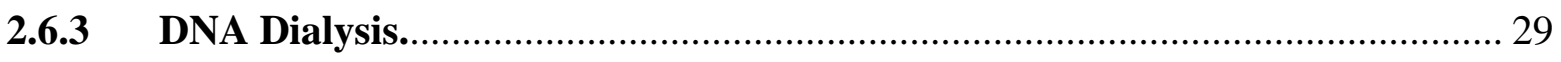

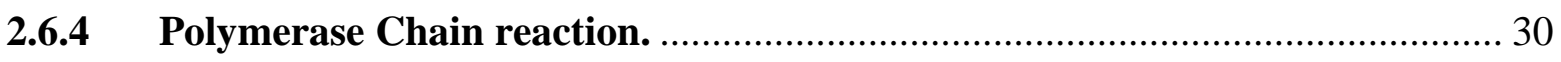

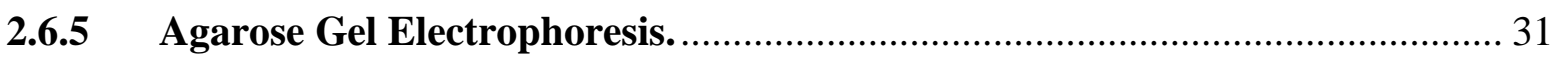

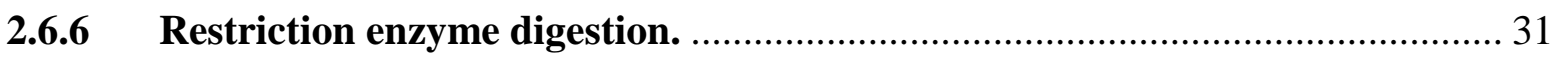

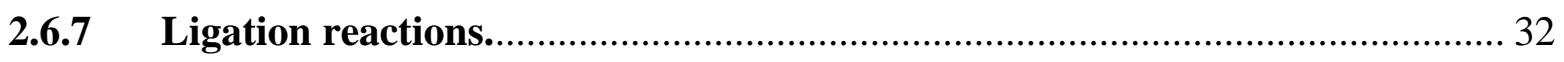

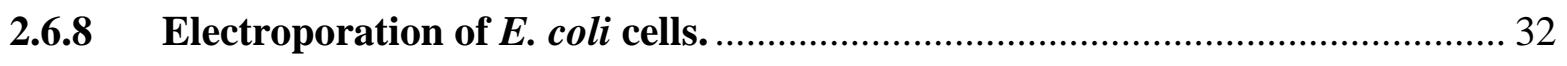

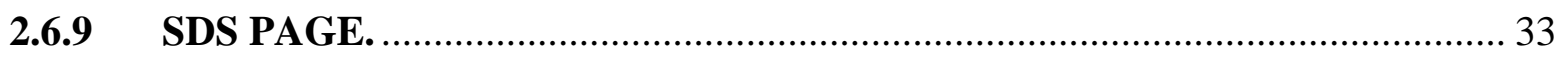

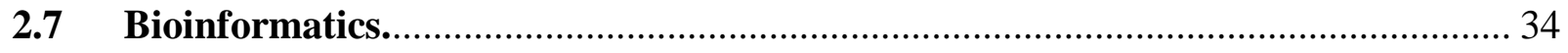

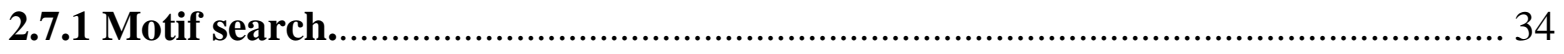

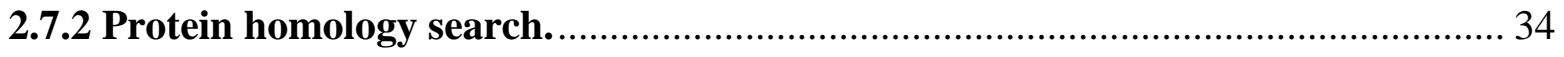

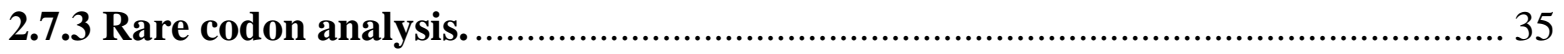

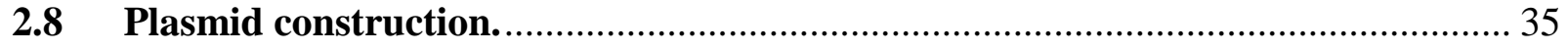

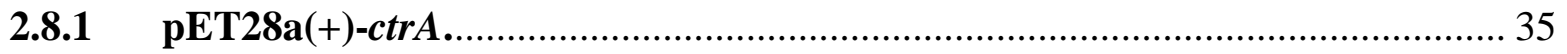

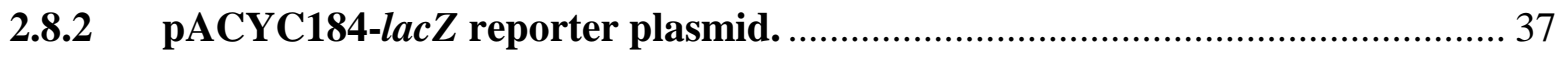

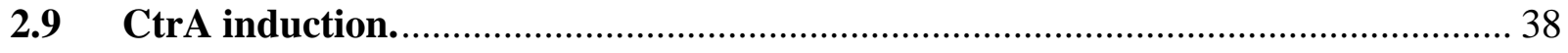

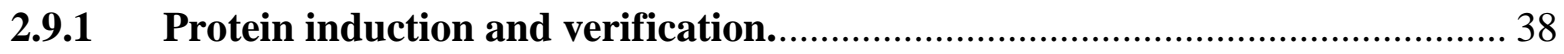

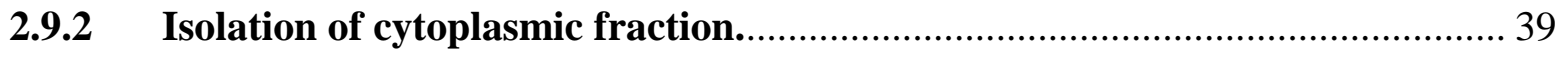

2.9.3 Histidine tag purification. ............................................................................ 40

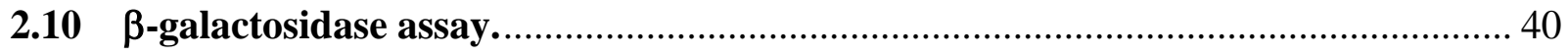

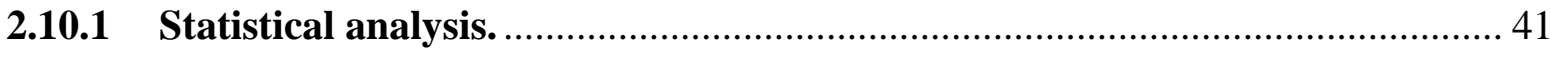

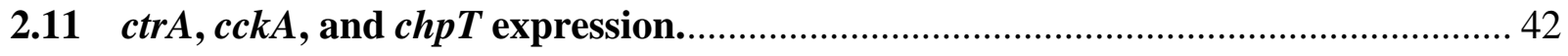

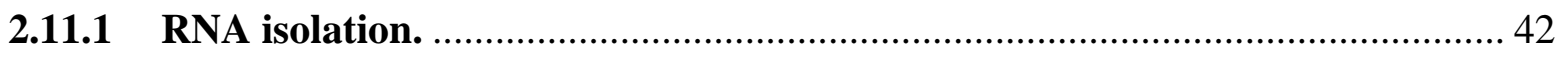

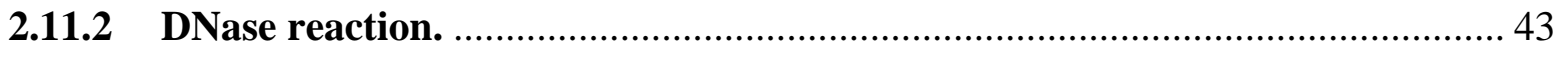

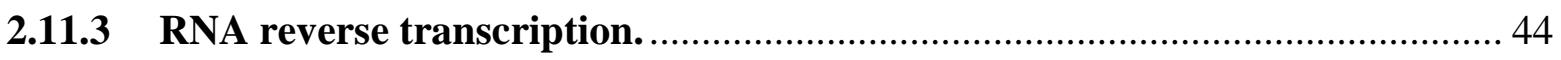

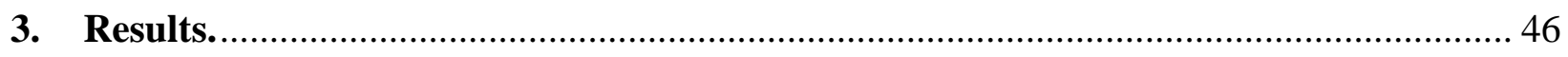

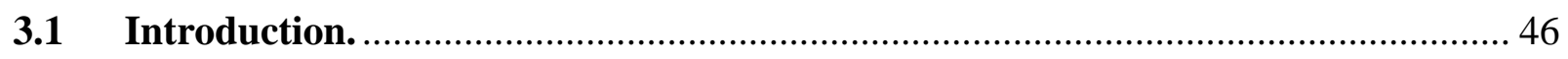

3.2 B. quintana homologue identity. ……………..................................................... 46 


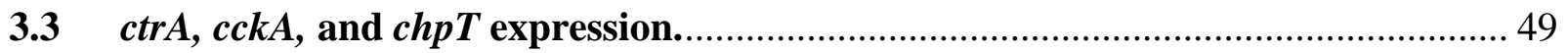

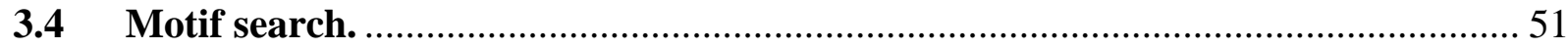

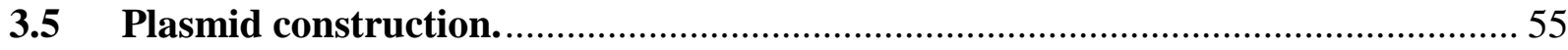

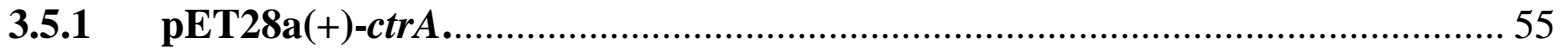

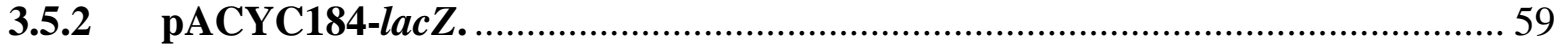

3.5.3 pACYC184-lacZ ctrA, ftsE, hemS, and $h b p C$ reporter plasmids.................. 63

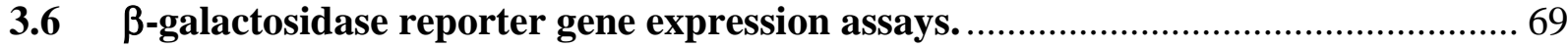

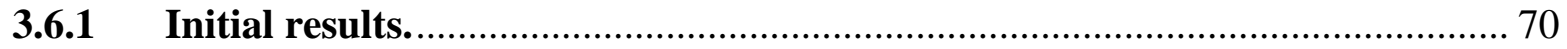

3.6.2 $\beta$-galactosidase assay protocol optimisation................................................ 71

3.6.3 $\quad \beta$-galactosidase measurements. ............................................................ 74

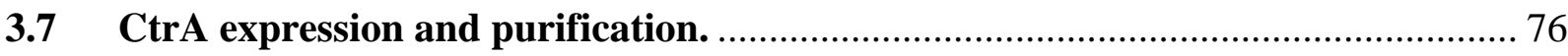

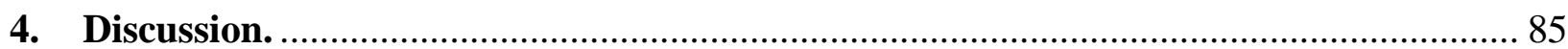

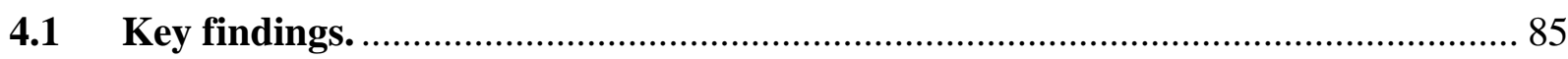

4.1.1 Regulator homology and gene expression. .................................................... 85

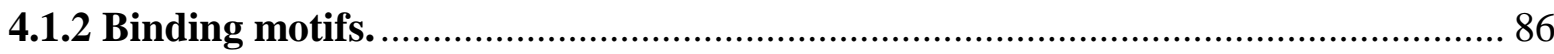

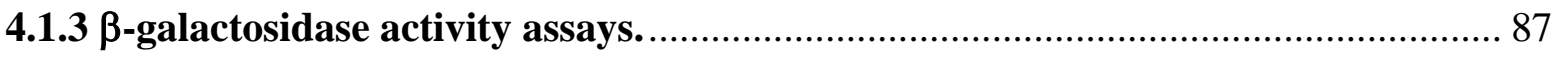

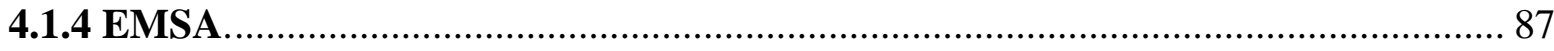

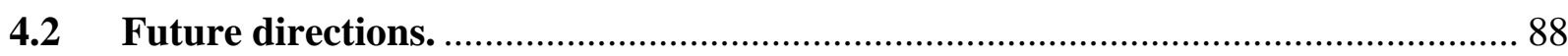

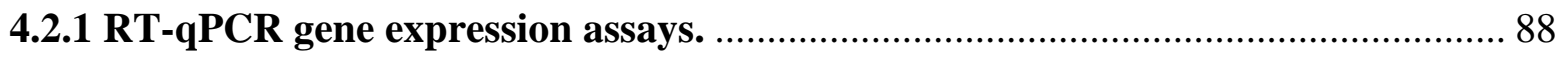

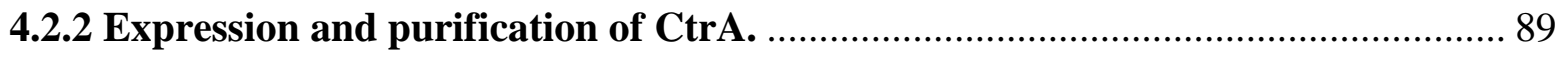

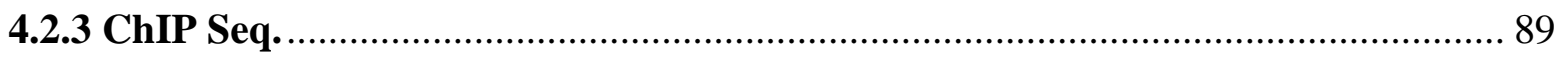

4.2.4 Conditional mutant and transcriptome sequencing. ..................................... 90

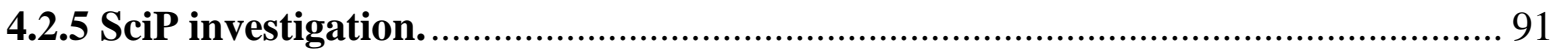

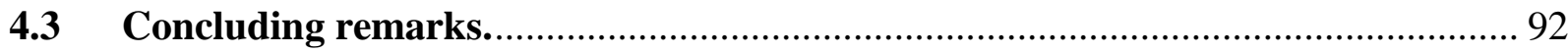

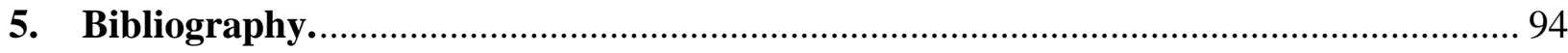

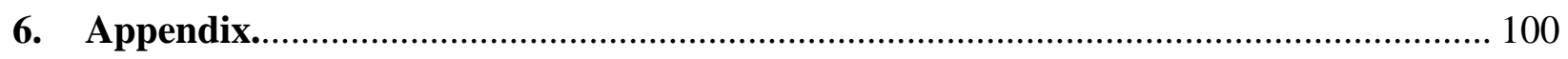


List of Figures.

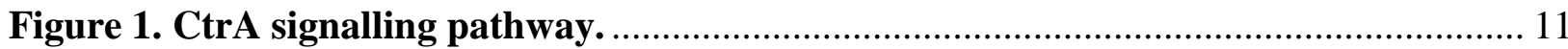

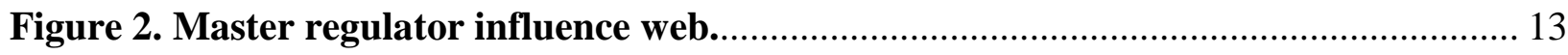

Figure 3. Regulation of the master cell regulators............................................................. 14

Figure 4. Schematic representation of the sciP, ctrA, and chpT genes organisation. ......... 48

Figure 5. $\operatorname{ctrA,~ckA,~and~chpT~expression~from~RT-PCR.........................................~} 50$

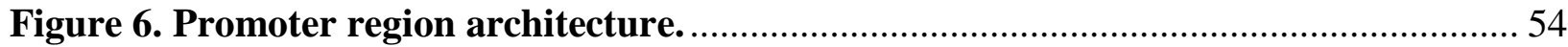

Figure 7. ctrA PCR product screen.............................................................................. 56

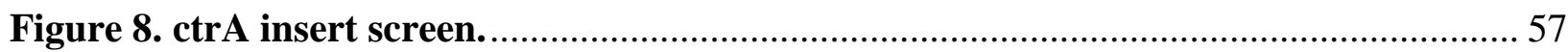

Figure 9. ctrA high concentration screen. ................................................................... 58

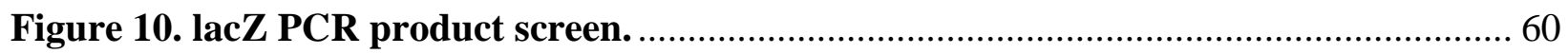

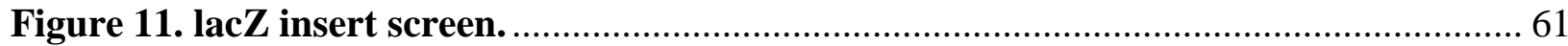

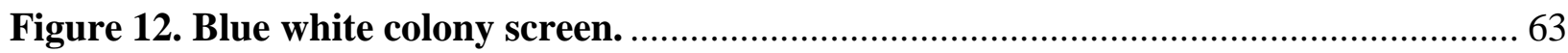

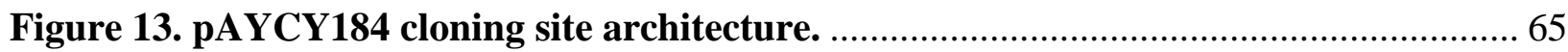

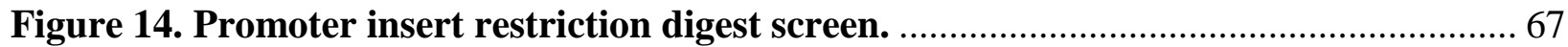

Figure 15. pET28a(+)-ctrA and pACYC184-lacZ reporter screen. ............................... 69

Figure 16. $\beta$-galactosidase activity pilot assay results. ............................................. 70

Figure 17. $\beta$-galactosidase activity assay results. ................................................... 74

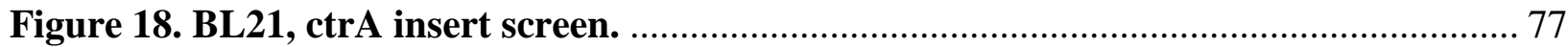

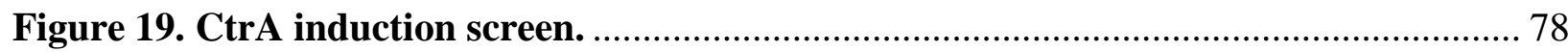

Figure 20. pRARE plasmid CtrA expression screen. ................................................... 81

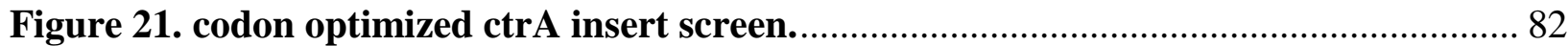

Figure 22. Small colony PCR gel. .............................................................................. 83

Figure 23. Small colony 18 plasmid digest................................................................. 84

List of Tables.

Table 1. Media supplements used in this project...................................................... 21

Table 2. Bacterial strains used during this project...................................................... 23

Table 3. Plasmids used or produced during this research. .............................................. 24

Table 4. Oligonucleotide primers used throughout this project................................... 26

Table 5. Standard PCR mix using the Q5 high fidelity polymerase (NEB)......................... 30

Table 6. Standard PCR temperature cycling parameters............................................ 30

Table 7. Components for restriction enzyme reactions...................................................... 31

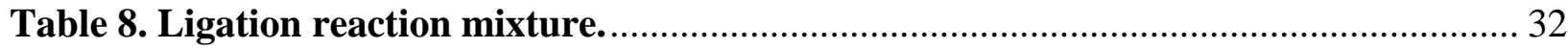

Table 9. Reverse transcription mixture. ....................................................................... 44

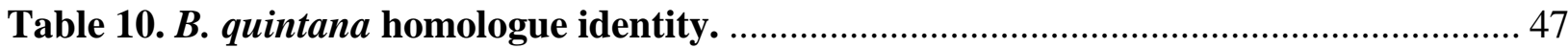

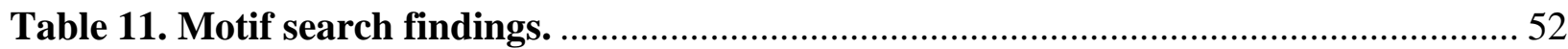

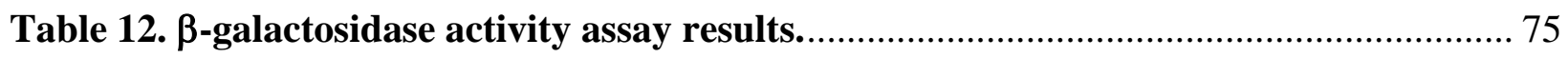

List of Appendix Figures.

Appendix 1. CtrA amino acid alignment. .................................................................. 100

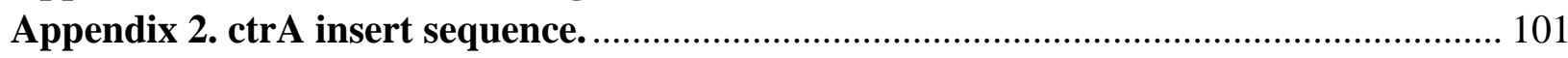


Appendix 3. lacZ insert sequence.

Appendix 4. codon-optimised CtrA sequence. 


\section{Abbreviations.}

AIDS - Acquired immunodeficiency syndrome.

bp - Base pairs.

cAMP - Cyclic adenosine monophosphate.

CIAP - Calf-intestinal alkaline phosphatase.

ChIP - Chromatin immunoprecipitation.

EDTA - ethylenediaminetetraacetic acid.

EMSA - Electrophoretic Mobility Shift Assay.

HIAR - Heart infusion agar.

ITPG - Isopropyl $\beta$-D-1-thiogalactopyranoside.

LB - Lysogeny broth.

OD - Optical density.

oriT - Origin of biparental conjugation.

PBS - Phosphate-Buffered Saline.

PCR - Polymerase Chain Reaction.

Qrt-PCR - Quantitative Reverse Transcriptase Polymerase Chain reaction.

TBS - Tris-buffered saline.

UV - Ultraviolet. 


\section{Introduction.}

\section{$1.1 \quad$ Bartonella spp.}

Bacteria belonging to the genus Bartonella are Gram-negative facultative intracellular pathogens, with each species of Bartonella infecting a single mammalian species or a closely related group of animals, including humans ${ }^{[2,3]}$. Bartonella infections are almost universal in mammalian species where biting arthropod ectoparasites, their transmission vector, are prevalent ${ }^{[4,5]}$; infections are less prevalent in domesticated animals that are treated to prevent arthropod parasites. Most species of Bartonella have only recently been discovered ${ }^{[6]}$; this is due to the low number of bacteria present over the course of the infection and the difficulty associated with culturing Bartonella spp. under lab conditions. With the development of our ability to identify species using genetic sequencing, such as 16s RNA genotyping ${ }^{[7]}$, and improved culturing methods, previously unknown species have been discovered and characterised ${ }^{[8]}$. These advances have led to the discovery of many new species, infecting a wide range of hosts.

\subsubsection{Pathogenesis.}

The wide range of Bartonella spp. means that they can lead to a variety of pathologies in both incidental and reservoir hosts. An incidental host is an organism which can be infected by a bacterium. However, it will not be able to develop a transmittable infection, like that which would develop in the reservoir host. Bartonella spp. is responsible for multiple diseases in humans, including trench fever, cat scratch disease, and Carrion's disease ${ }^{[9-11]}$. These diseases are caused by Bartonella quintana, Bartonella henselae, and Bartonella bacilliformis respectively; while these species represent the majority of Bartonella spp. causing human infections, at least 14 additional species have been reported to infect humans ${ }^{[12]}$. 
B. quintana infects humans as its host and is spread by human body lice (Pediculus humanus humanus), causing trench fever, which is a potentially serious illness ${ }^{[13]}$. First discovered during the World War One, trench fever was widespread among soldiers. Symptoms of infection were first observed by medical officer Major J H P Graham on the western front in 1915. He wrote, "A private belonging to an infantry regiment was admitted to a casualty clearing station from a field ambulance where he had been detained suffering from a febrile illness of three days' duration and of sudden onset." Additionally Major Graham recorded dizziness, severe lumbago, frontal headache, painful shins and thighs, and a 5 -day relapsing fever ${ }^{[14]}$, as well as splenomegaly, an abnormal enlargement of the spleen ${ }^{[15]}$. Symptoms ranged from mild to severe, with the disease having an incubation period of 15-25 days. However, it is possible for infected people to remain asymptomatic ${ }^{[16]}$. Entering the second half of the $20^{\text {th }}$ century, the incidence of trench fever declined due to improved living conditions and the implementation of delousing measures but made a re-emergence during the AIDS epidemic during the 1990s. This re-emergence lead to the bacteria regaining prominence due to its increased detection as an opportunistic pathogen ${ }^{[17]}$. In immunocompromised patients, such as those with AIDS, a persistent bacteraemia develops. Chronic B. quintana infections can cause bacillary angiomatosis, an uncontrolled growth of the blood vessels tissue that results in a tumor-like mass, that can occur in the skin or other organs around the body ${ }^{[18]}$. Endocarditis, an infection of the heart valves that results in inflammation and can be life-threatening, is another frequent complication ${ }^{[19]}$.

Cat scratch disease is the most common human disease caused by Bartonella spp. It is caused by B. henselae, for which cats are the reservoir host, and is spread between cats by the cat flea (Ctenocephalides felis). Humans acquire the infection when the bacteria enter the broken skin, 
usually due to cat scratches ${ }^{[16]}$. Although cat scratch disease was first described in 1950 , the causative agent remained unknown for many years ${ }^{[20,21]}$. Like B. quintana, B. henselae was first cultured and identified as the causative agent of cat scratch disease during the AIDS epidemic ${ }^{\text {[22] }}$ when it emerged as a significant opportunistic infection in immunocompromised patients ${ }^{[23,24]}$. Cat scratch disease can occur in otherwise healthy people, usually children, and causes prolonged regional lymphadenopathy along with fever. Serious complications have also been documented and may occur at higher rates than previously thought. Complications are more likely in immunocompromised patients, who can develop endocarditis, bacillary angiomatosis, and bacillary peliosis, characterised by blood-filled cavities in the liver ${ }^{[25]}$. B. henselae is closely related to $B$. quintana and is a genomic derivative of it. This close relation likely facilitates the ability of $B$. henselae to infect humans incidentally ${ }^{[26]}$.

B. bacilliformis causes Carrion's disease, which is very distinct from the diseases caused by other Bartonella spp. Like B. quintana, humans are the reservoir host for B. bacilliformis. While most Bartonella species that infect humans do not cause lysis or functional disturbance of infected red blood cells, B. bacilliformis is an exception, causing the death of red blood cells and potentially fatal anaemia ${ }^{[11]}$. Carrión's disease is a haemolytic anaemia that occurs during the acute phase, where up to $100 \%$, but on average $60 \%$, of erythrocytes are invaded and lysed ${ }^{[27]}$ leading to Oroya fever ${ }^{[28]}$. This is followed by verruga peruana, vasoproliferative skin lesions that occur during the chronic phase. Carrión's disease causes death in up to $88 \%$ of cases if the patient is not treated with antibiotics ${ }^{[16]}$. Genomic studies have shown that $B$. bacilliformis is descended from a lineage distantly related to $B$. quintana and B. henselae ${ }^{[29]}$. 


\subsubsection{History of B. quintana.}

Trench fever was first described in 1917 during World War One. However, there is evidence of it being present earlier in history. B. quintana DNA was found in mass graves containing the bodies of soldiers from Napoleon's grand army $(1805-1815)^{[30]}$. DNA evidence of B. quintana was also found in the molars of three individuals in the south of France, dating back 4000 years ${ }^{\text {[31], }}$ suggesting that B. quintana has been influencing human health far back in history.

During World War One, B. quintana infections were a significant drain on the Entente's forces of fighting ability. A total of $0.6 \%$ of troops were evacuated from the Western front due to sickness each week, with B. quintana infections making up an estimated $15 \%$ of the total evacuated troops ${ }^{[32]}$, and affecting approximately 800,000 Entente troops over the course of the war ${ }^{[33]}$. Whilst the incidence of trench fever has dropped since the early $20^{\text {th }}$ century, it's considered to be remerging in areas of poverty, as urban trench fever ${ }^{[34,35]}$.

\subsubsection{Prevalence.}

Both B. henselae and B. quintana infections occur worldwide in human populations. B. quintana infections are mostly associated with conditions where body lice tend to be prevalent, including homelessness, alcoholism, and residence in refugee camps or poor living conditions (e.g. war zones, areas of extreme poverty, etc.) ${ }^{[36]}$. Infections of $B$. henselae are the most prevalent of all Bartonella spp. infections, with 0.19 per 100,000 people infected annually in the USA, with a rate of 9 per 100,000 for children aged 5-9 years old. This results in estimated direct medical costs of $\$ 9,760,000$ USD each year ${ }^{[37]}$. 
In surveys of homeless shelters, it was found that $14 \%$ of those tested had B. quintana bacteraemia and $30 \%$ of the 71 people tested showed antibody titers for B. quintana ${ }^{[36]}$. Another study found that of non-hospitalized homeless people, 5.4\% (50 of 930) had B. quintana bacteraemia $^{[38]}$.

The rates of B. quintana are difficult to estimate because it often remains undiagnosed, due to the inefficiency of standard testing methods in detecting Bartonella spp. and the lack of any standardised diagnostic tests. The most commonly used diagnostic test is serologic testing. However, this can be problematic, due to cross-reactions with Coxiella burnetii and Chlamydia pneumoniae $^{[19,26]}$. Blood culturing, and PCR are also used in diagnosis ${ }^{[39,40]}$.

\subsubsection{Transmission.}

Generally, Bartonella spp. are transferred between reservoir hosts via a biting arthropod vector. Initial infection occurs when an arthropod carrying the bacteria takes a blood meal and defecates near the bite, causing the host to scratch the faeces into the wound and allow the bacteria to enter the body ${ }^{[16]}$. The bacteria can also be transferred between hosts directly, via a cat scratch or bite, for B. henselae ${ }^{[41]}$. It's been shown that B. quintana ${ }^{[5]}$, B. henselae ${ }^{[42]}$, and B. schoenbuchensis ${ }^{\text {[43] }}$ replicate in the digestive tract of their transmission vectors, but it is unknown whether other species do the same. The variation in the vectors for each member of the Bartonella genus and their specificity for their mammalian host likely contributes to limiting the bacteria to a single, or a few potential hosts, and for some species, to a specific geographical region ${ }^{[16]}$. For example, the phlebotomine sand fly is the vector for B. bacilliformis but is only found at high altitudes in the Andes Mountains, limiting the bacteria to that region too ${ }^{[44]}$. 


\subsubsection{Replication in the seeding niche.}

Once the dermis has been breached, the bacteria must travel to the bloodstream to establish a persistent infection. While this process is not well understood for species which commonly infect humans, research has shed light on the process for rodent-associated species, including Bartonella grahamii, Bartonella birtlesii, Bartonella doshiae, and Bartonella taylorii, in mouse models ${ }^{[45],}$ and Bartonella tribocorum in rat models. Broadly speaking, once in the dermal tissue, the bacteria are taken up by resident immune cells such as dendritic cells, which ferry them into the lymphatic system; from there the bacteria then enter the bloodstream where erythrocyte invasion occurs ${ }^{[11}$, 46, 47]. However, further research is required to fully understand this process. Once in the bloodstream, bacteria become closely associated with the endothelial cells of blood vessels, likely embedding into their extracellular matrix ${ }^{[48]}$. This is often referred to as the potential seeding, or replication, niche and is hypothesized to be where the bacteria emerge from to invade erythrocytes. This seeding happens at regular time intervals, for example, B. quintana is typically seeded every five days, causing a relapsing fever, also known as five-day (quintan) fever ${ }^{[49]}$.

\subsubsection{Bacteraemia.}

Following their seeding into the bloodstream, the bacteria invade erythrocytes, where they establish a persistent intraerythrocytic niche. Erythrocyte invasion only occurs in the reservoir host, due to the specificity of the bacteria's adherence and invasion proteins. Erythrocyte invasion is crucial for transmission, as the arthropod vector ingests the bacteria along with erythrocytes during a blood meal. Within the erythrocyte, the bacteria replicate and persist intracellularly for the duration of the erythrocyte's lifespan, typically 1-2 months, without impacting its function or

longevity ${ }^{[11]}$. B. quintana employs a stealth infection strategy, which allows them to establish a 
persistent bacteraemia of the bloodstream without causing septic shock or being cleared by the immune system ${ }^{[50]}$. Several mechanisms are key, including intracellular persistence in erythrocytes, which enables the bacteria to avoid antibodies and immune activation ${ }^{[45]}$. $B$. quintana also apparently disrupts immune function to avoid detection, at least in part by stimulating an overproduction of interleukin-10, resulting in an attenuated inflammatory response [51]. There are also very low levels of Bartonella in the bloodstream and inside red blood cells during infection; for B. quintana fewer than $1 \%$ of red blood cells were found to be harbouring intracellular bacteria. Of those cells infected, there was an average of eight bacterial cells per red blood cell ${ }^{[16]}$.

\subsubsection{Environmental stresses.}

During its life cycle, the Bartonella spp. will be exposed to a variety of stressful environments in both its mammalian host and its arthropod vector. These include low temperatures in the arthropod and oxidative stress. To survive this, Bartonella modifies its gene expression and metabolism to adapt to environmental conditions. It has also been shown that $B$. henselae produces heme binding and heme degrading proteins, such as $\mathrm{HbpC}$, and $\mathrm{HemS}$ respectively, in environments with high heme levels, such as the digestive system of the arthropod vector. The heme-binding and degrading proteins help the bacteria to resist the oxidative stress in this environment, by forming an antioxidant coat on its surface ${ }^{[52,53]}$. Heme binding proteins also help $B$. quintana to take up heme, which is important because $B$. quintana cannot synthesise its own heme and has a high need for it as a major source of iron ${ }^{[54]}$. Heme binding proteins were also shown to protect $B$. quintana from toxic levels of heme ${ }^{[55]}$. These adaptions allow the Bartonella genus to survive transmission to 
new hosts and stressful environments. The gene regulation involved in protecting $B$. quintana in response to environmental stress is not fully understood.

\subsection{Bacterial Cell Cycle Control.}

The proper regulation of the cell cycle is essential in bacteria, both for their propagation and survival in stressful environments. It is crucial for each step of the cell cycle to progress in the correct order, for example, if the cell began division before the DNA replication was complete and prepared for cell division, the chromosome would tear, leading to the death of the cell.

\subsubsection{Cell Cycle Regulation in Alpha-Proteobacteria.}

The Bartonella genus belongs to the class alpha-proteobacterium; the regulation of the bacterial cell cycle has been studied in detail in other members of this class, such as Caulobacter crescentus [56]. C. crescentus is an important model organism for the study of bacterial physiology and cell cycle regulation. Cell division in $C$. crescentus is asymmetric, with each round of replication resulting in a stalked cell and a motile swarmer cell. The asymmetric division of $C$. crescentus allows for cell cycle synchronisation of cultures. This, combined with a wealth of genetic and molecular tools, has enabled the detailed dissection of multiple $C$. crescentus genetic and regulatory networks ${ }^{[56-58]}$. Multiple master regulatory proteins controlling the cell cycle have been discovered in C. crescentus, including DnaA, CcrM, GcrA, SciP, and CtrA. These proteins coordinate DNA replication, DNA methylation, and act as global transcription factors ${ }^{[59]}$. Together these master regulators control the asymmetric cell division that takes place in $C$. crescentus, ensuring that all steps occur in the correct order and with the correct timing. 


\subsubsection{CtrA.}

The CtrA protein is an essential regulator and was originally discovered as a key cell cycle regulator in $C$. crescentus, regulating many genes to ensure the appropriate timing of gene expression but inhibiting initiation of DNA replication ${ }^{[60]}$. CtrA is phosphorylated and activated by its cognate sensor kinase, CckA, and binds directly to DNA. It has been shown to directly or indirectly regulate the expression of $26 \%$ of $C$. crescentus cell cycle-regulated genes ${ }^{[58]}$. When $C$. crescentus $\mathrm{Ctr} A$ is phosphorylated, it becomes active and binds to promoter regions to regulate at least 95 genes in the bacteria ${ }^{[61,62]}$. In C. crescentus $\mathrm{CtrA}$ also regulates the cell cycle by binding to the chromosomal origin of replication in five places, thus preventing the initiation of DNA replication until the appropriate time ${ }^{[60]}$. CtrA has been reported to bind two specific DNA motifs in the promoter regions of $C$. crescentus genes, TTAAN7TTAAC, and TTAACCAT ${ }^{[63]}$. These motifs are present in the promoter regions of genes directly regulated by CtrA binding in $C$. crescentus and include genes involved in DNA replication initiation, cell division, DNA methylation, polar morphogenesis, flagellar biosynthesis, and cell wall metabolism ${ }^{[61]}$. While CtrA has been well studied in Caulobacter crescentus, its activity has not been studied in Bartonella, which has a very different life cycle and environmental niche.

\subsubsection{CtrA Activation and Regulation.}

Like many proteins, CtrA can be present in two forms: phosphorylated and unphosphorylated. When phosphorylated, it is active and able to bind DNA and regulate gene expression ${ }^{[61,62]}$. CtrA can be phosphorylated by two independent signalling pathways. The first of these consists of a histidine kinase phosphorelay with a phosphoryl group transferred from the signalling proteins CckA, cognate sensor kinase ${ }^{[64,65]}$, to CtrA, via an intermediate, ChpT, a histidine 
phosphotransferase. This signalling chain accounts for the phosphorylation of CtrA, but it was also discovered that ChpT-P also phosphorylates $\mathrm{CpdR}{ }^{[66]}$. $\mathrm{CpdR}$ is another important protein, which leads to the proteolysis of CtrA by the ClpXP proteasome. Phosphorylated CpdR localizes the ClpXP complex to the cell pole in the stalked daughter cell in $C$. crescentus where, along with PopA and RcdA, it breaks down CtrA ${ }^{[67]}$. The removal of CtrA allows the stalked cell to re-enter S phase directly after division, if other conditions are met, by preventing CtrA from binding to the origin of replication, where it would inhibit DNA replication. This pathway is interesting since ChpT both activates CtrA and de-activates CpdR, meaning it regulates both the phosphorylation of CtrA directly, and its proteolysis indirectly ${ }^{[62]}$.

The second signaling chain involves the DivJ and DivK signalling molecules, along with a third histidine kinase, PleC, which reverses DivK phosphorylation. DivK is an essential response regulator involved in the regulation of the cell cycle in C. crescentus. Temperature sensitive divK gene mutants arrest in G1 phase, revealing an essential role for DivK in cell cycle progression ${ }^{[68]}$. DivK indirectly regulates the phosphorylation of CtrA. When CtrA is phosphorylated, expression of $\operatorname{divK}$ is activated in C. crescentus, leading to the production of DivK, which is inactive until phosphorylated itself. DivK phosphorylation is carried out by DivJ and can be reversed by PleC. The relative amounts of DivJ and PleC in the cell, as well as the amount of CtrA activating expression of the $\operatorname{div} K$ gene, dictates the level of phosphorylated DivK in the bacteria. Phosphorylated DivK then regulates CtrA phosphorylation by delocalising CckA, disrupting its activity and leading to a reduction in the amount of active CtrA. This provides an important regulatory feedback loop, essential to regulate CtrA in the bacteria and thus its coordinated 
progression through the cell cycle ${ }^{[66]}$. This signalling pathway is shown in Figure 1. CtrA signalling pathway.

Figure 1. CtrA signalling pathway.

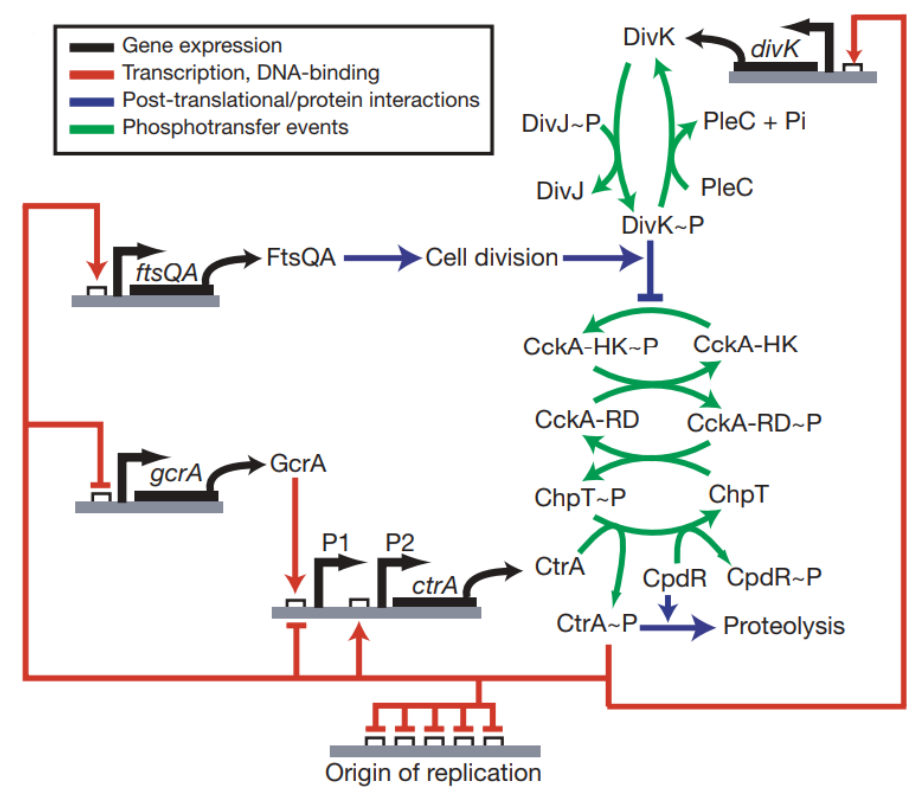

Reproduced from Biondi, E.G., et al., ${ }^{[66]}$ with permission from Springer Nature. This diagram shows the phosphorylation signaling chain, activating CtrA.

\subsubsection{CtrA Localisation.}

To achieve an asymmetrical cell division in C. crescentus, it is essential for CtrA and its related proteins to be correctly localised and at differing concentrations at the poles of each daughter cell ${ }^{[69]}$. CckA is a protein which undergoes asymmetrical polar localization. As detailed previously, CckA facilitates the phosphorylation of CtrA as well as the inhibition of the proteolytic breakdown of CtrA. CckA is localised to the swarmer progeny, leading to high levels of active CtrA in 
swarmer cells ${ }^{[70]}$. Other localised proteins include DivJ, and PleC, the levels of which indirectly determine the amount of $\mathrm{CtrA}{ }^{[71]}$. In the swarmer cell, $\mathrm{PleC}$ is more abundant, leading to the dephosphorylation of DivK and thus preventing it from disrupting the phosphorylation and stabilisation of CtrA; this delays cell division in the swarmer cell, allowing them to swim to new and potentially more favourable environments. In the stalked cell, DivJ is more abundant, leading to the opposite outcome, i.e., $\mathrm{CtrA}$ degradation through the ClpXP protease ${ }^{[72]}$. This results in low levels of CtrA and relatively high levels of DnaA and GcrA, which are other master regulatory molecules, allowing the stalked cell to immediately commence cell division and re-enter S-phase [73].

\subsubsection{Multiple Cell Cycle Regulators coordinate the $C$. crescentus cell cycle.}

The ctrA gene is part of a complex web of regulatory genes which are responsible for regulation and coordination of many cellular activities. In addition to $\mathrm{CtrA}$, four other master regulatory proteins, DnaA, GcrA, and SciP, and a cell cycle-regulated methyltransferase, CcrM, are involved in coordinating cell division in $C$. crescentus. Each of these proteins influences the expression of a host of cell cycle-regulated genes. Many genes have been shown to be regulated by multiple master regulatory genes, and a few have been found to be regulated by all five (

Figure 2$)^{[57,59,74]}$. This level of complexity gives the ability for greater control and subtlety in the regulation of genes.

Figure 2. Master regulator influence web. 


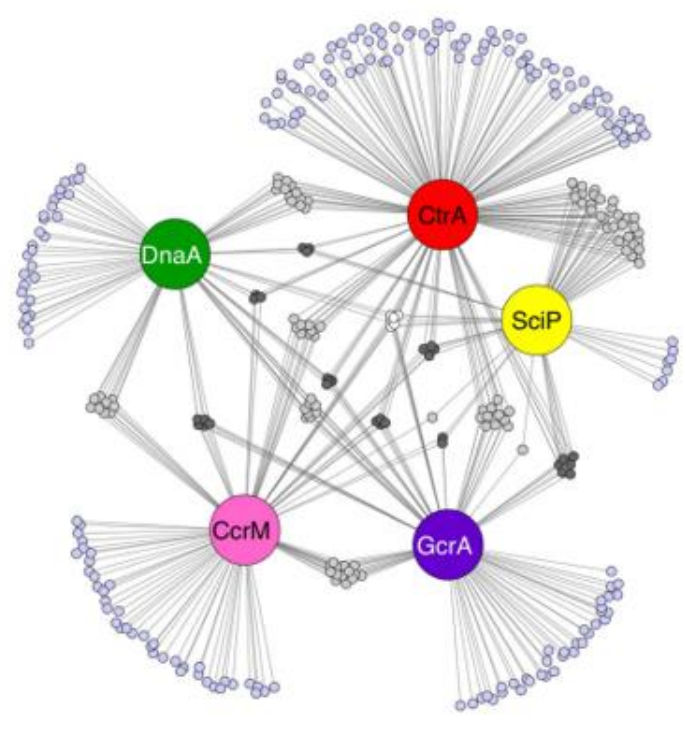

Reproduced from Zhou, B., et al., $2015^{[57]}$ (PLoS, open source publisher). This figure shows all C. crescentus cell cycle-regulated genes, represented as dots, connected to the master regulators that control their expression. Lavender dots are regulated by only one regulator, light grey dots are controlled by two regulators, dark grey dots are controlled by three, and white dots are controlled by all five regulators.

These five genes orchestrate the cell cycle of Caulobacter crescentus, but also influence and regulate expression of each other. DnaA, as well as its other activities, binds to and represses its own promoter while also binding and activating the promoter of $g c r A$. In turn, the expressed GcrA induces the transcription of $\operatorname{ctrA}$ and the resulting CtrA protein subsequently auto-inhibits or induces its promoter (under different conditions). CtrA also inhibits expression of gcrA and induces both the $s c i P$ and $c c r M$ promoters. SciP inhibits expression of both $c t r A$ and $c c r M$, while CcrM, in turn, inhibits $c t r A$ expression and induces the expression of the dnaA gene, through DNA methylation ${ }^{[57]}$. This forms a regulatory loop which navigates the bacteria through the cell cycle 
and facilitates the correct gene expression at each stage of the cycle. This genetic circuit is shown in Figure 3.

Figure 3. Regulation of the master cell regulators.

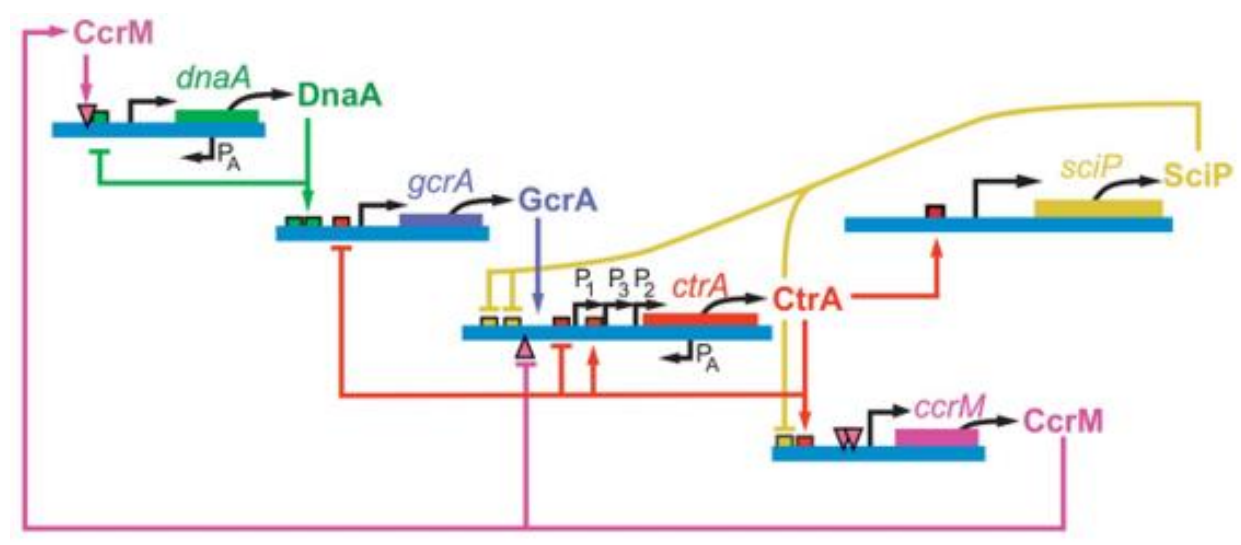

Reproduced from Zhou, B., et al., $2015^{[57]}$ (PLoS, open source publisher). This figure shows the genetic regulatory circuit of $c t r A$ in the $C$. crescentus cell cycle. DnaA initiates DNA replication. The circuit includes the transcription factors GcrA, CtrA, and SciP, and the DNA methylator CcrM, arrows indicate promoter activation and flat head arrows indicate promoter inhibition.

\subsubsection{CtrA, DnaA, and GcrA Coordinate an Oscillating Cell Cycle.}

For $C$. crescentus to navigate the cell cycle, it expresses varying amounts of essential master regulatory proteins, including CtrA, DnaA, and GcrA, at specific times throughout cell cycle progression ${ }^{[75]}$. Beginning at the swarmer progenitor stage, active CtrA is present in the cell, inhibiting gcrA as well as silencing DNA replication at the origin of replication ${ }^{[73]}$. When the bacteria transitions from $\mathrm{G} 1$ to $\mathrm{S}$ phase, $\mathrm{CtrA}$ is degraded, freeing the origin of replication and enabling DNA replication. DnaA is also expressed, which initiates DNA replication at the origin of replication and promotes GcrA synthesis ${ }^{[76]}$. As $\mathrm{S}$ phase continues, GcrA concentration 
increases, promoting the expression of polar development and replication elongation genes, eventually leading to chromosome segregation. When transitioning to G2 phase, ctrA transcription is promoted by GcrA, which then activates CtrA, silencing the origin of replication and inhibiting the gcrA promoter ${ }^{[75]}$. CtrA then induces the transcription of cell division genes to facilitate binary fission e.g. fts $Q$, a gene which codes for a component of the FtsZ cell division ring. During division, CtrA, DnaA, and GcrA are differentially localised in each daughter cell, resulting in a swarmer cell with high levels of CtrA in G1 phase, and a stalked cell that, with low CtrA and high DnaA and GcrA, is able to re-enter S phase immediately, due to the lack of CtrA inhibition ${ }^{[74]}$.

\subsubsection{CtrA in other alpha-proteobacteria.}

Unlike C. crescentus, many members of the alpha-proteobacteria are associated with a plant or animal host, and these bacteria retain homologues of the $c \operatorname{tr} A$ gene and its associated signalling partners. One of these is Ehrlichia chaffeensis, an obligate intracellular rickettsial pathogen which causes human monocytic ehrlichiosis, an acute flu-like illness ${ }^{[77,78]}$. E. chaffeensis has two phases of development, beginning as smaller dense-cored cells and eventually developing into larger intracellular reticulate cells; following replication the reticulate cells become dense-cored cells again ${ }^{[79]}$ before exiting the host cell ${ }^{[80]}$. A ctrA homologue was found in E. chaffeensis and was shown to regulate several genes involved in the differentiation of dense-cored into reticulate cells and may provide resistance to physicochemical and oxidative stress in dense-cored cells ${ }^{[81]}$.

The mammalian pathogen, Brucella abortus, is closely related to the Bartonella genus. Like Bartonella, it is a facultative intracellular pathogen, but it invades and replicates within macrophages, as opposed to erythrocytes ${ }^{[82]}$. Brucella abortus is primarily a zoonotic pathogen 
and is typically acquired through contact with animals or consumption of unprocessed animal products. As an alpha-proteobacterium, B. abortus has a conserved $\operatorname{ctr} A$ gene, which contributes to the regulation of its cell cycle. In B. abortus, the CtrA protein binds DNA to regulate the promoters of genes involved in cell cycle progression, as well as multiple genes that encode outer membrane components important for the synthesis of lipopolysaccharides and their export to the outer membrane ${ }^{[83]}$. B. abortus mutants with conditional loss of CtrA function ceased dividing and gained a long-branched morphology, confirming that CtrA regulates cell division. These mutants also had a modified outer membrane protein composition, showing CtrA activity influences membrane composition, which can have many pleiotropic effects. In B. abortus there is an 8-hour post infection delay in bacterial division intracellularly, with the bacteria arresting in G-1 phase. During this time, there is a complete block on cell growth and DNA replication ${ }^{[84]}$. This is a potentially essential adaptation for B. abortus to survive in its intracellular niche and is thought to be a widespread adaptation for intracellular alpha-proteobacterial pathogens, to survive and establish an intracellular proliferative niche. This suggests that $\mathrm{Ctr} A$ and other master regulator proteins may play a crucial role in the infection cycle and virulence of intracellular alphaproteobacterial pathogens.

While a post-invasion arrest is not observed when $B$. quintana invades erythrocytes, the intracellular bacteria undergo limited division, replicating to only eight bacteria per blood cell then entering a quiescent state where any further division is halted. Bartonella spp. in general, are found in low numbers in their mammalian hosts, this is likely a key part of their stealth invasion strategy, as limited division limits the immune response triggered ${ }^{[15]}$. If B. quintana underwent uncontrolled cell division inside the erythrocyte, the cell would be lysed, exposing the bacteria to the immune 
system and perhaps causing the host to be unwell. An overtly sick host would also compromise the bacteria's transmission to its arthropod vector, by limiting interactions with new hosts. This nuanced and specific control is achieved in B. quintana with the use of complex interconnected signalling and regulatory networks that remain unexplored. Environmental signals, detected by bacterial sensory proteins, may feed into the signalling cascades, which eventually reach regulatory proteins and control the activation of other proteins or gene expression. This complex level of control, involving multiple levels and cross-talk between signaling pathways, is essential for multiple essential processes; hence multiple sensitive regulatory systems are required to modulate the activity of CtrA, ensuring survival of the bacterial cell.

\subsection{Research Aims.}

A crucial part of the Bartonella spp. infection process is the halt in replication whilst within the circulating erythrocytes. Since activated CtrA plays a role in delaying progression into cell division in the $C$. crescentus swarmer cell, we wondered if it might play a similar role in B. quintana. 
Similarly, CtrA plays a key role in control of virulence of the related pathogen B. abortus. We therefore hypothesised that a CtrA homologue could be involved in the cell cycle regulation and virulence of B. quintana. To study this, various research aims were chosen.

1. To find homologues of the C. crescentus regulatory genes in B. quintana and demonstrate their expression.

2. To identify B. quintana genes, likely directly regulated by CtrA, with binding sites within the promoter region.

3. To assess the influence CtrA has over the expression of genes with the binding motif within the promoter region, using a reporter plasmid.

4. To demonstrate the direct interaction between the CtrA protein and the promoter regions of our genes of interest. This will be done using an electrophoretic mobility shift assay (EMSA). 


\section{Materials and Methods.}

\subsection{Bacterial growth media.}

\subsubsection{Solid media.}

Solid media was poured and allowed to set in a UV-treated biosafety cabinet.

\subsubsection{Chocolate agar.}

Ten $\mathrm{g}$ of $\mathrm{BBL}^{\mathrm{TM}}$ freeze-dried bovine haemoglobin and $36 \mathrm{~g}$ of GC Agar base solution were each separately combined with $500 \mathrm{~mL}$ of distilled water. Both solutions were gently heated to boiling and stirred until dissolved, then were autoclaved for 15 minutes at $121{ }^{\circ} \mathrm{C}$, and allowed to cool to $45-50{ }^{\circ} \mathrm{C}$. The $500 \mathrm{~mL}$ solutions of GC base and haemoglobin were aseptically combined along with $10.0 \mathrm{~mL}$ of reconstituted sterile IsoVitaleX enrichment (BBL $\left.{ }^{\mathrm{TM}}\right)$ and mixed well. This combined solution was then transferred into sterile Petri dishes in $27 \mathrm{~mL}$ volumes.

\subsubsection{HIAR plates.}

Twenty g of Heart Infusion Agar base solution (Difco) was added to a 1 L flask along with 500 $\mathrm{mL}$ water before being heated to boiling. The media was then autoclaved for 15 minutes at 121 ${ }^{\circ} \mathrm{C}$. It was then allowed to cool to $45-50{ }^{\circ} \mathrm{C}$ before $25 \mathrm{~mL}$ of defibrinated sheep blood was added to the flask in the biosafety cabinet. The solution was then pipetted in $28-29 \mathrm{~mL}$ volumes into Petri dishes. The plates were then allowed to dry for 15 minutes before being stored at $4{ }^{\circ} \mathrm{C}$. 


\subsubsection{LB agar.}

Thirty-six g of Invitrogen ${ }^{\mathrm{TM}} \mathrm{LB}$ agar powder was combined with distilled water to form a $1 \mathrm{~L}$ solution which was then autoclaved for 15 minutes at $121{ }^{\circ} \mathrm{C}$. Once cooled to $45-50{ }^{\circ} \mathrm{C}, 25 \mathrm{~mL}$ of the media was poured into sterile Petri dishes. For selective plates, antibiotic supplements (Error! Reference source not found.) were added to the media once it cooled to $45-50{ }^{\circ} \mathrm{C}$.

X-gal was also applied to the surface of LB agar plates for blue/white screening to detect $\beta$ Galactosidase activity.

\subsubsection{Liquid media.}

\subsubsection{Lysogeny Broth (LB).}

Twenty g of premixed Lysogeny Broth powder (AcuMedia) was combined with distilled water to form a $1 \mathrm{~L}$ solution; this was autoclaved for 15 minutes at $120{ }^{\circ} \mathrm{C}$. This was stored at room temperature until use.

\subsubsection{M199S.}

M199S was made by aseptically combining $100 \mu \mathrm{L}$ sodium pyruvate $(100 \mathrm{mM})$ with, $100 \mu \mathrm{L}$ GlutaMax (200mM), 8 mL M199 medium (Gibco), and $2 \mathrm{~mL}$ foetal bovine serum. This was filter sterilised and stored at $4{ }^{\circ} \mathrm{C}$ until use. 


\subsubsection{2x YT medium.}

2x YT powder (Sigma Aldrich) was dissolved in water at a concentration of $31 \mathrm{~g} / \mathrm{L}$. This was then autoclaved for 15 minutes at $121^{\circ} \mathrm{C}$. Before the addition of glucose or antibiotics, the media was allowed to cool to $50{ }^{\circ} \mathrm{C}$.

\subsubsection{4 $\beta$-galactosidase assay media.}

This was produced by combining LB broth, then adding kanamycin $(50 \mu \mathrm{g} / \mathrm{mL})$, chloramphenicol (35 $\mu \mathrm{g} / \mathrm{mL})$, ITPG $(0.04 \mathrm{mM})$, and filtered glucose $(2 \mathrm{mg} / \mathrm{ml})$. This solution was made immediately prior to use.

\subsubsection{Supplements.}

Table 1. Media supplements used in this project.

\begin{tabular}{|l|l|l|}
\hline $\begin{array}{l}\text { Supplement. } \\
\text { Kanamycin. }\end{array}$ & Stock solutions. & $\begin{array}{l}\text { Concentration in } \\
\text { media. }\end{array}$ \\
\hline $\begin{array}{l}\text { Chloramphenicol. } \\
\text { Filtered Glucose. }\end{array}$ & $35 \mathrm{mg} / \mathrm{mL}$, in water. & $50 \mu \mathrm{g} / \mathrm{mL}$ \\
\hline X-gal. & $0.2 \mathrm{~g} / \mathrm{mL}$, in water. & $35 \mu \mathrm{g} / \mathrm{mL}$ \\
\hline \begin{tabular}{l} 
Supplements were stored at $-20{ }^{\circ} \mathrm{C}$ except for filtered glucose, which was stored at $4{ }^{\circ} \mathrm{C}$. \\
\hline
\end{tabular}
\end{tabular}




\subsection{Buffers.}

\subsubsection{Z-Buffer.}

Z-Buffer consists of the following chemicals dissolved to the final concentration indicated in water: $\mathrm{NaH}_{2} \mathrm{PO}_{4}(0.074 \mathrm{M}), \mathrm{Na}_{2} \mathrm{HPO}_{4}(0.126 \mathrm{M}), \mathrm{MgSO}_{4}(2 \mathrm{mM}), \mathrm{MnSO}_{4}(0.4 \mathrm{mM}), \mathrm{CTAB}$ (399 $\mu \mathrm{g} / \mathrm{ml})$, Sodium deoxycholate $(199.5 \mu \mathrm{g} / \mathrm{ml})$, and $\beta$-mercaptoethanol $(0.174 \mathrm{M})$. The Z-buffer solution was stored at room temperature without the addition of $\beta$-mercaptoethanol, which was added immediately before being used in an assay.

\subsubsection{T-base.}

T-base was made and stored at $-20^{\circ} \mathrm{C}$ in single use aliquots, by combining the following in a water: $\mathrm{K}_{2} \mathrm{HPO}_{4}(0.08 \mathrm{M}), \mathrm{KH}_{2} \mathrm{PO}_{4}(0.044 \mathrm{M}),\left(\mathrm{NH}_{4}\right)_{2} \mathrm{SO}_{4}(15.1 \mathrm{mM})$, Tri-sodium citrate $(1 \mathrm{~g} / \mathrm{L}), \mathrm{ONPG}$ (Ortho-Nitrophenyl- $\beta$-galactoside) $(8 \mathrm{mg} / \mathrm{mL})$.

\subsubsection{ONPG assay buffer.}

Used for $\beta$-galactosidase assays, this buffer consists of $50 \mathrm{mM} \mathrm{NaPO}_{4}$ buffer ( $\mathrm{pH} 7$ ), Z-Buffer, and T-Base, combined at a ratio of 9:4:1 respectively.

\subsubsection{Tris buffer.}

Tris buffer was made by combining $10 \mathrm{mM}$ Tris, $1 \mathrm{mM}$ EDTA, $50 \mathrm{mM} \mathrm{NaCl}$, with water to a final $\mathrm{pH}$ of 8.0 . 


\subsection{Bacterial strains.}

Table 2. Bacterial strains used during this project.

\begin{tabular}{|c|c|c|}
\hline Bacterial strain. & Characteristics. & Source. \\
\hline E. coli DH5a. & $\begin{array}{l}\text { Cloning strain used for the } \\
\text { construction and cloning of } \\
\text { plasmids. } \\
\text { supE } 44 \text { DlacU } 169 \text { ( } \theta 80 \text { lacZ } \\
\text { DM5) hsdR } 17\end{array}$ & Life Technologies \\
\hline E. coli BL21. & $\begin{array}{l}\text { Host for protein expression } \\
\text { plasmid. } \\
\mathrm{F}^{-} \text {ompT gal dcm lon } h s d S_{B}\left(\mathrm{r}_{\mathrm{B}}^{-}\right. \\
\left.\mathrm{m}_{\mathrm{b}}^{-}\right) \lambda(\mathrm{DE} 3)\end{array}$ & Novagen \\
\hline E. coli k12 ER2420. & Contains pACYC184 plasmid. & $\begin{array}{l}\text { New England BioLabs \#E4152S } \\
\text { [85] [86]. }\end{array}$ \\
\hline E. coli SOS-R2 & $\begin{array}{l}\text { SOS E. coli reporter strain that } \\
\text { carries the lacZ gene in its } \\
\text { chromosome. } \\
\text { ADA-510 } \Delta n f s, \Delta n f s B \\
\Delta a z o R \Delta \text { nemA } \Delta \text { tolC }\end{array}$ & $\begin{array}{l}\text { Kindly provided by the Ackerley } \\
\text { lab }{ }^{[87]} \text {. }\end{array}$ \\
\hline JK-31 B. quintana. & $\begin{array}{l}\text { Marseille-type } B \text {. quintana } \\
\text { strain isolated in March } 1993 \\
\text { from a cutaneous bacillary } \\
\text { angiomatosis lesion of a } \\
\text { human patient in San } \\
\text { Francisco, CA. }\end{array}$ & $\begin{array}{l}\text { This strain was obtained through } \\
\text { BEI Resources, NIAID, NIH: } \\
\text { Bartonella quintana, Strain JK31, } \\
\text { NR-31832. }{ }^{[88]} \text {. }\end{array}$ \\
\hline
\end{tabular}




\subsection{Plasmids.}

Plasmids used and /or constructed throughout this study are described below in Table 3 .

Table 3. Plasmids used or produced during this research.

\begin{tabular}{|c|c|c|c|}
\hline Plasmid. & Size. & Features. & Source \\
\hline pET28a(+) & 5367 bp. & $\begin{array}{l}\text { Kanamycin resistance } \\
\text { Cloning/ expression region } \\
\text { with His tag. }\end{array}$ & Novagen. \\
\hline pET28a(+)-ctrA. & 6063 bp. & $\begin{array}{l}\text { Wild-type ctrA gene from } B \text {. } \\
\text { quintana JK-31 inserted into } \\
\text { the expression site. }\end{array}$ & This study. \\
\hline $\begin{array}{l}\text { pET28a(+)-ctrA } \\
\text { (Codon optimised.) }\end{array}$ & $6063 \mathrm{bp}$. & $\begin{array}{l}\text { Codon optimized ctrA gene } \\
\text { from } B \text {. quintana JK-31 } \\
\text { introduced to expression site. }\end{array}$ & This study. \\
\hline pACYC184. & 4245 bp. & $\begin{array}{l}\text { Chloramphenicol resistance } \\
\text { gene, cloning/expression } \\
\text { region. }\end{array}$ & $\begin{array}{l}\text { New England } \\
\text { Biolabs. }\end{array}$ \\
\hline pACYC184-lacZ. & 7320 bp. & $\begin{array}{l}\text { The full lac } Z \text { gene, amplified } \\
\text { from the SOS-R } 2 \text { genome, } \\
\text { cloned into the unique HindIII } \\
\text { and XbaI restriction sites of } \\
\text { pACYC184. }\end{array}$ & This study. \\
\hline $\begin{array}{l}\text { pACYC184-lacZ- } \\
\text { ctrA. }\end{array}$ & 7645 bp. & $\begin{array}{l}\text { Plasmid with the ctrA } \\
\text { promoter region immediately } \\
\text { upstream of the lacZ gene in } \\
\text { pACYC184-lacZ. }\end{array}$ & This study. \\
\hline $\begin{array}{l}\text { pACYC184-lacZ- } \\
\text { ftsE. }\end{array}$ & 7645 bp. & $\begin{array}{l}\text { Plasmid with the ftsE } \\
\text { promoter region immediately } \\
\text { upstream of the lacZ gene in } \\
\text { pACYC184-lacZ. }\end{array}$ & This study. \\
\hline $\begin{array}{l}\text { pACYC184-lacZ- } \\
\text { hbpC. }\end{array}$ & 7645 bp. & $\begin{array}{l}\text { Plasmid with the } h b p C \\
\text { promoter region immediately } \\
\text { upstream of the lacZ gene in } \\
\text { pACYC184-lacZ. }\end{array}$ & This study. \\
\hline $\begin{array}{l}\text { pACYC184-lacZ- } \\
\text { hemS. }\end{array}$ & 7645 bp. & $\begin{array}{l}\text { Plasmid with the hemS } \\
\text { promoter region immediately } \\
\text { upstream of the lacZ gene in } \\
\text { pACYC184-lacZ. }\end{array}$ & This study. \\
\hline pRARE & 4694 bp. & $\begin{array}{l}\text { Contains genes for tRNA } \\
\text { molecules which are rare in } E \text {. } \\
\text { coli. }\end{array}$ & $\begin{array}{l}\text { Novagen (Merck } \\
\text { Millipore); } \\
\text { Ackerley Lab }\end{array}$ \\
\hline
\end{tabular}




\subsection{1 pET28a(+)}

The B. quintana ctrA gene was cloned and expressed in the pET28a(+) expression plasmid. Included in the plasmid is the ColE1 ori, a kanamycin resistance gene, and the cloning /expression region with a histidine tag. The many restriction sites allow for DNA to be inserted within the expression region downstream of the $\mathrm{T} 7$ promoter with the option of the addition of a polyhistidine tag. For the insertion of the ctrA gene the BamHI and NdeI restriction sites were used for cloning; the ATG start site of $c t r A$ was incorporated into the ATG sites of the NdeI restriction site. The gene cloned into pET28a(+) can be induced by IPTG when the plasmid is in the BL21 host strain.

\subsection{2 pACYC184.}

The pACYC814 plasmid is compatible with the pET28a(+) plasmid, enabling co-expression within a single bacterial cell, due to different origins of replication. The pACYC184 plasmid contains the p15A ori. The promoterless lac $Z$ gene was cloned into this plasmid to generate a reporter plasmid. 


\subsection{Oligonucleotide primers.}

Multiple DNA primers (Integrated DNA Technologies) were used throughout this project to construct the plasmids used as well as test for gene expression in RT-PCR assays. All the primers used are listed below in Table 4.

Table 4. Oligonucleotide primers used throughout this project.

\begin{tabular}{|c|c|c|}
\hline $\begin{array}{l}\text { Oligonucleotide } \\
\text { primers. }\end{array}$ & Sequence. & Features. \\
\hline Bq-ctrA-F & $\begin{array}{l}\text { 5' - GCG CAT ATG CGC GTA TTA TTA ATT } \\
\text { GAA GAT GA - 3' }\end{array}$ & $\begin{array}{l}\text { Used to amplify ctrA from } B \text {. } \\
\text { quintana gDNA; introduces an } \\
\text { NdeI restriction site to the start } \\
\text { of the gene (the ATG in the } \\
\text { NdeI site is also the start } \\
\text { codon). }\end{array}$ \\
\hline Bq-ctrA-R & $\begin{array}{l}5^{\prime}-\text { GCG GGA TCC TTA AGC GGT TTT } \\
\text { ACG TAC GTT TTC TTC }-3 \text {, }\end{array}$ & $\begin{array}{l}\text { Used to amplify } c t r A \text { from } B \text {. } \\
\text { quintana gDNA, introducing a } \\
\text { BamHI site to the end of the } \\
\text { PCR product. }\end{array}$ \\
\hline LacZ_F & $\begin{array}{l}\text { 5' - GCG AAG CTT CTC GAG GCG ATG } \\
\text { CAT ATG ATT ACG GAT TCA CTG GCC } \\
\text { GTC G-3, }\end{array}$ & $\begin{array}{l}\text { Used to amplify the lac } Z \text { gene } \\
\text { from the chromosome of the } E \text {. } \\
\text { coli SOS-R } 2 \text { reporter strain. } \\
\text { Incorporates a HindIII site } \\
\text { (underlined), an XhoI site } \\
\text { (bold), and an NsiI site } \\
\text { (highlighted). }\end{array}$ \\
\hline LacZ_R & $\begin{array}{l}\text { 5' - GCG TCT AGA TTA TTT TTG ACA CCA } \\
\text { GAC CAA CTG G - 3, }\end{array}$ & $\begin{array}{l}\text { Used to amplify the lac } Z \text { gene } \\
\text { from the SOS strain. } \\
\text { Incorporates an XbaI site for } \\
\text { cloning. }\end{array}$ \\
\hline Bq-ftsE-prom-F & $\begin{array}{l}5^{\prime}-\text { GCG CTC GAG CAG ACA CTC TCT } \\
\text { GTT CAT AAT AAG CCA G - 3' }\end{array}$ & $\begin{array}{l}\text { Amplifies the promoter of the } \\
\text { B. quintana ftsE gene and } \\
\text { inserts an XhoI site at the start. }\end{array}$ \\
\hline Bq-ftsE-prom-R & $\begin{array}{l}\text { 5' - GCG ATG CAT TTG TTG TTA CCA CTT } \\
\text { CTG CTT TTA TG - 3, }\end{array}$ & $\begin{array}{l}\text { Amplifies the promoter of the } \\
\text { B. quintana ftsE gene and } \\
\text { inserts an NsiI restriction site. }\end{array}$ \\
\hline
\end{tabular}




\begin{tabular}{|c|c|c|}
\hline Bq-hbpC-prom-F & $\begin{array}{l}\text { 5' - GCG CTC GAG GCT TTC CTT TGC AGT } \\
\text { TGA TGA GAG AG }-3 \text { ' }\end{array}$ & $\begin{array}{l}\text { Amplifies the wild type } B \text {. } \\
\text { quintana } h b p C \text { promoter } \\
\text { region and inserts an XhoI site. }\end{array}$ \\
\hline $\begin{array}{l}\text { Bq-hbpC-prom- } \\
\text { R }\end{array}$ & $\begin{array}{l}\text { 5' - GCG ATG CAT AAT TTT CTC TCC ATA } \\
\text { GCT TAA TAT TTG }-3 \text {, }\end{array}$ & $\begin{array}{l}\text { Amplifies the } B . \text { quintana } \\
h b p C \text { promoter and introduces } \\
\text { an NsiI site. }\end{array}$ \\
\hline Bq-hemS-prom-F & $\begin{array}{l}5^{\prime}-\text { GCG CTC GAG CTG GGA TTT ATA } \\
\text { ATC TAT TTA ATG AG }-3 \text {, }\end{array}$ & $\begin{array}{l}\text { Amplifies the wild type } B \text {. } \\
\text { quintana hemS promoter } \\
\text { region and inserts an XhoI site. }\end{array}$ \\
\hline $\begin{array}{l}\text { Bq-hemS-prom- } \\
\text { R }\end{array}$ & $\begin{array}{l}\text { 5' - GCG ATG CAT AGA TTT GCC TTA TGT } \\
\text { TAT TTA TTG AG }-3 \text { ' }\end{array}$ & $\begin{array}{l}\text { Amplifies the } B \text {. quintana } \\
\text { hemS promoter and introduces } \\
\text { an NsiI site. }\end{array}$ \\
\hline Bq-ctrA-prom-F & $\begin{array}{l}5^{\prime}-\text { GCG } \frac{\text { CTC GAG ACT TTT CGC CTC }}{\text { CAC TAT AGG ATG AAG AG }-3 \text {, }}\end{array}$ & $\begin{array}{l}\text { Amplifies the wild type } B \text {. } \\
\text { quintana ctrA promoter region } \\
\text { and inserts an XhoI site }\end{array}$ \\
\hline Bq-ctrA-prom-R & $\begin{array}{l}\text { 5' - GCG ATG CAT TTT ATA TCC CTC ACT } \\
\text { TTG TTC CTC TC }-3 \text { ', }\end{array}$ & $\begin{array}{l}\text { Amplifies the } B \text {. quintana ctrA } \\
\text { promoter and introduces an } \\
\text { NsiI site. }\end{array}$ \\
\hline T7_F & $5^{\prime}$ - TAA TAC GAC TCA CTA TAG GG $-3^{\prime}$ & $\begin{array}{l}\text { Primer used to amplify the } \mathrm{T} 7 \\
\text { promoter from } \mathrm{pET} 28 \mathrm{a}(+)\end{array}$ \\
\hline T7_R & & $\begin{array}{l}\text { Reverse primer for the } \mathrm{T} 7 \\
\text { promoter amplification. }\end{array}$ \\
\hline CtrA_RTPCR_F & 5' - ATA AAG TCC GGG GGT TTG GC - 3' & $\begin{array}{l}\text { Amplifies a section of the } c t r A \\
\text { gene following reverse } \\
\text { transcription. }\end{array}$ \\
\hline CtrA_RTPCR_R & 5' - CAC GTA ACA CAT AGC CCC GT - 3' & $\begin{array}{l}\text { Used along with } \\
\text { CtrA_RTPCR_F to detect } c t r A \\
\text { expression. }\end{array}$ \\
\hline CckA_RTPCR_F & 5' - AGC CGC ACG GTT AGC ATT AT - 3' & $\begin{array}{l}\text { Primer for RT-PCR, amplifies } \\
\text { a section of } c c k A \text {. }\end{array}$ \\
\hline CckA_RTPCR_R & 5' - TTT GAG GCA AGC CCA TTT GC - 3' & $\begin{array}{l}\text { Reverse primer for } c c k A \text { RT- } \\
\text { PCR amplification. }\end{array}$ \\
\hline ChpT_RTPCR_F & 5' - TGG CTG TCA TTT CGG CAA GT - 3' & $\begin{array}{l}\text { Used to detect } \operatorname{chpT} \text { expression } \\
\text { in RT-PCR. }\end{array}$ \\
\hline ChpT_RTPCR_F & 5' - TTT GCA ATT GGT GCG TTG GG - 3' & $\begin{array}{l}\text { Along with ChpT_RTPCR_F } \\
\text { amplifies a section of } c h p T \text {. }\end{array}$ \\
\hline
\end{tabular}

The introduced restriction sites are underlined throughout, except where indicated. 


\subsection{Standard Experimental Protocols.}

\subsubsection{Bacterial Growth Conditions.}

All bacterial glycerol stocks were stored in cryotubes at $-80^{\circ} \mathrm{C}$ in either LB with glycerol for $E$. coli or M199S with 20\% DMSO for B. quintana stocks. All work with B. quintana was performed in a Class II biosafety cabinet.

B. quintana strain $\mathrm{JK} 31$ was cultured on non-selective chocolate agar at $37^{\circ} \mathrm{C}$ for $7-10$ days inside candle jars. The bacteria cells were streaked from the frozen stocks onto chocolate agar. Once these plates were confluent with growth, B. quintana cultures were harvested and transferred to fresh plates and incubated. These plates were then either used in experimental protocols or further passaged to give more confluent plates. After several passages, the confluent plates were discarded and replaced with plates produced fresh from the frozen stock.

E. coli DH5 $\alpha$ or BL21 were started from frozen stocks and grown overnight either on an LB agar plate at $37{ }^{\circ} \mathrm{C}$ with $5 \% \mathrm{CO}_{2}$ or in $5 \mathrm{~mL}$ of $\mathrm{LB}$ liquid media in a shaking incubator at $37{ }^{\circ} \mathrm{C}, 200$ rpm, with antibiotic supplementation where necessary.

\subsubsection{DNA Purification.}

\subsubsection{Bartonella genomic DNA Isolation.}

The Presto $^{\text {TM }}$ Mini gDNA (DNature) Bacterial kit was used to purify B. quintana gDNA. Confluent B. quintana was scraped from a plate in a Class II biosafety cabinet and suspended in $1 \mathrm{~mL}$ of 
M199S in a $1.5 \mathrm{~mL}$ microcentrifuge tube. This was centrifuged for one minute at 13,200 $\mathrm{g}$ to pellet the cells. Following this, the gDNA isolation was carried out as described in the Presto $^{\mathrm{TM}}$ Mini gDNA (DNature) protocol.

\subsubsection{Plasmid isolation.}

Plasmids were purified from E. coli using the Presto ${ }^{\mathrm{TM}}$ Mini Plasmid Kit (Geneaid). E. coli containing the plasmid of interested were cultured overnight in $5 \mathrm{~mL}$ of LB containing a selective antibiotic at $37^{\circ} \mathrm{C}$ with shaking. Bacteria from this culture were pelleted by centrifuging $1.5 \mathrm{~mL}$ of culture suspension for one minute, before discarding the supernatant. The plasmid was purified from the pelleted cells according to the Presto ${ }^{\mathrm{TM}}$ Mini Plasmid Kit (Geneaid) protocol. Eluted DNA was stored at $-20^{\circ} \mathrm{C}$ until use.

\subsubsection{DNA purification.}

DNA from PCR or other enzymatic reactions was purified using the DNA Clean \& Concentrator ${ }^{\mathrm{TM}}-5$ (Zymo) following the protocol provided. An extra 2-minute spin was done following the wash to dry the column and remove any trace ethanol. The purified DNA was either stored at $-20^{\circ} \mathrm{C}$ or used immediately.

\subsubsection{DNA Dialysis.}

Prior to electroporation, DNA was dialysed to increase ligation efficiency and to remove contaminating salts. This was done using a pitted $1 \%$ agarose gel containing glucose in a 
microcentrifuge tube. The solution containing DNA to be dialysed was transferred to the well and left for 40 minutes to one hour. Alternatively, DNA to be dialysed was pipetted onto a nitrocellulose membrane floating on distilled water in a Petri dish and incubated for 30-40 minutes. The dialysed DNA was carefully removed and either used in electroporation or stored at $-20{ }^{\circ} \mathrm{C}$.

\subsubsection{Polymerase Chain reaction.}

PCR reactions were generally performed using the Q5 high fidelity polymerase (NEB) in $0.2 \mathrm{~mL}$ PCR tubes in thermal cyclers (Kyratec). The standard reaction mixture and cycling parameters are shown below in Table 5 and Table 6 .

Table 5. Standard PCR mix using the Q5 high fidelity polymerase (NEB).

\begin{tabular}{|l|l|}
\hline Advantage reaction mixture. & Volume. \\
\hline Template DNA $(\mathbf{1} \mathbf{n g}-\mathbf{1 0 0} \mathbf{\text { ng}})$. & $1 \mu \mathrm{L}$ \\
\hline Forward primer $(\mathbf{1 0} \boldsymbol{\mu M})$ & $2.5 \mu \mathrm{L}$ \\
\hline Reverse primer $(\mathbf{1 0} \boldsymbol{\mu M})$ & $2.5 \mu \mathrm{L}$ \\
\hline dNTP mix, 10 M of each dNTP. & $1 \mu \mathrm{L}$ \\
\hline Q5 polymerase (NEB). & $0.5 \mu \mathrm{L}$ \\
\hline Q5 PCR buffer (5x). & $10 \mu \mathrm{L}$ \\
\hline ddH2 $\mathbf{O}$ & $32.5 \mu \mathrm{L}$ \\
\hline & Total $50 \mu \mathrm{L}$ \\
\hline
\end{tabular}

Table 6. Standard PCR temperature cycling parameters.

\begin{tabular}{|l|l|l|l|}
\hline PCR conditions. & Temperature & Step time. & $\begin{array}{l}\text { Number of } \\
\text { cycles. }\end{array}$ \\
\hline Pre-heat. & $98^{\circ} \mathrm{C}$ & 1 minute. & \\
\hline Denaturation. & $98^{\circ} \mathrm{C}$ & 30 seconds. & 35 cycles. \\
\hline Annealing/Extension. & $72^{\circ} \mathrm{C}$ & 1 minute. & \\
\hline Post cycle extension. & $72^{\circ} \mathrm{C}$ & 1 minute. & \\
\hline Post cycle hold. & $4^{\circ} \mathrm{C}$ & Post cycle hold. & \\
\hline
\end{tabular}

Note, the annealing temperature and extension time varied depending on the primers used and the length of the PCR product. 


\subsubsection{Agarose Gel Electrophoresis.}

Gels were made by combining $0.6 \mathrm{~g}$ of LE Agarose Hyagarose ${ }^{\mathrm{TM}}$ powder (Hydragene) with 60 $\mathrm{mL}$ of $1 \times$ TAE buffer. The agarose was melted by microwave for 1-2 minutes and $3 \mu \mathrm{L}$ of RedSafe non-toxic nucleic acid staining solution (JH Science) was added and mixed. The solution was then poured into the gel electrophoresis apparatus. Five $\mu \mathrm{L}$ of the DNA reference ladder Hyperladder ${ }^{\mathrm{TM}}$ (Bioline) was added to one well, $1 \mu \mathrm{L}$ of loading buffer $5 \mathrm{x}$ (Bioline) was added to $5 \mu \mathrm{L}$ of DNA solution and loaded onto the gel. Gels were run at $100 \mathrm{~V}$ for 60 minutes before being visualised under ultraviolet light or scanned with a typhoon FLA 9500.

\subsubsection{Restriction enzyme digestion.}

PCR products and plasmids were digested using restriction enzymes when appropriate. This was done by combining the following components.

Table 7. Components for restriction enzyme reactions.

\begin{tabular}{|l|l|}
\hline For PCR products. & Volume \\
\hline Purified PCR product. & $5 \mu \mathrm{L}$ \\
\hline Restriction enzyme 1. & $1-0.5 \mu \mathrm{L}$ \\
\hline Restriction enzyme 2. & $1-0.5 \mu \mathrm{L}$ \\
\hline Restriction buffer. & $2 \mu \mathrm{L}$ \\
\hline ddH $_{2} \mathrm{O}$. & $11-12 \mu \mathrm{L}$ \\
\hline & Total $20 \mu \mathrm{L}$ \\
\hline For plasmid. & \\
\hline Purified Plasmid & \\
\hline Restriction enzyme 1. & $1-0.5 \mu \mathrm{L}$ \\
\hline Restriction enzyme 2. & $1-0.5 \mu \mathrm{L}$ \\
\hline Restriction buffer. & $2 \mu \mathrm{L}$ \\
\hline ddH ${ }_{2}$ O. & $14-15 \mu \mathrm{L}$ \\
\hline & Total $20 \mu \mathrm{L}$ \\
\hline
\end{tabular}


These solutions were then incubated for $5-6$ hours at $37^{\circ} \mathrm{C}$, the samples were then purified using the DNA Clean \& Concentrator ${ }^{\mathrm{TM}_{-}}$5 (Zymo) (2.6.2) or immediately used in gel electrophoresis (Agarose Gel Electrophoresis.2.6.5).

\subsubsection{Ligation reactions.}

Ligation reactions were carried out using Life Technologies T4 DNA Ligase and 10× Ligase buffer. The standard ligation reaction was set up by combining the following.

Table 8. Ligation reaction mixture.

\begin{tabular}{|l|l|}
\hline Components & Volume. \\
\hline T4 DNA Ligase. & $1 \mu \mathrm{L}$ \\
\hline 10x Ligation buffer. & $1 \mu \mathrm{L}$ \\
\hline Purified PCR product. & $5 \mu \mathrm{L}$ \\
\hline Purified Plasmid. & $3 \mu \mathrm{L}$ \\
\hline & Total $10 \mu \mathrm{L}$ \\
\hline
\end{tabular}

This reaction mixture was incubated overnight in a thermal cycler that was set to continuously cycle overnight between $10{ }^{\circ} \mathrm{C}$ and $30{ }^{\circ} \mathrm{C}, 30$ seconds each, this temperature variation has been shown to facilitate efficient ligation reactions ${ }^{[89]}$.

\subsubsection{Electroporation of $E$. coli cells.}

E. coli DH5 $\alpha$ or BL21 were grown overnight in $5 \mathrm{~mL} \mathrm{LB}$ broth at $37^{\circ} \mathrm{C}$ in a shaking incubator. This culture was then used to produce electrocompetent cells following a standard protocol ${ }^{[78]}$.

To microcentrifuge tubes, $40 \mu \mathrm{L}$ of electrocompetent cell suspension was added along with $2 \mu \mathrm{L}$ of the plasmid or purified, dialysed ligation reaction. Once mixed they were transferred to a cold $2 \mathrm{~mm}$ electroporation cuvette which was pulsed at $25 \mu \mathrm{F}$ capacitance, $200 \Omega$ resistance, and 2.5 $\mathrm{kV}$. Immediately following the electroporation, $1 \mathrm{~mL} 37{ }^{\circ} \mathrm{C} \mathrm{LB}$ or $2 \mathrm{X}$ YT broth was transferred 
into the electroporation cuvette before being removed to a Falcon tube. The solution was incubated at $37^{\circ} \mathrm{C}$ for one hour in a shaking incubator, before various dilutions were plated onto selective LB plates. The plates were incubated at $37{ }^{\circ} \mathrm{C}$ overnight and colonies were screened the following morning.

Colonies from selective LB plates were cultured overnight in $5 \mathrm{~mL}$ LB broth at $37{ }^{\circ} \mathrm{C}$ supplemented with appropriate selective antibiotics. The following morning, plasmid DNA was isolated and digested with restriction enzymes. The DNA products were then run on an agarose gel and observed under ultraviolet light or scanned.

\subsubsection{SDS PAGE.}

Protein solutions were combined with NuPAGE LDS sample buffer (Life Technologies) at a 1:1 ratio and heated at $85^{\circ} \mathrm{C}$ for 3 minutes. Samples were then loaded onto $1.0 \mathrm{~mm}$ NuPAGETM 4-12 $\%$ Bis-Tris gels (Life Technologies). Gels were run for 35 minutes at $200 \mathrm{~V}$ using NuPAGE® MES SDS Running Buffer (Life Technologies), and SeeBlue ${ }^{\circledR}$ Plus2 Prestained Standard ladder (Life Technologies) to determine the size of protein bands present in the gels. To visualize protein bands, gels were stained with SimplyBlue ${ }^{\mathrm{TM}}$ Safe Stain (Life Technologies), before being destained with water. The gels were then scanned or photographed to identify protein bands in the gels. 


\subsection{Bioinformatics.}

\subsubsection{Motif search.}

NCBI BLAST tools (https://blast.ncbi.nlm.nih.gov/Blast.cgi) were used to detect CtrA half (TTAACCAT) and full (TTAAN 7 TTAAC) DNA binding motifs throughout the genome of $B$. quintana Toulouse (NCBI Reference Sequence: NC_005955.1). Once detected these binding motif locations were compared to predicted locations of genes on the chromosome, binding motifs which were located within $400 \mathrm{bp}$ of a gene start site were considered to potentially be within the regulatory region of that gene. Genes found to have CtrA binding motifs located between 0-400 bp upstream of their start sites were recorded and evaluated as candidates for further study. We included genes that had a CtrA binding motif within the predicted coding region, but near the start of the gene.

\subsubsection{Protein homology search.}

To compare the amino acid sequences of B. quintana and C. crescentus homologues of CtrA, ChpT, CckA, SciP, DnaA, CcrM, and GcrA, we use NCBI Protein BLAST tools. The amino acid sequence of each of these proteins from C. crescentus was compared to the predicted amino acid sequences of the corresponding proteins in B. quintana Toulouse. Putative homologous proteins were identified and their percentage amino acid identity recorded. 


\subsubsection{Rare codon analysis.}

To test for rare codons for E. coli present in the B. quintana ctrA gene, its sequence was analysed using GenScript ${ }^{\circledR}$ Rare codon analysis tool (https://www.genscript.com/tools/rare-codonanalysis).

\subsection{Plasmid construction.}

\subsection{1 pET28a(+)-ctrA.}

To construct the pET28a(+)-ctrA plasmid, the $c t r A$ gene was amplified by PCR using $B$. quintana JK-31 genomic DNA as a template. The gene was amplified with primers Bq-ctrA-F and Bq-ctrA$\mathrm{R}$, using standard PCR protocols (2.6.4). The Bq-ctrA-F and Bq-ctrA-R primers were engineered to introduce BamHI and NdeI restriction sites to the PCR product, enabling cloning of the product into pET28a $(+)$ in the correct orientation. Primers were also designed to ensure the protein would be expressed with an $\mathrm{N}$-terminal histidine tag translational fusion. The concentration and purity of the purified PCR product and the intact $\mathrm{pET} 28 \mathrm{a}(+)$ vector were measured using a Nanodrop spectrophotometer (Thermo Fisher Scientific), with an expected 260/280 ratio of approximately 1.8.

Both the purified PCR product and the pET28a(+) plasmid were digested with BamHI and NdeI enzymes for $4-5$ hours at $37^{\circ} \mathrm{C}$. The plasmid was then treated with $1 \mu \mathrm{L}$ of calf intestinal alkaline phosphatase (CIAP; Invitrogen) for 10 minutes, followed by addition of EDTA and heat 
inactivation of CIAP at $65^{\circ} \mathrm{C}$ for 15 minutes. The plasmid and digested insert were both purified using a Zymo Clean \& Concentrator column and combined.

For this ligation, a molar ratio of $1: 3$ to $1: 5 \mathrm{pET} 28 \mathrm{a}(+)$ to $c t r A$ insert was used in a $20 \mu \mathrm{L}$ ligation reaction solution. The ligation reaction was purified with a Zymo column followed by drop dialysis, then electroporated into electrocompetent E. coli DH5 $\alpha$. Following the screening for plasmids containing the $c t r A$ insert, a few plasmids were confirmed by Sanger sequencing. Once the plasmid was confirmed to be correct it was electroporated into E. coli BL21cells for the expression and purification of the protein.

\subsubsection{1 pET28a(+)-ctrA codon optimised.}

A version of B. quintana ctrA that was codon-optimised for expression in E. coli was obtained using the codon optimisation tool on the IDTDNA website (http://sg.idtdna.com/CodonOpt). Both BamHI and NdeI restriction sites were engineered onto the ends of the sequence, ensuring that the product would retain an in-frame N-terminal histidine tag when cloned into pET28a(+). The codon-optimised sequence was synthesised by IDTDNA as a gBlock double-stranded DNA sequence. The gBlock product was resuspended in TE and was cloned into pET28a(+) using essentially the same method as described for the PCR-amplified insert. For these cloning steps, the LB plates and media were supplemented with glucose to suppress uninduced expression of the codon-optimised ctrA gene. A final concentration of $2 \mathrm{mg} / \mathrm{mL}$ filtered glucose was used, added to the LB once it had cooled to around $50^{\circ} \mathrm{C}$, along with the antibiotics. 


\subsection{2 pACYC184-lacZ reporter plasmid.}

To construct a LacZ reporter plasmid, we first amplified the full lacZ gene from the chromosome of an E. coli SOS reporter strain, SOS-R2 ${ }^{[87]}$. The lacZ gene was amplified using the LacZ_F and LacZ_R primers (Table 4), which introduce HindIII and XbaI restriction sites at each end of the molecule, to enable cloning into the pACYC184 plasmid in the correct orientation. The extension time of the standard PCR protocol (Table 6) was increased to 3 minutes, since the lacZ gene is approximately $3000 \mathrm{bp}$.

The PCR products were purified using a Zymo Clean \& Concentrator column; at the same time, the pACYC184 plasmid, purified from E41525 E. coli (NEB), was digested with the same enzymes and purified with a Zymo column. The plasmid and insert were then ligated as described previously. The ligation was dialyzed and electroporated into DH5 $\alpha$, followed by selection on chloramphenicol plates. Resulting pACYC184-lacZ plasmids which had the correct size insert were sent for sequencing to confirm their successful construction.

Next promoter regions of interest were cloned just upstream of the lac $Z$ gene in the pACYC184lac $Z$ reporter plasmid. The promoter regions of genes potentially regulated by CtrA were amplified with their corresponding primers and cloned upstream of the lac $Z$ gene. We also generated a control plasmid with the T7 IPTG-inducible promoter upstream the lacZ gene. The primers used to amplify the promoter regions were engineered to incorporate XhoI and NsiI restriction sites, to enable cloning of the promoter regions directly upstream of the lacZ gene in the correct orientation. The NsiI restriction site includes an ATG, which was incorporated into the start site of the lacZ 
gene, ensuring there was no gap between the promoter and the gene. Once the promoter regions were amplified, they were each digested with XhoI and NsiI, as was the pACYC184-lacZ plasmid. Digested plasmid and PCR products were ligated, and dialysed, and electroporated into E. coli DH5 $\alpha$. Resulting plasmids were screened by restriction digest and confirmed by Sanger sequencing. The pACYC184-lacZ-T7 plasmid was used to test the activity of the $\beta$-galactosidase by observing the formation of a blue product in colonies grown in the presence of IPTG and Xgal.

Once the completed pACYC184-lacZ reporter plasmids had been confirmed by restriction digest and sequencing, they were electroporated into the E. coli BL21strain that also contained the pET28a(+)-ctrA plasmid. Colonies were selected on LB plates containing kanamycin and chloramphenicol, to select for both plasmids. E. coli BL21strains containing both plasmids were then used in the $\beta$-galactosidase assay.

\subsection{CtrA induction.}

\subsubsection{Protein induction and verification.}

To induce the expression of CtrA, E. coli BL21 containing pET28a(+)-ctrA were grown overnight on selective kanamycin LB plates. The following day a colony was collected and used to inoculate a $5 \mathrm{~mL}$ kanamycin $\mathrm{LB}$ broth and grown overnight at $37^{\circ} \mathrm{C}$ with shaking. The next morning a fresh tube of broth was inoculated using overnight culture to give an $\mathrm{OD}_{600}$ of 0.1 , and its growth was monitored until it reached an $\mathrm{OD}_{600}$ of 0.6 , at which point a $1 \mathrm{~mL}$ control sample was taken as an uninduced control. IPTG was added to the remaining solution at a final concentration of $0.4 \mathrm{mM}$ 
and incubated for another 2-3 hours. The culture was then put on ice for 5 minutes before taking 1 $\mathrm{mL}$ samples. Collected samples were centrifuged at maximum speed in a microcentrifuge to pellet the bacteria. To lyse the bacteria, the pellets were suspended in $100 \mu \mathrm{L}$ PBS and $100 \mu \mathrm{L}$ SDS sample buffer and heated to $85^{\circ} \mathrm{C}$ for 3 minutes. Samples were then stored at $-20^{\circ} \mathrm{C}$ or immediately run on NuPAGE 4-12\% Bis-Tris, after dilution to achieve equal total protein concentrations. This protein induction was also scaled up to using 100-300 mL of inoculated LB supplemented with appropriate antibiotics, before being incubated under the same conditions, then chilled on ice for 30 minutes.

\subsubsection{Isolation of cytoplasmic fraction.}

To isolate the cytoplasmic fraction proteins, the induced and uninduced samples were centrifuged at $10,000 \times g$ for 10 minutes, before discarding the supernatant and replacing it with BugBuster® protein extraction reagent $5 \mathrm{~mL} / \mathrm{g}$ (Novagen) per gram bacterial pellet. To lyse the cells, the samples were incubated for 20 minutes on a shaker at room temperature, before being centrifuged at $16,000 \times g$ at $4{ }^{\circ} \mathrm{C}$ for 20 minutes. The resulting pellet, consisting of insoluble cell debris, was then discarded. To confirm that the induced protein was present in the soluble fraction, a sample

of the supernatant was analysed using SDS-PAGE gels. Small samples of both the induced and uninduced cultures were taken prior to the disposal of the insoluble fraction for testing, to detect the presence CtrA in the insoluble fraction. 


\subsubsection{Histidine tag purification.}

The engineered pET28a(+)-ctrA plasmid adds a translational fusion of a six histidine tag to the $\mathrm{N}-$ terminus of the expressed CtrA protein. This tag enables the induced protein to be purified using the HIS-Select® spin columns (Sigma Aldrich). The manufacturer's protocol for purification of proteins under native conditions was followed. The resulting amount of purified protein was with visualised using SDS polyacrylamide gel electrophoresis.

The concentration of purified CtrA protein was measured using Quick Start ${ }^{\mathrm{TM}}$ Bradford $1 \times$ Dye Reagent (Bio-Rad), as per the manufacturer's instructions, or using the NanoDrop spectrophotometer. To increase the protein concentration, Amicon® ultra $0.5 \mathrm{~mL}$ centrifuge filters (Micron) were used. Purified protein solutions were filter sterilised using a syringe with a $30 \mathrm{~mm}$ PES membrane with $0.22 \mu \mathrm{L}$ pore size (BioFil) and stored at $4{ }^{\circ} \mathrm{C}$ or used immediately.

\section{$2.10 \beta$-galactosidase assay.}

We used a $\beta$-galactosidase assay to detect interactions between $B$. quintana $\mathrm{Ctr} A$ and promoters of interest, identified through bioinformatics analysis, using an previously described modified method $^{[90]}$.

Briefly, E. coli BL21 strains containing the pET28a(+)-ctrA, and pACYC184-lacZ reporter plasmids were incubated overnight in LB with chloramphenicol and kanamycin supplements. Their $\mathrm{OD}_{600}$ absorbance was measured the following morning. The cultures were then diluted with 
$\beta$-galactosidase assay media (0) to a final volume of $1 \mathrm{~mL}$ and an $\mathrm{OD}_{600}$ of 0.1 . Controls were set up for each strain, including media lacking ITPG and a control strain with a promoter-less lacZ gene on the pACYC184-lacZ plasmid. All cultures were then incubated in Falcon tubes in a shaking incubator set at $30^{\circ} \mathrm{C}, 200 \mathrm{RPM}$, for $2.5-3$ hours, or until the cultures reached an $\mathrm{OD}_{600}$ of 0.5-0.7. This incubation period allowed for CtrA induction and expression, as well as $\beta$ galactosidase production. After the incubation, the $\mathrm{OD}_{600}$ of each cell suspension was measured, before 5-20 $\mu \mathrm{L}$ aliquots of each sample were transferred to a 96-well plate and combined with $130-145 \mu \mathrm{L}$ of ONPG assay buffer for a total volume of $150 \mu \mathrm{L}$. The reactions were allowed to proceed in a $37{ }^{\circ} \mathrm{C}$ incubator with no shaking for 15-20 minutes, or when sufficient colour was produced. To stop the reaction, $50 \mu \mathrm{L}$ of $1 \mathrm{M} \mathrm{Na}_{2} \mathrm{CO}_{3}$ was added to each well. The solutions were then measured at $\mathrm{OD}_{420}$ and $\mathrm{OD}_{550}$, and applied to the following equation:

$$
\text { Miller Units }=\left(\mathrm{OD}_{420}-1.75 \times \mathrm{OD}_{550}\right) /\left(\mathrm{T} \times \mathrm{OD}_{550}\right)
$$

Where $\mathrm{T}$ is the reaction incubation time in minutes.

\subsubsection{Statistical analysis.}

$\beta$-galactosidase assay data was analysed using an independent samples $\mathrm{T}$ test. Data sets for each promoter pair were imported into IBM SPSS Statistics (IBM) and analysed for statistical assumptions and the $\mathrm{P}$ value for the differences between means of induced and uninduced samples was calculated. 


\section{$2.11 \operatorname{ctr} A, \operatorname{cck} A$, and $\operatorname{chp} T$ expression.}

\subsubsection{RNA isolation.}

While working with RNA, all steps were performed in a Class II biosafety cabinet using RNasefree reagents and equipment.

B. quintana was collected from confluent plates, resuspended in M199S and pelleted by centrifugation. The supernatant was discarded completely, and the pellet was frozen at $-80^{\circ} \mathrm{C}$ overnight or longer, a step that helps lyse the bacterial cell envelope. In the biosafety cabinet, the pellets were thawed briefly at room temperature and resuspended in $50 \mu 1$ of a lysozyme solution ( $0.4 \mathrm{mg} / \mathrm{mL}$ lysozyme in TE; Sigma) by gently tapping of the sides of the tubes. The resuspended bacteria were incubated for 5 minutes at room temperature. To lyse the bacterial cells, $950 \mu 1$ of TRIzol reagent (Life Technologies) was added to each sample. Tubes were closed and vortexed at top speed for 30-60 seconds, then incubated for a further 5 minutes at room temperature. Chloroform $(200 \mu \mathrm{L})$ was added to each sample. The tubes were sealed and mixed by shaking by hand for 15 seconds, then incubated at room temperature for 2-3 minutes. The phases were separated via centrifugation at $4^{\circ} \mathrm{C}$ at $16,000 \times \mathrm{g}$ for 15 minutes. RNA was contained in the colourless upper phase, which was pipetted to a fresh tube while avoiding the disruption of the lower phases. The aqueous phases of up to four bacterial pellets were combined in a single 50-ml Falcon tube at this stage. 
To further purify the RNA samples, an equivalent volume of ethanol was slowly added to the extracted upper phase samples while gently simultaneously vortexing the tube at the lowest possible speed. This RNA-ethanol solution was then loaded into Direct-zol' ${ }^{\text {TM }}$ RNA MiniPrep Plus (Zymo) columns in $700 \mu \mathrm{L}$ aliquots, centrifuged for 30 seconds, and the flow-through discarded. This was repeated as needed until the whole sample had been applied to the columns. From this stage, the RNA-cleanup protocol, provided by the manufacturer, was followed, with the exception of an extra, final wash step to ensure there was absolutely no ethanol carried over on the column. The final RNA samples were eluted in $50 \mu 1$ of RNAse-free water.

A small sample $(5 \mu \mathrm{l})$ was taken from the isolated RNA for analysis of concentration and purity using the NanoDrop spectrophotometer. After purification, RNA was stored at $-80{ }^{\circ} \mathrm{C}$ or used immediately.

\subsubsection{DNase reaction.}

To remove contaminating genomic DNA from the RNA preparations, DNase I 1X reaction buffer (New England BioLabs®) was added to $10 \mu \mathrm{g}$ RNA resuspended in a final volume of $100 \mu \mathrm{L}$. Two units of DNase I (New England BioLabs®) were added to the suspension and mixed thoroughly before being incubated at $37{ }^{\circ} \mathrm{C}$ for 10 minutes. To inactivate the DNase, $1 \mu \mathrm{L}$ of EDTA 0.5 M was added and the sample was heat inactivated for 10 minutes at $75{ }^{\circ} \mathrm{C}$. 


\subsubsection{RNA reverse transcription.}

The reverse transcription of the isolated RNA to cDNA was carried out using the GoScript ${ }^{\mathrm{TM}}$ reverse transcription system (Promega). A random hexamer primer was used to amplify all RNA species in the cell. The following reagents were mixed and briefly centrifuged: purified B. quintana RNA (est. $100-500 \mathrm{ng}), 1 \mu \mathrm{L}$ of random hexamer primers $(0.5 \mu \mathrm{g} /$ reaction), and nuclease-free water, giving a total volume of $5 \mu \mathrm{L}$. This solution was heated for 5 minutes at $70{ }^{\circ} \mathrm{C}$, to denature RNA secondary structures, then rapidly cooled for 5 minutes on ice. The sample was briefly centrifuged to collect the liquid at the bottom of the microcentrifuge tube and was combined with the reverse transcription mix, which was produced by combining the reagents shown in Table 9 on ice.

Table 9. Reverse transcription mixture.

\begin{tabular}{|l|l|}
\hline Reverse transcription mixture. & Volume. \\
\hline GoScript $^{\text {TM }}$ 5X Reaction Buffer. & $4.0 \mu \mathrm{L}$ \\
\hline MgCl2 1.5-5.0 mM. & $2.0 \mu \mathrm{L}$ \\
\hline GoScript $^{\text {MM Reverse Transcriptase. }}$ & $1.0 \mu \mathrm{L}$ \\
\hline PCR Nucleotide Mix. & $1.0 \mu \mathrm{L}$ \\
\hline Nuclease-Free Water. & $7.0 \mu \mathrm{L}$ \\
\hline & Total $15 \mu \mathrm{L}$ \\
\hline
\end{tabular}

This was mixed well and kept on ice until use. Fifteen $\mu \mathrm{L}$ of the reverse transcription reaction mix was added to a prepared reaction tube, containing $5 \mu \mathrm{L}$ of $B$. quintana RNA and primer mix, for a final volume of $20 \mu \mathrm{L}$. The reaction tube was then incubated in a thermal cycler at $25{ }^{\circ} \mathrm{C}$ for five minutes to allow for annealing. Next, the reaction tube was incubated in a $42{ }^{\circ} \mathrm{C}$ for up to an hour to allow for the extension of the cDNA molecules. To inactivate the reverse transcription before 
PCR, the sample was incubated in a $70{ }^{\circ} \mathrm{C}$ heat block for 15 minutes. This results in single stranded cDNA molecules, which were stored at $-20{ }^{\circ} \mathrm{C}$ until used.

The RT-PCR products were then amplified using PCR (2.6.4). Also included were positive control reactions, with genomic DNA template, and negative controls (i.e., samples that omitted reverse transcriptase). Following reverse transcription, all the tested samples were run on a gel to detect expression of our genes of interest in viable bacteria. 


\section{Results.}

\subsection{Introduction.}

CtrA is a conserved, essential master regulatory protein found in alpha-proteobacteria, and has been shown to regulate the cell cycles and virulence of bacteria in this class ${ }^{[83]}$. However, its role in the cell cycle and virulence of B. quintana has not been characterised. In this research project, our aim was to identify genes potentially directly regulated by CtrA and demonstrate CtrApromoter interactions. We anticipated that identification of genes potentially regulated by CtrA would provide insights into its role in the life cycle and virulence of B. quintana.

\subsection{B. quintana homologue identity.}

Starting this project, it was important to first establish the similarities of the CtrA and master regulatory proteins between $B$. quintana and $C$. crescentus, in which the role of CtrA has been dissected in detail ${ }^{[56-58]}$. CtrA is one of five master regulatory genes in C. crescentus, but these are not universal throughout the alpha-proteobacteria class. Searching for these genes in the $B$. quintana str. Toulouse genome would identify their presence in B. quintana. We could next ask the question of whether B. quintana CtrA has a comparable role to that of C. crescentus, and to determine the best course of action to answer that question.

The B. quintana str. Toulouse genome (NCBI Reference Sequence NC_005955.1) was used in all bioinformatics work because it has the best annotated B. quintana genome. The percentage identity between the predicted amino acid sequences of regulatory proteins of the two species was analysed. To do this a protein BLAST against the proteome of B. quintana str. Toulouse was 
performed using the amino acid sequence of the ChpT, CckA, CtrA, SciP, DnaA, CcrM, and GcrA protein found in $C$. crescentus. Once the B. quintana homologues were identified, protein alignments were performed, using the NCBI protein BLAST tool, on the identified B. quintana proteins, comparing them to the amino acid sequence of their homologous proteins in $C$. crescentus. Gene locations on the chromosome were also recorded (Table 10).

Table 10. B. quintana homologue identity.

\begin{tabular}{|l|l|l|}
\hline $\begin{array}{l}\text { Protein or peptide } \\
\text { sequence. }\end{array}$ & $\begin{array}{l}\text { Chromosome location and locus tag } \\
\text { (NCBI). }\end{array}$ & $\begin{array}{l}\text { Amino acid } \\
\text { percentage } \\
\text { identity. }\end{array}$ \\
\hline CtrA. & $1,124,285-1,124,986$ (BQ_RS04685). & $81 \%$ \\
\hline $\begin{array}{l}\text { CtrA DNA binding } \\
\text { domain. }\end{array}$ & $\begin{array}{l}1,124,415-1,124,986 \text { (last } 110 \text { amino } \\
\text { acids of CtrA) }\end{array}$ & $82 \%$ \\
\hline CckA. & $870,492-872,981$ (BQ_RS03665). & $41 \%$ \\
\hline ChpT. & $1,125,200-1,125,838$ (BQ_RS04690). & $28 \%$ \\
\hline SciP & $1,122,930-1,123,205$ (BQ_RS04675). & $81 \%$ \\
\hline DnaA & $146,196-147,767$ (BQ_RS00560). & $39 \%$ \\
\hline CcrM & $458,452-459,501$ (BQ_RS01890). & $61 \%$ \\
\hline GcrA & $137,737-138,270$ (BQ_RS00520). & $42 \%$ \\
\hline
\end{tabular}

Summary of $C$. crescentus master cell cycle regulators and identification of their homologues in B. quintana str. Toulouse genome. The location of the gene on the B. quintana str. Toulouse genome is indicated, as well as the percent amino acid identity between the predicted B. quintana homologue amino acid sequences and $C$. crescentus proteins. 
This shows the CtrA protein, and specifically its DNA binding domain, share high percentage identity with their $C$. crescentus homologues (appendix 1), suggesting it is likely that $B$. quintana CtrA binds a similar DNA motif. SciP also showed a high amino acid percentage identity suggesting its activity is also highly conserved between $B$. quintana and C. crescentus. Some of the other proteins, such as ChpT, showed a lower percentage identity, suggesting that their role in the cell may have diverged more compared to CtrA. The locations of $\operatorname{ctr} A, \operatorname{chpT}$, and $s c i P$ are very close together on the B. quintana chromosome, shown in Figure 4.

Figure 4. Schematic representation of the sciP, $\operatorname{ctr} A$, and $\operatorname{chpT}$ genes organisation.

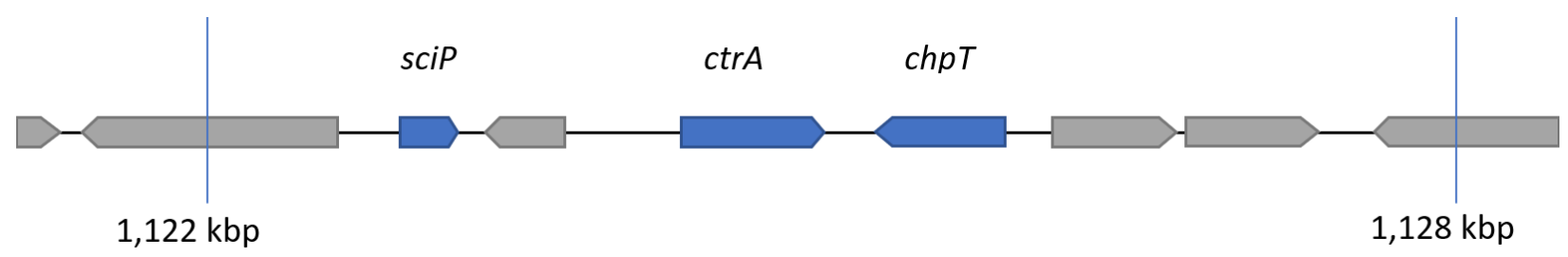

This figure shows the architecture of a small gene locus on the chromosome of B. quintana str. Toulouse, containing the $s c i P$, $\operatorname{ctr} A$, and $\operatorname{chpT}$ genes.

Other members of the alpha-proteobacteria class have also shown similar organisation, with $B$. bacilliformis having the same organisation and orientation of genes. The corresponding genes of S. meliloti and Mesorhizobium loti are also very similarly organised. C. crescentus deviates from theses alpha-proteobacteria members with its $\operatorname{chpT}$ gene located approximately $0.5 \mathrm{Mbp}$ upstream of $\operatorname{ctr} A$ and sciP being about $2.2 \mathrm{Mbp}$ downstream ${ }^{[91]}$. 


\section{3 ctrA, cckA, and $\operatorname{chpT}$ expression.}

Having identified the gene homologues of CtrA, CckA, and ChpT, we next wanted to show that the genes are expressed in $B$. quintana. These genes produce proteins constituting the core signalling pathway that activates $\mathrm{CtrA}$ in $C$. crescentus. Their expression is central to the regulation of $\mathrm{Ctr} A$, and our homology search (3.2) revealed that these three genes are present in B. quintana. Because of the importance of this signalling pathway in C. crescentus, a clear next step was to detect the expression of these genes by RT-PCR, using purified B. quintana str. JK-31 RNA.

Total RNA was purified from plates of confluent B. quintana str. JK-31. The concentration and purity of the RNA was tested with a NanoDrop spectrophotometer, with a total of $1120 \mathrm{ng}$ RNA extracted with an A260/A280 of 1.98. We used a sample of the total RNA as a template for PCR with the CtrA_RTPCR_F and CtrA_RTPCR_R primers. No PCR product was detected on a gel, indicating that genomic DNA had not been carried over.

From the total bacterial RNA, 44.8 ng was reverse transcribed, using random hexamer primers, to generate cDNA. A negative control was treated identically, but with the reverse transcriptase enzyme omitted. The resulting cDNA was used as a template for PCR, with purified genomic DNA from the $B$. quintana JK-31 strain included as a positive control. The PCR products were analysed using gel electrophoresis (Figure 5). 
Figure 5. ctrA, $c c k A$, and $c h p T$ expression from RT-PCR.
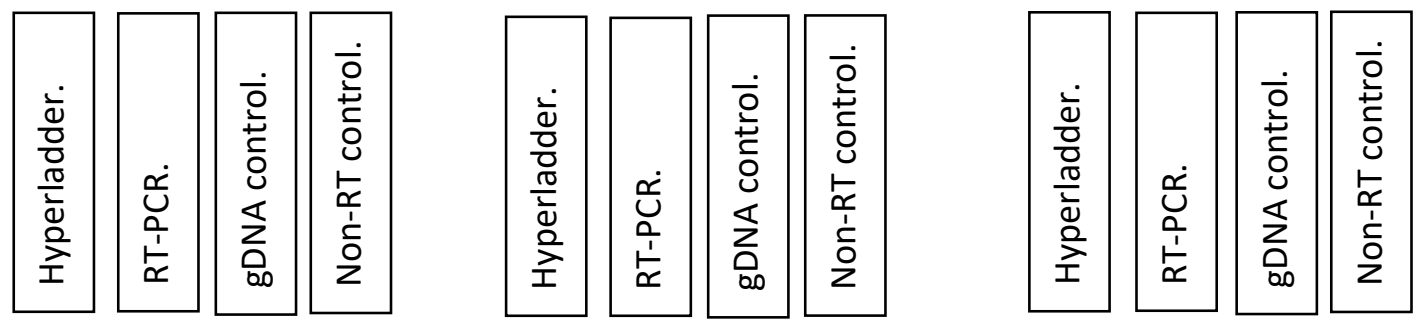

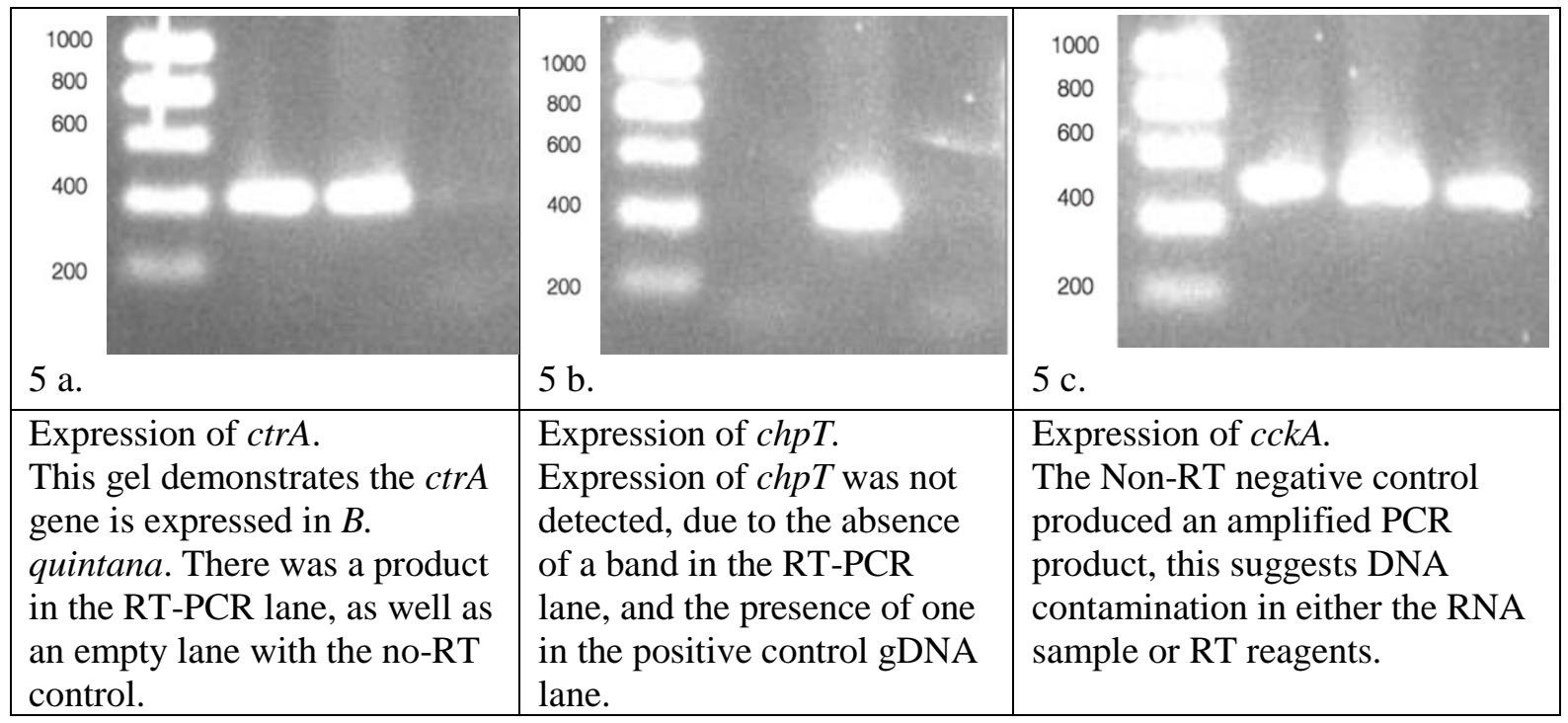

This shows the results of the RT-PCR for $c t r A, c c k A$, and $\operatorname{chp} T$, in $5 \mathrm{a}, \mathrm{b}$, and c respectively. From this ctrA expression was detected but there was no detection of $\operatorname{chpT}$ expression. Conclusive results could not be determined for $c c k A$ due to gDNA contamination.

The expression of ctrA was detected, as we expected ( 5 a). However, there was a complete lack of detected $\operatorname{chp} T$ expression, which was surprising (5 b). ChpT is a histidine phosphotransferase, which transfers a phosphoryl group to CtrA, making it an essential component in the activation of CtrA in $C$. crescentus ${ }^{[66]}$. The presence of $c \operatorname{trA}$ but not $\operatorname{chpT}$ expression was an unexpected result. If we assume this pathway operates in the same manner as in $C$. crescentus, this would mean that CtrA is being expressed but not activated. However, we established that ChpT only shares $28 \%$ identity between $B$. quintana str. Toulouse and $C$. crescentus, suggesting that the activity of ChpT 
has diverged between them. The presence of an amplified product in the Non-RT control for the $c c k A$ expression test $(5 \mathrm{c})$ meant this result was inconclusive. Further attempts to detect $c c k A$ expression were made, using DNase digestions to remove contaminating DNA, but unfortunately this issue could not be resolved within the time constraints of this project.

\subsection{Motif search.}

To discover B. quintana genes potentially directly regulated by $\mathrm{CtrA}$, we searched the genome of B. quintana str. Toulouse for DNA binding motifs. Two CtrA-binding motifs have been described in $C$. crescentus, including the full motif (TTAAN 7 TTAAC) and a half motif (TTAACCAT). We used BLAST searches to look for both full and half CtrA binding motifs within $400 \mathrm{bp}$ of the start site of a gene. A range of $400 \mathrm{bp}$ was used because this approximates the size of a gene's potential regulatory region. CtrA binding sites occurring in the first $50 \mathrm{bp}$ of coding sequence for a gene were included as well. BLAST searches were used because we reasoned that the high similarity of B. quintana $\mathrm{Ctr}$ A to $C$. crescentus $\mathrm{CtrA}$ suggested conserved binding motifs, and this was an efficient way to detect genes of interest.

A BLAST search identified 76 instances of the TTAACCAT motif throughout the B. quintana str. Toulouse genome. In total, we identified $21 \mathrm{~B}$. quintana genes that contained at least one CtrA binding site within their regulatory region (Table 11). 
Table 11. Motif search findings.

\begin{tabular}{|c|c|c|c|}
\hline Detected genes. & $\begin{array}{l}\text { Binding site } \\
\text { distance } \\
\text { upstream of start } \\
\text { codon. }\end{array}$ & Gene locus tag (NCBI). & $\begin{array}{l}\text { Annotated gene } \\
\text { product (NCBI). }\end{array}$ \\
\hline $\operatorname{com} C$ & $147 \mathrm{bp}$ & BQ00390 & $\begin{array}{l}\text { ComM, Competence } \\
\text { protein. }\end{array}$ \\
\hline BQ00400 & 268bp & BQ00400 & Hypothetical protein. \\
\hline BQ01910 & $31 \mathrm{bp}$ & BQ01910 & Hypothetical protein. \\
\hline$h p b C$ & 338 bp & BQ02410 & $\begin{array}{l}\text { Hemin binding } \\
\text { protein C. }\end{array}$ \\
\hline pheP & $175 \mathrm{bp}$ & BQ02690 & $\begin{array}{l}\text { Phenylalanine- } \\
\text { specific permease. }\end{array}$ \\
\hline BQ02680 & $9 \mathrm{bp}$ & BQ02680 & Hypothetical protein. \\
\hline BQ02760 & $67 \mathrm{bp}$ & BQ02760 & $\begin{array}{l}\text { Phage-related protein } \\
\text { (pseudo). }\end{array}$ \\
\hline htrAl & $\begin{array}{l}\text { Makes up the first } \\
8 \mathrm{bp} \text { of the gene. }\end{array}$ & BQ03970 & Serine peptidase. \\
\hline hemS & $244 \mathrm{bp}$ & BQ04150 & $\begin{array}{l}\text { Hemin degrading } \\
\text { protein. }\end{array}$ \\
\hline $\operatorname{radA}$ & $7 \mathrm{bp}$ & BQ04450 & DNA repair protein. \\
\hline BQ05030 & $\begin{array}{l}\text { First } 8 \text { bps of the } \\
\text { gene. }\end{array}$ & BQ05030 & $\begin{array}{l}\text { Hypothetical protein } \\
\text { (pseudo). }\end{array}$ \\
\hline BQ05210 & $112 \mathrm{bp}$ & BQ05210 & Response regulator. \\
\hline BQ07710 & $47 \mathrm{bp}$. & BQ07710 & Hypothetical protein. \\
\hline $\operatorname{rps} M$ & $28 \mathrm{bp}$ & BQ08010 & $\begin{array}{l}\text { 30s ribosomal proteir } \\
\text { s13 }\end{array}$ \\
\hline thyA & $80 \mathrm{bp}$ & BQ08650 & Pseudo gene. \\
\hline BQ08730 & $67 \mathrm{bp}$ & BQ08730 & $\begin{array}{l}\text { sco } 1 / 2 \text { family } \\
\text { protein. }\end{array}$ \\
\hline BQ10450 & $104 \mathrm{bp}$ & BQ10450 & Hypothetical protein. \\
\hline BQ10950 & $170 \mathrm{bp}$ & BQ10950 & Hypothetical protein. \\
\hline$f t s E$ & $160 \mathrm{bp}$ and $114 \mathrm{bp}$ & BQ12340 & $\begin{array}{l}\text { Cell division protein } \\
\text { FtsE. }\end{array}$ \\
\hline BQ13050 & $228 \mathrm{bp}$ & BQ13050 & Hypothetical protein. \\
\hline $\operatorname{dacA3}$ & $95 \mathrm{bp}$ & BQ13220 & $\begin{array}{l}\text { Penicillin-binding } \\
\text { protein. }\end{array}$ \\
\hline
\end{tabular}

Locations of the TTAACCAT CtrA binding motif identified in promoter regions (i.e., within 400 bp of a gene start site) in the genome of B. quintana str. Toulouse (NCBI Reference sequence NC_005955.1). 
We identified 21 instances of potential promoter regions containing at least one CtrA binding motif in B. quintana, a significantly lower number than that seen in $C$. crescentus, which has direct binding of at least 95 genes $^{[62]}$. While TTAACCAT motifs were found upstream of 21 genes, there were no instances of the TTAAN 7 TTAAC motif found anywhere in the genome of either $B$. quintana or B. henselae, despite the prevalence of this motif in the C. crescentus genome, and its documented interaction with $C$. crescentus CtrA. This may be due to our screening method which only identifies motifs that have an identical sequence to the one searched for. This means that if the full (TTAAN 7 TTAAC) CtrA binding motif has a slightly different sequence in $B$. quintana it might be overlooked in our screen, although a BLAST search would be expected to identify sequences with slight deviations from the core motif. Other alpha-proteobacteria have been found to have modified full CtrA binding motifs ${ }^{[92]}$. This may explain the notable absence of CtrAbinding sites in the promoters of $s c i P$ and $c t r A$ from our search. It has been shown that CtrA binds its own promoter in C. crescentus as part of its own regulation and as a key part of the regulatory circuit ${ }^{[57]}$, making the lack of a detected binding motif surprising. Furthermore, there was no detected binding motif found associated with sciP, another master regulatory gene regulated by CtrA in C. crescentus.

Unlike the other promoter regions, the promoter of $f t s E$ had two TTAACCAT motifs within it, suggesting that CtrA may bind two sites within the $f t s E$ promoter. FtsE is a component of the FtsZ ring, which is an essential structure for cell division. Because CtrA is known to regulate cell division ${ }^{[59]}$, these factors made $f t s E$ an ideal candidate for further research. 
Two interesting genes found in this search were $h e m S$ and $h b p C$. These genes are both involved in the management of heme in B. quintana. This is an important function because B. quintana is exposed to toxic levels of heme, due to red blood cell lysis, during its transmission in the digestive tract arthropod vector. In the mammalian host, heme is a critical source of iron for B. quintana metabolism.

We therefore selected the promoter regions of ftsE, hemS, $h b p C$, and $c t r A$ itself for further study. FtsE, HemS, and $\mathrm{HbpC}$ each play a role in cell division or virulence, making their further investigation intriguing. We also included the promoter of ctrA itself, because previous research demonstrated that CtrA interacts with its own promoter region in C. crescentus. Although we did not identify any CtrA-binding sites, we were interested to see if interactions could occur via an uncharacterised $\mathrm{CtrA}$ binding site. The sequence and features of these promoter regions of interest containing CtrA DNA binding sites were analysed, and their features are shown in Figure 6.

Figure 6. Promoter region architecture.

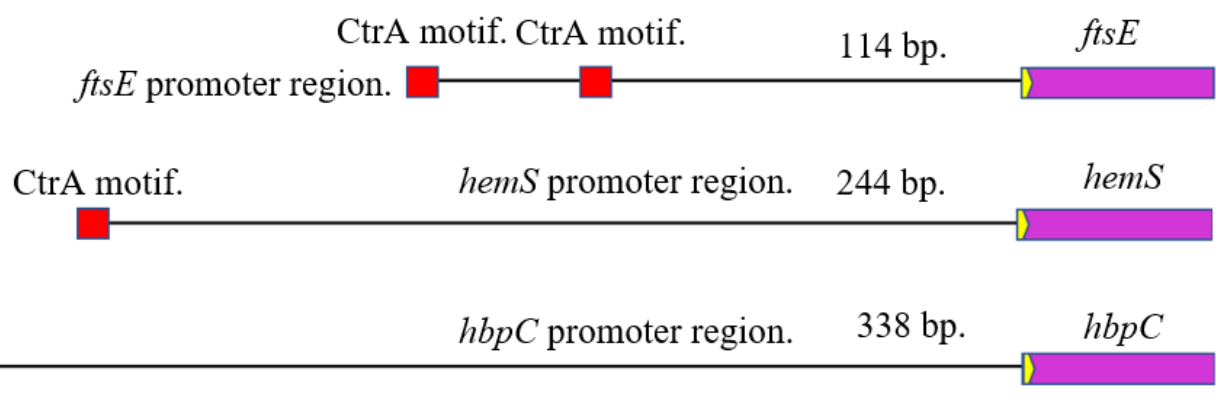

Schematic representation of promoter region structure in B. quintana genes of interest which contain at least one CtrA binding motif. This representation shows the TTAACCAT motif, 
Coding region, and gene ATG Start site as coloured triangle representing the site where translation initiation occurs.

\subsection{Plasmid construction.}

With our genes of interest selected, preparation began to test for interactions of CtrA with promoters of interest. One experiment we considered would be to generate a null or conditional ctrA mutant, as has been done in related bacteria ${ }^{[84]}$. However, in all bacteria tested $c t r A$ is an essential gene; while it is unknown whether it is essential in B. quintana, we thought it is likely. Because of this, we opted to test for CtrA-promoter interactions using a $\beta$-galactosidase reporter gene expression assay and electrophoretic mobility shift assay (EMSA). This way no ctrAdeficient B. quintana mutant would be generated and interactions could be tested in E. coli. Working with $E$. coli is preferable to $B$. quintana due to its shorter incubation periods and its resilience to modification techniques such as electroporation. To achieve this two plasmids were constructed, pET28a(+)-ctrA, encoding an inducible CtrA protein, and a pACYC184-lacZ reporter plasmid, which enables cloning of promoters of interest upstream of the lac $Z$ gene, to provide a detection system for CtrA-promoter interactions.

\subsection{1 pET28a(+)-ctrA.}

The pET28a(+)-ctrA plasmid was designed to express the CtrA protein, it also added a His selection tag to the protein allowing for its purification and use in EMSA. 
To begin construction of the plasmid, purified pET28a(+) was isolated from E. coli DH5a. The plasmid was digested, to open the cloning/expression region. The ctrA gene was amplified from JK-31 B. quintana gDNA. This was done using the Bq-ctrA-F and Bq-ctrA-R primers (Table 4) in a PCR reaction. The product was then verified by gel electrophoresis (Figure 7).

\section{Figure 7. ctrA PCR product screen.}

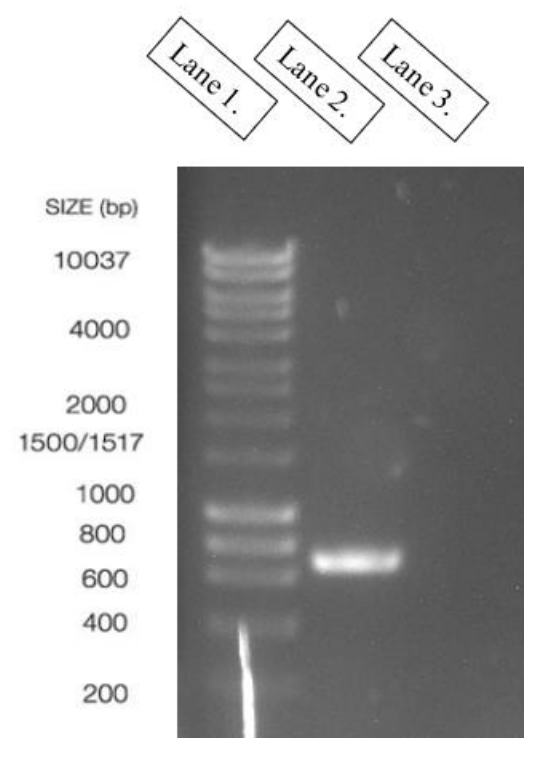

This gel was produced using the products of the PCR reaction using the CtrA primers to amplify ctrA from $B$. quintana gDNA.

Lane 1: Hyperladder.

Lane 2: PCR product of the ctrA_F and ctrA_R primers with $B$. quintana gDNA. Lane 3: Control PCR with no gDNA template.

Figure 7 shows a single band in the second lane, approximately 700 bp in size, the expected size of $c t r A$. The primers used to amplify $c t r A$ were engineered to introduce unique NdeI and BamHI restriction sites, which were used to clone the PCR product into pET28a(+). Colonies that grew on LB plates with kanamycin were cultured and plasmids were isolated and digested.

Successful cloning occurred when PCR products from two amplifications of $c t r A$ were combined, to increase the amount of insert present. The insert was also concentrated by eluting in a lower volume and by combining the digested insert and plasmid on a single Zymo column before the 
ligation. A molar ratio of $1: 3$ to $1: 5 \mathrm{pET} 28 \mathrm{a}(+)$ to $c t r A$ insert was used for ligation reactions. Following the electroporation into and overnight growth and selection of colonies, there were many more colonies, which were collected for screening (Figure 8).

\section{Figure 8. ctrA insert screen.}

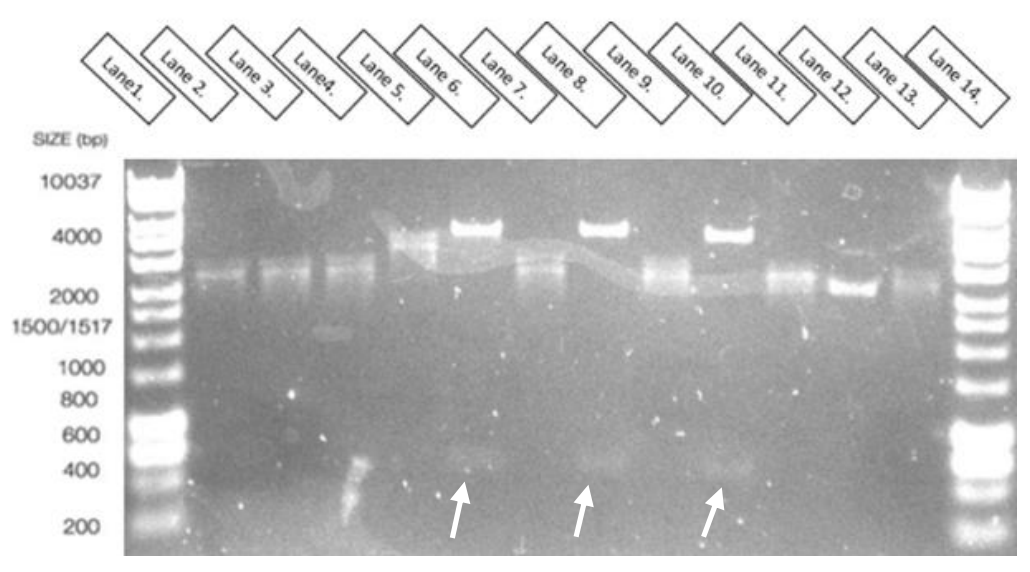

This gel contains the plasmids from the test colonies. Plasmids were digested with BamHI and NdeI restriction enzymes.

Lane 1 and 14: Hyperladder. Lanes 2-13: Colony 34-45.

Figure 8 show that a variety of different sized DNA bands were contained in these colonies. However, colonies 38, 40, 42 (lanes 6, 8, and 10) contained a band at the size of the ctrA insert (Figure 8 , indicated by arrows). These bands were difficult to see and were only visible when the UV was turned onto high and the camera adjusted to pick up very faint bands. Because of this, the digestion screening was repeated using $7.5 \mathrm{~mL}$ overnight culture to isolate plasmid, and $16 \mu \mathrm{L}$ of isolated plasmid was digested instead of the standard protocol to achieve brighter bands. These screened samples were then run on a gel (Figure 9). 
Figure 9. $\operatorname{ctr} A$ high concentration screen.

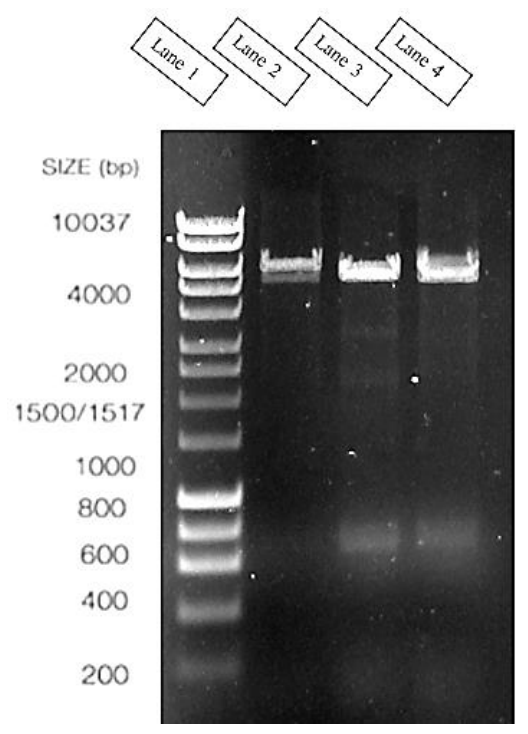

This gel shows the isolated and digested plasmids 38,40 , and 42 which were identified as potentially containing the $c t r A$ insert.

Lane 1: Hyperladder.

Lane 2: Colony 38.

Lane 3: Colony 40.

Lane 4: Colony 42.

Figure 9 shows bands of the size of the $c t r A$ insert in lanes 3, and 4 . There is also a noticeable size difference between the digested and non-digested plasmids, shown by the two separate large plasmid bands. The pET28 $\alpha$-ctrA plasmid of colony 38 showed incomplete digestion. However, the plasmids of colonies 40 and 42 were digested and show the insert, because of this these two plasmids were sent for sequencing, using the $\mathrm{T} 7$ promoter primer and $\mathrm{T} 7$ terminator primer to amplify the insert and surrounding sequence. Once the sequencing data was returned it was analysed using NCBI protein blast, to identify any mutations (Appendix 2).

The sequencing data showed that the forward reaction of the colony 40 plasmid didn't amplify the molecule for sequencing. This suggesting there was a mutation in the primers binding site, the T7 promoter. Because of this, the plasmid from colony 40 was not used any further in this project. The sequencing data showed that the $c t r A$ insert was successfully incorporated into the pET28a(+) plasmid of Colony 42 correctly, hereafter referred to as pET28a(+)-ctrA. Both the forward and reverse sequencing reactions for the pET28a(+)-ctrA plasmid showed that there was a $100 \%$ 
sequence match with no gaps with the $B$. quintana $c t r A$ gene. This confirmed that the $c t r A$ gene was inserted with no mutations. The complete pET28a(+)-ctrA plasmid was then electroporated into E. coli BL21 to use in reporter expression and electrophoretic mobility shift assays. The E. coli BL21expresses the T7 polymerase, which is required for the pET28a(+)-ctrA plasmid expression, because it has $\mathrm{T} 7$ polymerase binding sites in its promoter region.

\subsection{2 pACYC184-lacZ.}

To carry out gene expression studies of CtrA and the promoters of our B. quintana genes of interest (ctrA, ftsE, hemS, and $h b p C$ ), we first needed to synthesise a reporter plasmid, pACYC184-lacZ. This plasmid contained a promoterless lacZ gene with two unique restriction sites, XhoI and NsiI, which were engineered into the 5' end to facilitate directional cloning of promoter regions directly upstream of lacZ. The ATG site of NsiI was incorporated into the ATG start site of lacZ to enable promoters to be cloned upstream without any spacer sequence. When the promoters upstream of the lac $Z$ gene are induced, $\beta$-galactosidase is expressed from the lac $Z$ gene. The levels of $\beta$ galactosidase induction be detected and quantified using a chromogenic assay.

Construction of the pACYC184-lacZ plasmid began by culturing an E. coli SOS-R2 reporter strain that had the full lacZ gene on its chromosomal DNA ${ }^{[87]}$. The E. coli genomic DNA was purified and used as a template for a PCR reaction to amplify lacZ, using primers LacZ_F and LacZ_R (Table 4). The products of the PCR reaction were visualised using gel electrophoresis (Figure 10). 
Figure 10. lacZ PCR product screen.

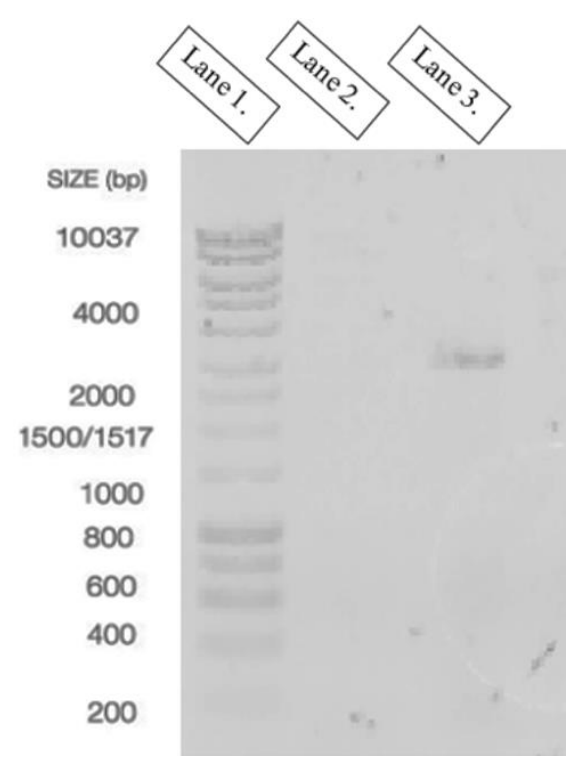

This gel shows that there was a single product, in the test reaction, with a size of approximately $3000 \mathrm{bp}$.

Lane 1: Hyperladder.

Lane 2: control, containing LacZ_F and LacZ_R, no gDNA.

Lane 3: amplified lacZ from gDNA.

Figure 10 shows a single amplified product, approximately $3000 \mathrm{bp}$, the expected size of the lac $Z$ gene. The negative control, with no DNA added, had no amplified product. The LacZ_F and LacZ_R primers used to amplify this gene incorporate two unique restriction sites to either end for the gene, allowing for the correct orientation when cloning into the pACYC184 plasmid. In addition, the LacZ_F primer contained two additional unique restriction sites, XhoI and NsiI, that were engineered for subsequently cloning of promoter regions into the reporter plasmid.

The next step was to clone the lacZ PCR product into the pACYC184 plasmid. The pACYC184 plasmid was isolated from cultured E. coli E41525 (New England Biolabs). We cloned the lacZ reporter gene into the unique XbaI and HindIII sites of pACYC184, at the 1425 and 1524 coordinates of the plasmid, respectively, in a region between the origin and the tetracycline resistance gene. Amplification of the lacZ insert resulted in the incorporation of XbaI and HindIII sites, which were used to clone the insert into pACYC184. Electroporated DH5 $\alpha$ were plated onto 
chloramphenicol selective plates and incubated overnight. The next day colonies were collected from the selective plates and screened for the lacZ insert using digestion screening (Figure 11). As with the construction of the pET28 $\alpha$-ctrA plasmid initial attempts at generating the pACYC184lac $Z$ plasmid were unsuccessful until the protocol was optimised.

\section{Figure 11. lacZ insert screen.}

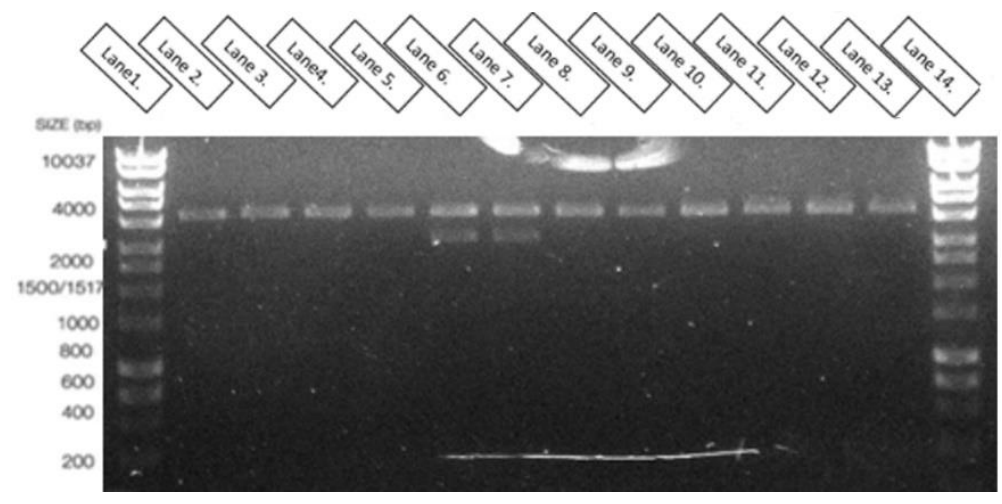

This gel contains plasmids isolated from DH-5 $\alpha$ E. coli, following electroporation, overnight selection, and HindIII, XbaI digestion of pACYC184-lacZ plasmids.

Lanes 1 and 14: Hyperladder.

Lanes 2-13: digested plasmids 13-24.

Figure 11 shows that colonies 17 and 18, in lanes 6 and 7, contain a DNA insert the size of the lacZ insert, approximately $3000 \mathrm{bp}$, and all lanes containing a band the size of pACYC184. The plasmids containing the potential lacZ insert were sent for sequencing.

The sequence data (Appendix 3) revealed that both sequenced genes had a mutation in the section sequenced by the reverse primer. The mutation was a substitution, causing a switch from an alanine to a valine. Both amino acids are hydrophobic and aliphatic, with similar structures, and we predicted this mutation might not impact the activity of the LacZ enzyme since these amino acids are similar and not within the active site. 
The forward sequencing reaction of the lac $Z$ gene of colony 17 revealed a unique mutation converting an aspartic acid to an asparagine; aspartic acid has an acidic side chain while asparagine is polar with a neutral side chain. These amino acids are quite different, meaning this mutation is more likely to affect the enzymatic activity of the LacZ produced. Because of this mutation the plasmid from colony 17 was not used.

One issue which arose from this data is that the Sanger sequencing could only reliably sequence approximately the first $1000 \mathrm{bp}$ from either side of the insert. This was a problem since the lac $Z$ insert is $3000 \mathrm{bp}$ long, so the middle $1000 \mathrm{bp}$ could not be sequenced using universal primers. To test the activity of the $\beta$-galactosidase enzymes produced, the IPTG-inducible T7 promoter was cloned upstream of the lacZ gene in the pACYC184-lacZ plasmid. This enabled us to assess the activity of LacZ, following its induction with ITPG.

A blue-white screen was used to determine if the pACYC184-lacZ plasmid produced a functioning $\beta$-galactosidase enzyme. These plasmids were electroporated into BL21 strains, which were transferred to selective LB plates, with ITPG and X-gal applied to the surface of the agar. Following an overnight incubation, the plates were inspected, the tested plasmid resulted in blue colonies (Figure 12), showing that the induced $\beta$-galactosidase enzymes were active and able to catalyse the breakdown of X-gal. 
Figure 12. Blue white colony screen.

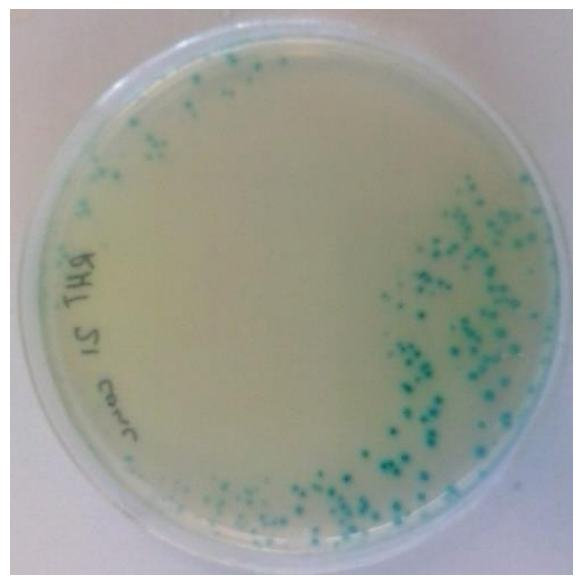

This figure shows a typical plate from the blue-white screen carried out to test the activity of the $\beta$ galactosidase expressed from the inserted gene, the blue color indicates expression of the $l a c Z$ gene, producing $\beta$-galactosidase.

This pACYC184-lacZ reporter plasmid provided a useful tool for subsequent interaction studies.

\subsection{3 pACYC184-lacZ ctrA, ftsE, hemS, and hbpC reporter plasmids.}

To measure CtrA interaction with our promoters of interest, plasmids containing a reporter gene (lacZ) under the control of each promoter of interest (ctrA, ftsE, hemS, and $h b p C$ ) were constructed. The pACYC184-lacZ plasmid features a promoterless lacZ gene, which does not produce $\beta$ galactosidase. Immediately prior to this $l a c Z$ gene we cloned our promoters of interest. We reasoned that if $\mathrm{CtrA}$ interacted with our promoters of interest, it would influence the expression of $l a c Z$, leading to $\beta$-galactosidase induction. Furthermore, we expected the expression of $l a c Z$ to only be affected when CtrA expression was induced by IPTG. To carry out these studies, it was essential that our CtrA-bearing plasmid and the lac $Z$ reporter plasmid must be compatible in a single E. coli BL21 cell. This was possible because the two plasmids have different and compatible origins, with pET28a(+) containing ColE1 and pACYC184 having p15A ori. 
Once it was confirmed that the lac $Z$ gene was producing a functioning $\beta$-galactosidase enzyme, promoters of interest ( $c t r A$, ftsE, hemS, and $h b p C$ ) were amplified by PCR using primers that incorporated a 5' XhoI site and a 3' NsiI site, the engineered restriction sites that enabled directional cloning of the promoter upstream of lac $Z$ in the correct orientation. As with the other DNA inserts, the promoters were amplified from B. quintana JK-31 genomic DNA using specific primers (Table 4). The NsiI restriction site includes an ATG which is incorporated into the start codon of lac $Z$, enabling the cloning of the promoters directly upstream of $l a c Z$, this is shown in Figure 13. 
Figure 13. pAYCY184 cloning site architecture.

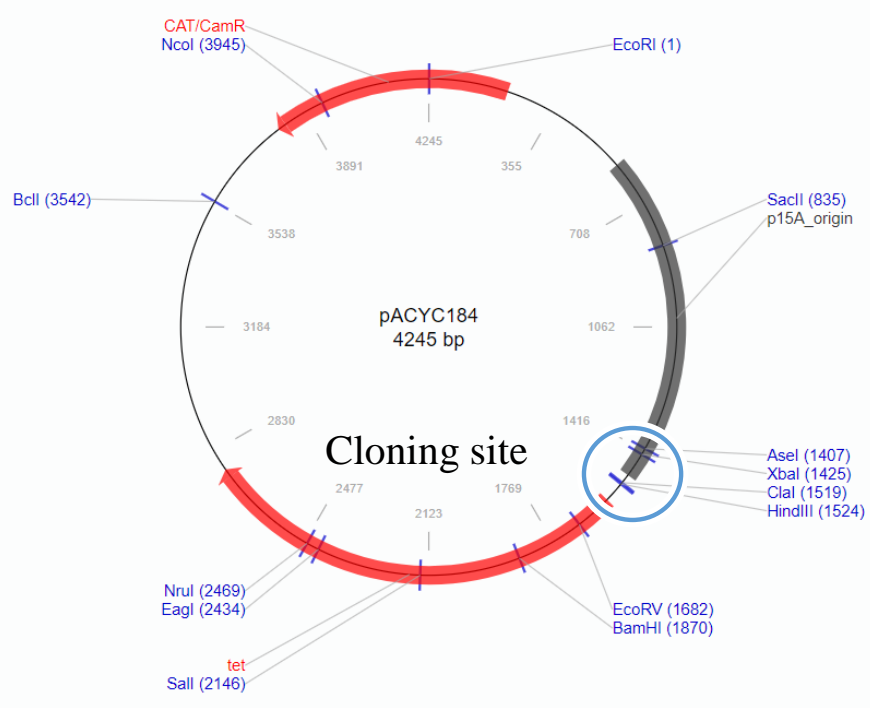

pACYC184 plasmid schematic, showing the chloramphenicol $($ CAT/CamR $)$ and tetracycline (tet) resistance genes, as well as our cloning site between the p15A oriT and tet.

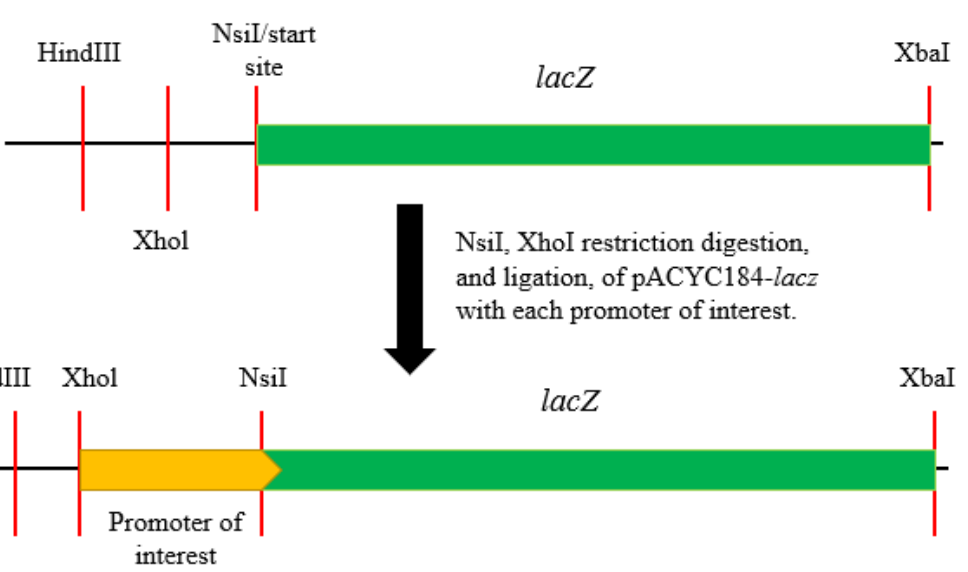

This shows the cloning site containing the inserted lacZ reporter gene with of our promoter of interest directly up stream with no intervening sequence between. Also shows the organisation of restriction sites prior to the $l a c Z$ gene.

The pACYC184 plasmid does not include an XhoI restriction site, so we incorporated one between the lacZ start codon and the HindIII restriction site in the LacZ_F primer. The LacZ_F primer sequence was 5' - GCG AAG CTT CTC GAG GCG ATG CAT ATG ATT ACG GAT TCA CTG 
GCC GTC G - 3'. The LacZ_F primer added a HindIII site (shown in red) to allow the cloning of lacZ into pACYC184, an XhoI site (shown in green), and an NsiI site (shown in blue), which incorporates the lac $Z$ start codon (bold). This allowed for the incorporation of our promoters of interest directly upstream of the lac $Z$ gene with the correct orientation.

Amplified promoter sequences were cloned into pACYC184-lacZ, into the unique XhoI and NsiI sites that resulted from construction of the reporter plasmid. Colonies that grew were selected for plasmid purification and restriction digestion screening (Figure 14). From this digestion we expected to see bands at approximately $400 \mathrm{bp}$, the size of the promoter region inserts. 


\section{Figure 14 a.}

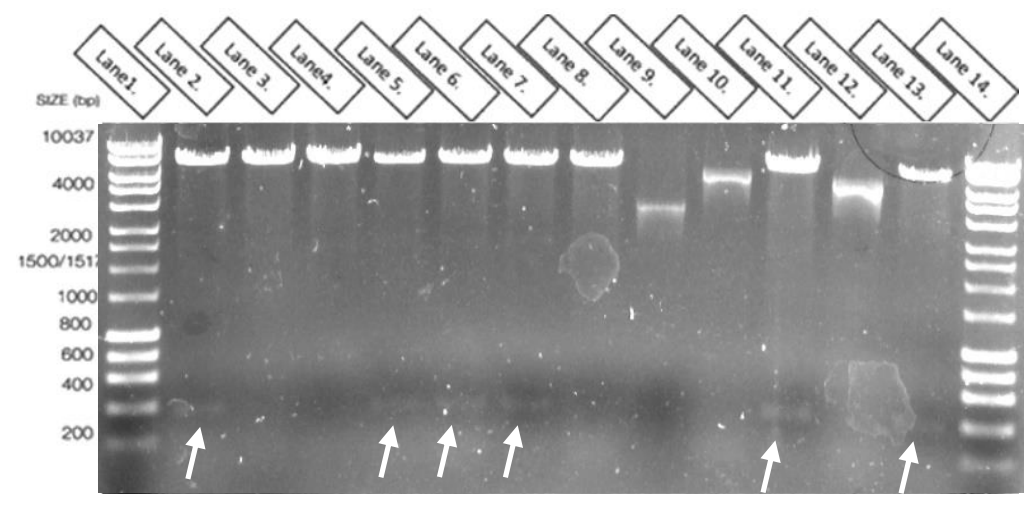

This gel was run using the digested plasmids harvested from ctrA promoter and $f t s E$ promoter reporter plasmids. Lane 1 and 14: Hyperladder. Lane 2-7: ctrA promoter colonies 1-6. Lane 8-13: ftsE promoter colonies 1-6.

Figure 14 b.

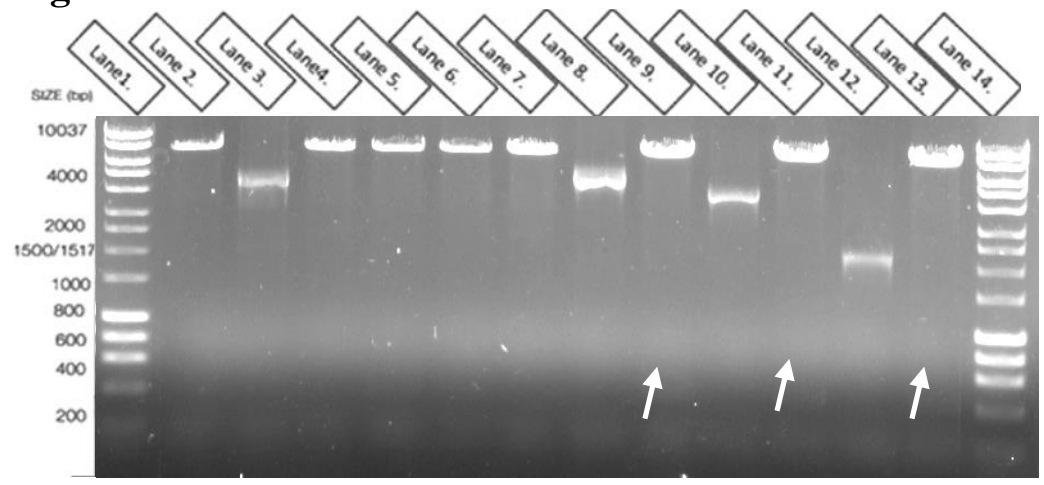

This gel shows the digested plasmids of colonies electroporated with the hemS, and $h b p C$ promoters and pACYC-lacZ plasmids.

Lane 1 and 14: Hyperladder.

Lane 2-7: hemS promoter colonies 1-6.

Lane 8-13: $h b p C$ promoter colonies 1-6.

Due to the small size of the insert (400 bp) and the relatively low copy number of pACYC184 in E. coli, it was difficult to see DNA bands clearly, especially in the hemS promoter samples. So further hemS promoter colonies were collected for analysis. However, bands were detected in the $c t r A$, ftsE, and $h b p C$ reporter plasmids, indicated by arrows (Figure 14 a, b). ctrA promoter colonies 1, 4, 5, 6, ftsE promoter colonies 4, 6 (Figure 14 a), and $h b p C$ promoter colonies 2, 4, and 6 showed bands at $400 \mathrm{bp}$ (Figure $14 \mathrm{~b}$ ). There were some unexpected restriction digest products in some lanes which were not at the expected size of the pACYC184-lacZ plasmid, but all the lanes containing bands of the expected size of the promoters were in lanes that also had bands which 
were the expected size of the pACYC184-lacZ plasmid. To visualise the hemS promoter, insert colonies were picked and grown in $10 \mathrm{~mL}$ of $\mathrm{LB}$ broth, allowing for more total bacteria to be collected the following day and giving a higher plasmid concentration for digestion screening. This showed the hemS promoter was successful integration of into the pACYC-lacZ plasmid (data not shown).

Each of the four pACYC184-lacZ reporter plasmids with B. quintana promoter regions cloned upstream of the promoterless lac $Z$ gene were electroporated into BL21 cells also harbouring the pET28a(+)-ctrA plasmid. E. coli containing both plasmids were selected by growing on plates supplemented with both kanamycin and chloramphenicol. As an extra test to identify strains with both a $c t r A$ expression and lac $Z$ reporter plasmid, we carried out plasmid purification and restriction digest of plasmids with BamHI and NdeI and screened to verify that the bacteria contained both relevant plasmids (Figure 15). From this digestion we expected a $\sim 5.3$ Kbp product from the cleaved pET28a(+) plasmid, a $\sim 4 \mathrm{Kbp}$ product from the pACYC184 plasmid, a $\sim 3.3 \mathrm{Kbp}$ product from the lacZ- B. quintana promoter fragment, and a $\sim 0.7 \mathrm{Kbp}$ band from the $c t r A$ insert. 
Figure 15. pET28a(+)-ctrA and pACYC184-lacZ reporter screen.

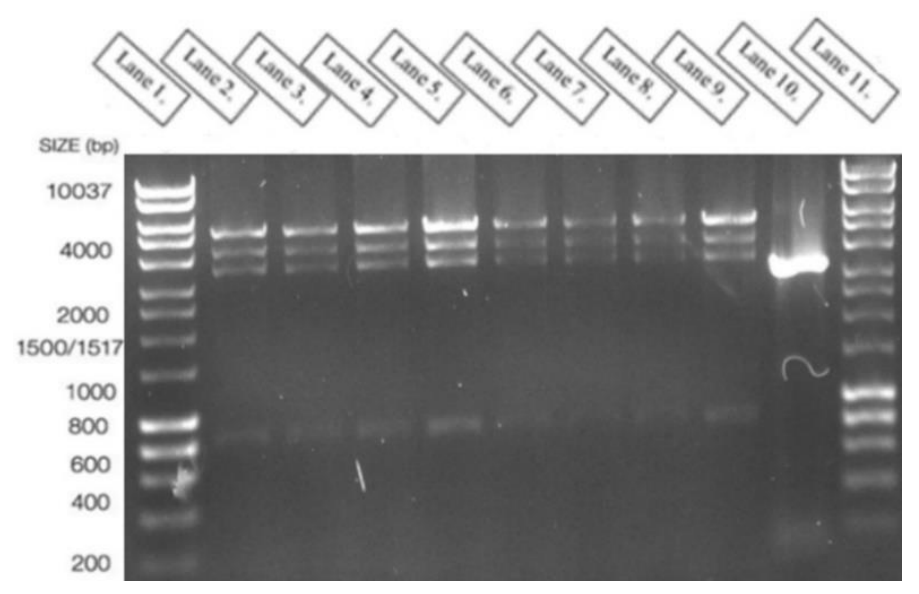

Shows isolated and digeted (BamHI and NdeI) pET28a(+)-ctrA and pACYC184-lacZ plasmids with cloned promoters.

Lanes 1 and 11 - Hyperladder $1 \mathrm{~kb}$, Lanes 2-3 pACYC-lacZ-ctrA, pET28a(+)-ctrA. Lanes 4-5 pACYC-lacZ-ftsE, pET28a(+)-ctrA. Lanes 6-7 pACYC-lacZ-hbpC, pET28a(+)-ctrA. Lanes 8-9 pACYC-lacZ-hemS, pET28a(+)-ctrA. Lane 10 Unrelated to this digest.

Figure 15 shows that all tested colonies harbour the pET28a(+)-ctrA and pACYC184-lacZ reporter plasmids with introduced promoter regions. All the lanes tested resulted in four products that matched the predicted digestion fragment sizes. This provided evidence that the BL21 cells had received the appropriate plasmids and were ready for use in $\beta$-galactosidase assays.

\section{6 $\beta$-galactosidase reporter gene expression assays.}

We used $\beta$-galactosidase assays to measure gene expression. The regulatory gene of interest, $c t r A$, was cloned on an expression plasmid, under an IPTG-inducible promoter. The levels of $\beta$ galactosidase activity were measured and compared between conditions when the ctrA gene was induced or not. The promoters of interest, including that of $c t r A$ and those that had predicted CtrAbinding sites, were amplified and cloned upstream of the lac $Z$ reporter gene; interactions between CtrA and our promoters would be detected as the difference in expression between conditions where $\operatorname{ctrA}$ was induced or not. Once both the pET28a(+)-ctrA, and pACYC184-lacZ reporter plasmids with introduced $B$. quintana promoters were constructed and transferred into BL21 $E$. 
coli for CtrA expression, everything was prepared for the $\beta$-galactosidase activity assay to test the interactions between $\operatorname{ctr} A$ and our promoters of interest.

\subsubsection{Initial results.}

Work on the $\beta$-galactosidase activity assay began with a small pilot experiment as a proof of concept that the protocol and reagents worked, (Figure 16).

Figure 16. $\beta$-galactosidase activity pilot assay results.

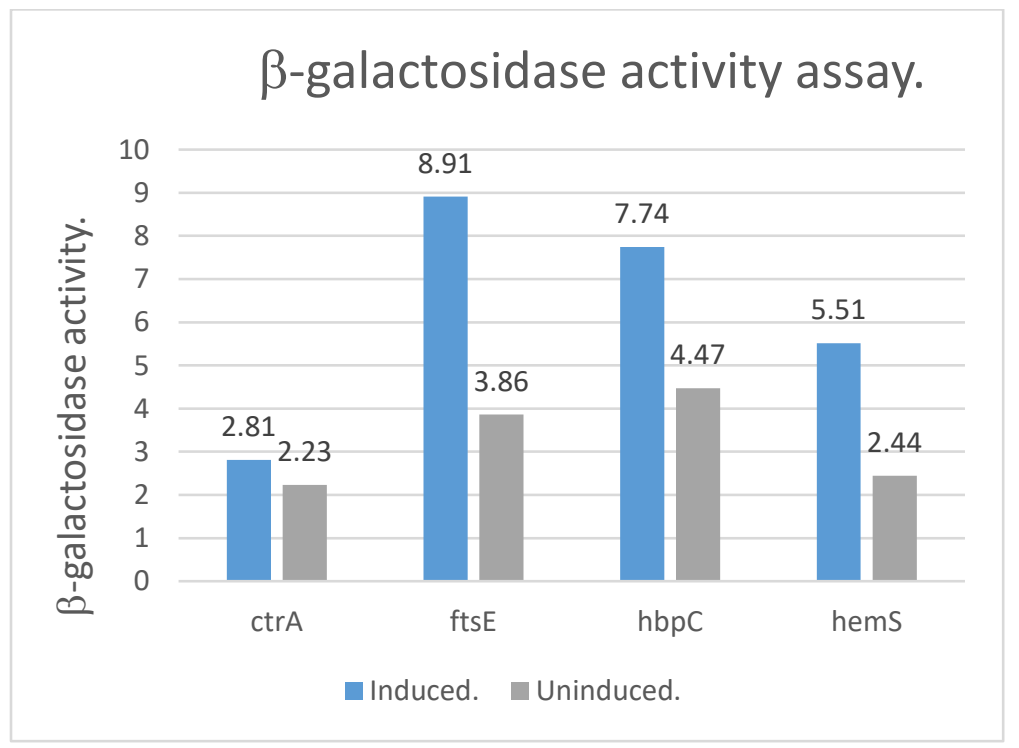

This data was collected from duplicates for the induced samples and single measurements for the un-induced samples, so statistical analyses were not carried out here. $\beta$-galactosidase activity of samples induced with IPTG to produce CtrA are show by blue bars, and uninduced are show with grey. Each promoter of intrest reporter is labled with ctrA, ftsE, $h b p C$, or hemS, below their bars.

As shown in Figure 16, there were promising initial indications that there may be differences in $\beta$ galactosidase expression between induced and uninduced CtrA samples. When the lacZ gene was under control of the $f t s E, h b p C$, and hemS regulatory regions, an approximately 2 -fold increase in $\beta$-galactosidase activity was observed when $\mathrm{Ctr} A$ expression was induced. Differences in $\beta$ - 
galactosidase levels when $l a c Z$ was under the control of the $c t r A$ regulatory region were less obvious. This result was not entirely unexpected, as we did not identify any putative CtrA-binding sites in the regulatory region of ctrA. This also showed that the assay was working correctly in detecting different levels of $\beta$-galactosidase activity. We next aimed to optimise and scale up the experiment.

\subsection{2 $\beta$-galactosidase assay protocol optimisation.}

The $\beta$-galactosidase experiment was next scaled up to collect sufficient data to demonstrate a significant difference between the conditions, i.e., testing the impact of CtrA induction on the activity of the four promoters we were investigating. Four biological replicates of each CtrAinduced sample were incubated as well as an uninduced sample. We included as an additional control a sample containing pET28a(+)-ctrA and the pACYC184-lacZ plasmid, with no promoter controlling lacZ expression. This strain produces CtrA but no promoter sequence for it to interact with is provided and basal levels of $\beta$-galactosidase are produced. When this was first attempted, the samples had low $\mathrm{OD}_{600}$ following their induction stage, reaching $\mathrm{OD}_{600}$ values of around 0.15 0.2 after a 3.5 -hour incubation. This is very slow growth considering that the samples began at an $\mathrm{OD}_{600}$ of 0.1 . This may have been an issue with the shape of the wells of the 24-well plate that were being used to incubate the samples; they provide a smaller surface area, and consequently less aeration, compared to a Falcon tube. Going forward, all assays were done in $50 \mathrm{~mL}$ Falcon tubes for optimal growth of $E$. coli strains. 
While the trend seen in the pilot experiment (Figure 16) was still seen, we found that the $\mathrm{OD}_{600}$ values, as well as the $\beta$-galactosidase activity calculated from them, were proving quite variable. When the $\mathrm{OD}_{600}$ values measured from the spectrophotometer versus a plate reader were compared they were very inconsistent. The spectrophotometer often gave the overnight cultures an $\mathrm{OD}_{600}$ of 3 while the plate reader gave a value of 1.6-1.7. We assumed that, generally, the plate reader was much more accurate. Because of this, all absorbance measurements were henceforward exclusively read with the plate reader.

The $\mathrm{OD}_{600}$ absorbance values for cultures following the induction of $c t r A$ were a little higher than what was optimal, so the incubation time was reduced from 3.5 hours to $2.5-3$ hours, or until the cultures reached an $\mathrm{OD}_{600}$ of $0.5-0.7$, to ensure that the bacteria were assayed during exponential growth. The $\mathrm{OD}_{420}$ values were also too high for the $h b p C$, hemS, and particularly the ftsE, often reaching an $\mathrm{OD}_{420}$ of above 2 . This was problematic, since the reaction may have been going to completion, thus altering the reaction kinetics; ideally there should be enough substrate for the $\beta$ galactosidase to be saturated for the entire duration of the incubation. For accurate results, the reaction should be incubated until an $\mathrm{OD}_{420}$ of $0.6-0.9$ is reached. This was done by initially monitoring the solution by eye, then adding the stop solution once it began to turn yellow, to establish a suitable incubation time. As a result, less of the induced culture was used in the ONPG assay step, with the amount added reduced from $20 \mu \mathrm{L}$ to $5 \mu \mathrm{L}$. Since the reaction was happening too quickly, time-based errors were introduced. The longer the incubation, the less significant these errors became, so a 15-20 minute incubation was used. Different strains were incubated in separate timed assays, to ensure fewer reaction mixtures had to be prepared at once. This also made it easier 
to start and stop the assay consistently with easily measurable times, and allowed for individual optimisations, time, volume, etc. Furthermore, the equation used to calculate the $\beta$-galactosidase activity was modified, from:

$$
\text { Miller Units }=1000 \times\left[\left(\mathrm{OD}_{420}-1.75 \times \mathrm{OD}_{550}\right)\right] /\left(\mathrm{T} \times \mathrm{V} \times \mathrm{OD}_{600}\right)
$$

To:

$$
\text { Miller Units }=\left(\mathrm{OD}_{420}-1.75 \times \mathrm{OD}_{550}\right) /\left(\mathrm{T} \times \mathrm{OD}_{550}\right)
$$

The 1000-fold multiplication was removed from the beginning of the formula and the (T x V x OD600) component was replaced with ( $\mathrm{x}$ 0D550). In the original equation, the $\mathrm{OD}_{550}$ value was used to account for cell debris in the ONPG assay media and $\left(\mathrm{OD}_{420}-1.75 \mathrm{x} \mathrm{OD}_{550}\right)$ is included to account for its absorbance at $420 \mathrm{~nm}$. However, it can also be used to represent the number of bacteria introduced into the ONPG assay media, since it measures the amount of cell debris it is directly proportional to the concentration of cells in the solution, which is accounted for by the $\left(\mathrm{OD}_{600} \mathrm{x} \mathrm{V}\right)$ factor, so $\left(\mathrm{T}_{\mathrm{x}} \mathrm{OD}_{550}\right)$ can account for the same variable $\left(\mathrm{OD}_{600} \mathrm{x} \mathrm{V}\right)$ with fewer opportunities for measurement errors. This modified method has been shown to have a higher degree of accuracy compared to the original. This adjustment allows for the assay to be conducted in microwell plates where small pipetting volume deviations have a large effect on Miller units/ calculated $\beta$-galactosidase activity ${ }^{[90]}$. These changes greatly reduced the variability of the data collected and made the assay much more accurate. 


\subsection{3 $\beta$-galactosidase measurements.}

With the protocol optimised, the $\beta$-galactosidase data was collected to demonstrate interactions between CtrA and the promoters of interest. The data was collected over 3 separate experimental days, therefore providing both technical replicates and biological replicates. Along with the ctrA, ftsE, $h b p C$, and $h e m S$ plasmids tested, a control with no promoter before the lacZ gene was also included. This provided 12 replicates for each induced sample, except $h b p C$ and $h e m S$, which each had an experimental outlier removed since debris in their wells artificially increased their absorbance, skewing their $\beta$-galactosidase activity data. The uninduced samples each had 3 replicates. The results are shown below in Figure 17 and Table 12.

Figure 17. $\beta$-galactosidase activity assay results.

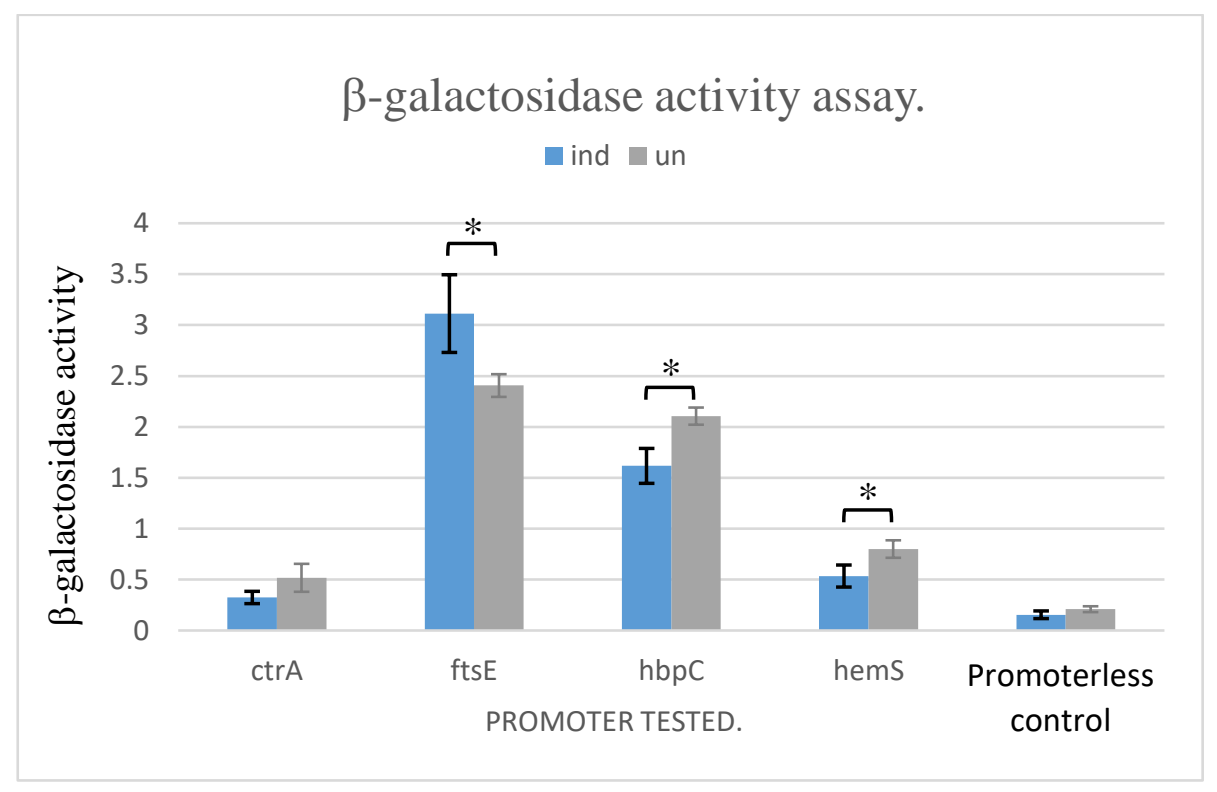

This graph shows the $\beta$-galactosidase activity data of the induced and uninduced samples of $c t r A, f t s E, h b p C$, hemS , and promoterless controls. $\beta$-galactosidase activity of induced samples is shown with blue bars and uninduced with grey. Data indicate mean values plus or minus 
standard deviations from three independent experiments performed in triplicates. *Significantly different $(P<0.05)$ by Student's $t$-test.

Table 12. $\beta$-galactosidase activity assay results.

\begin{tabular}{|l|r|r|r|}
\hline & Induced mean. & Uninduced mean. & P value. \\
\hline $\boldsymbol{c t r} \boldsymbol{A}$. & 0.32 & 0.52 & 0.1288 \\
\hline $\boldsymbol{f t s} \boldsymbol{E}$. & 3.11 & 2.41 & 0.0001 \\
\hline $\boldsymbol{h b p} \boldsymbol{C}$. & 1.62 & 2.11 & 0.0002 \\
\hline $\boldsymbol{h e m S .}$ & 0.54 & 0.80 & 0.0114 \\
\hline $\begin{array}{l}\text { Promoterless } \\
\text { control. }\end{array}$ & 0.16 & 0.21 & 0.1197 \\
\hline
\end{tabular}

This table contains the analysed data collected in the $\beta$-galactosidase assay, including the $\beta$ galactosidase activity, mean values of the samples, and $\mathrm{P}$ values.

Once collected the data was analysed using an independent sample T test, to calculate the P value of the detected the $\beta$-galactosidase activity between the CtrA-induced and -uninduced samples of each promoter group tested. This revealed that $f t s E, h b p C$, and hemS had statistically significant differences in $\beta$-galactosidase activity between the induced and uninduced groups (Table 12). This showed that CtrA was interacting with these promoters. Interestingly there seems to be both promoter activation and inhibition, with CtrA evidently inducing the ftsE promoter and inhibiting both the $h b p C$ and hemS promoters, compared to their uninduced counterparts. Though it remains to be tested, this could be due to the fact that there were two CtrA binding sites in the ftsE promoter region. Alternatively, the location of the CtrA binding sites could determine whether they induce or inhibit gene expression. There was no statistically significant difference between the CtrA- 
induced and -uninduced ctrA promoter samples or promoterless control groups. This was not unexpected, as we did not identify CtrA binding motif in the promoter of $c t r A$. There were also differing levels of $\beta$-galactosidase activity between the different promoters when CtrA was not induced groups, indicating that these promoters have varying basal activity in E. coli.

\subsection{CtrA expression and purification.}

To demonstrate the direct binding of CtrA to our promoters of interest it was necessary to express CtrA at a level sufficient for its purification. This involved the introduction of the pET28a(+)-ctrA plasmid in to E. coli BL21, induction of CtrA expression, and His tag purification. With the purified CtrA we could then test for this direct CtrA-promoter interaction by EMSA.

The expression of CtrA began with the electroporation of the confirmed pET28a(+)-ctrA into the E. coli BL21 strain. To confirm that the plasmids were introduced correctly, plasmids were reisolated from the transformed BL21, and screened by restriction digestion, with the expectation of the presence of a $700 \mathrm{bp}$ band and a pET28a(+) plasmid band (Figure 18). 
Figure 18. BL21, ctrA insert screen.

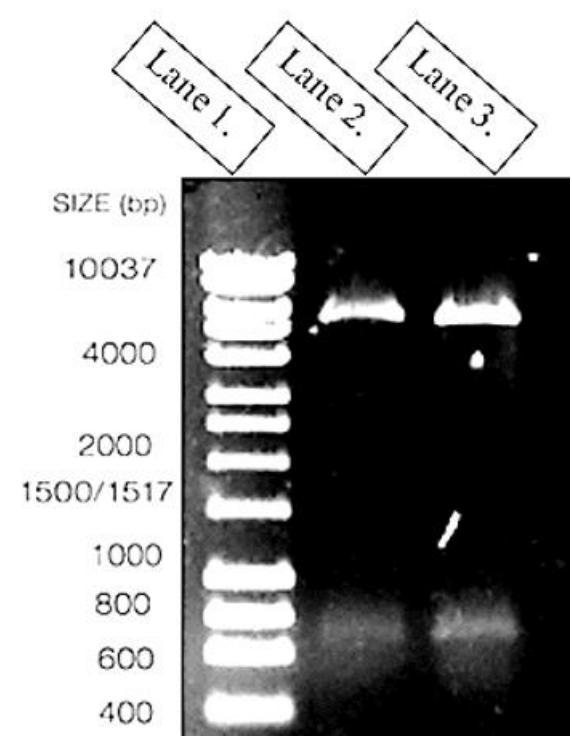

This gel contains isolated and BamHI, NdeI digested pET28a(+)-ctrA plasmid from BL21 cells. 700 bp bands are preset in lanes containing digested plasmid, showing the presence of the $c t r A$ insert.

Lane 1: Hyperladder,

Lane 2: pET28a(+)-ctrA 7.

3: $\operatorname{pET} 28 \mathrm{a}(+)-\operatorname{ctrA} 9$.

The gel in figure 18 shows there are inserts the size of the $c t r A$ in these plasmids, showing $E$. coli received the engineered plasmid. BL21 cells containing the pET28a(+)-ctrA 7 plasmids were used from here on.

To test the induction and expression of CtrA, E. coli BL21 harbouring the pET28a(+)-ctrA plasmid were incubated with IPTG $(0.04 \mathrm{mM})$. Two samples were induced, one for 24 hours at $18^{\circ} \mathrm{C}$ and the other for 3 hours at $37^{\circ} \mathrm{C}$, to find the optimal induction parameters. The $\mathrm{OD}_{600}$ of the samples were used to dilute the samples so that approximately equivalent total protein amounts were loaded onto each gel. Following the lysis of the bacteria and denaturation of proteins, the solutions were run on Bis-Tris gel, stained with SimplyBlue ${ }^{\mathrm{TM}}$ Safe Stain, and scanned to visualise protein bands (Figure 19). 
Figure 19. CtrA induction screen.

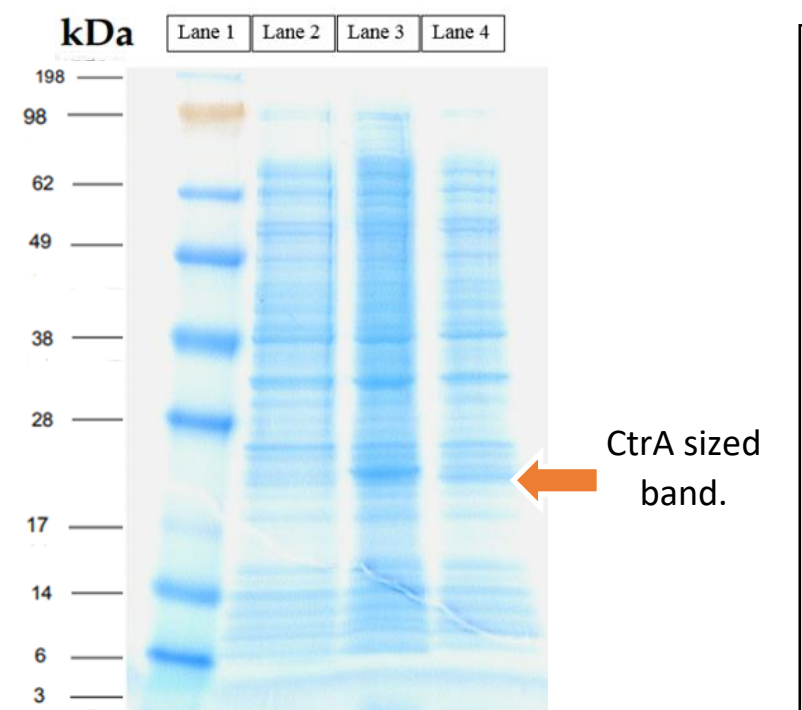

This Tris-glycine gel shows the total extracted protein of BL21 cells containing the pET28a(+)-ctrA plasmid after expression was induced and incubated at various temperatures and times.

An orange arrow indicates CtrA sized bands at 26-kDa, with larger bands being present in the induced samples.

Lane 1: Seeblue ${ }^{\circledR}$ Plus2 pre-stained protein standard (Novex),

Lane 2: BL21 pET28a(+)-ctrA, un-induced sample, Lane 3: BL21 pET28a (+)-ctrA, 24 hour, $18^{\circ} \mathrm{C}$ incubation,

Lane 4: BL21 pET28a(+)-ctrA, 3 hour, $37^{\circ} \mathrm{C}$ incubation.

This gel shows bands of about $26-\mathrm{kDa}$ (the predicted size of B. quintana CtrA) in both induced samples and comparatively very little in the uninduced sample. This demonstrated that CtrA is likely being induced in the BL21 pET28a(+)-ctrA cells, with more being produced with the 24 hour, $18^{\circ} \mathrm{C}$ incubation. Culturing bacteria expressing foreign proteins at a low temperature for an extended duration often results in enhanced production of the protein compared to shorter incubations at higher temperatures, so this result is not surprising. Because of this the 24 hour, $18^{\circ} \mathrm{C}$ incubation was used henceforth for CtrA purification.

When attempting to purify the expressed CtrA some issues became apparent when the His-Select purified sample was tested on a SDS-PAGE gel. On the first attempt, a distinct protein band was present after His-Select purification; however, it was approximately 10kDa larger than what was expected for CtrA. During the purification, the column was overloaded with protein, which may 
have clogged it allowing this protein to remain it the purification matrix until the elution step. To remedy this a smaller volume of cellular lysate was loaded into the column in subsequent attempts.

With less lysate loaded onto the His-Select purification column, the largest contamination band was significantly reduced, but there were still very low levels of a protein band of the size of CtrA, as well as small amounts of other proteins. This may have been due to low levels of CtrA expression in the bacteria. There had been sufficient expression to collect usable data from the $\beta$ galactosidase assays expression assays, so we had expected to be able to purify CtrA from these bacteria. The ability to collect $\beta$-galactosidase assay data but not be able to purify significant amounts of CtrA may be because only a relatively low level of CtrA was needed to affect the expression of lacZ via our promoters of interest, compared to the much higher levels of CtrA we were trying to induce and purify for EMSA.

There can be multiple causes for low protein expression in transgenic bacteria, including codon bias. To estimate the impact of codon bias, we used the GenScript ${ }^{\circledR}$ Rare codon analysis tool (https://www.genscript.com/tools/rare-codon-analysis), assessing the likelihood that the $B$. quintana ctrA gene would be expressed in E. coli, as a heterologous host.

\begin{tabular}{|c|c|c|c|}
\hline \multicolumn{4}{|c|}{ Rare Codon Analysis Result } \\
\hline & Actual Value & Ideal Value & Terms \\
\hline CAI & $\begin{array}{l}0.67 \downarrow \\
\text { Free Codon } \\
\text { Optimization }\end{array}$ & $0.8-1.0$ & $\begin{array}{l}\text { - A CAI of } 1.0 \text { is considered ideal. } \\
\text { - The lower the number, the higher the chance that your gene } \\
\text { will be expressed poorly. } \\
\text { - GenScript's OptimumGene }{ }^{\mathrm{TM}} \text { codon optimization tool can } \\
\text { typically improve your sequence. }\end{array}$ \\
\hline GC Content & $41.09 \%$ & $30 \%-70 \%$ & $\begin{array}{l}\text { - The ideal percentage range of GC content is between } 30 \% \\
\text { and } 70 \% \text {. }\end{array}$ \\
\hline CFD & $14 \%$ & $<30 \%$ & $\begin{array}{l}\text { - This un-optimized gene employs tandem rare codons that } \\
\text { can reduce the efficiency of translation or even disengage } \\
\text { the translational machinery. } \\
\text { - GenScript's OptimumGene }{ }^{\mathrm{TM}} \text { can give you the option to } \\
\text { solve this problem. }\end{array}$ \\
\hline
\end{tabular}


This analysis (above) showed that the GC content and CFD (Codon Frequency distribution) of $B$. quintana ctrA are within the optimal range for expression in E. coli, but that the CAI (Codon Adaption Index) is, at 0.67 , lower than the ideal range $(0.8-1.0)$, meaning that the production of CtrA in E. coli is likely to be reduced due to rare codons for E. coli.

\subsubsection{CtrA optimised expression, pRARE.}

The first attempt to increase protein expression was by introducing the pRARE plasmid from Novagen into the BL21 pET28a(+)-ctrA expression strain. This plasmid encodes multiple tRNAs which are rare in E. coli and can help reduce the effect of codon bias, as well as providing chloramphenicol resistance for selection. If the expression was increased it would allow for the purification of CtrA for use in EMSA assays.

Electrocompetent BL21 cells containing the pET28a(+)-ctrA plasmid were prepared and electroporated with the pRARE plasmid. Colonies were selected on a kanamycin, chloramphenicol LB plates and screened for the introduction of the plasmid. With the E. coli BL21 bacteria harbouring the pET28a(+)-ctrA and pRARE plasmids, the expression of CtrA was tested to determine if it had improved, using the same induction procedures and SDS-PAGE screening (Figure 20). 
Figure 20. pRARE plasmid CtrA expression screen.

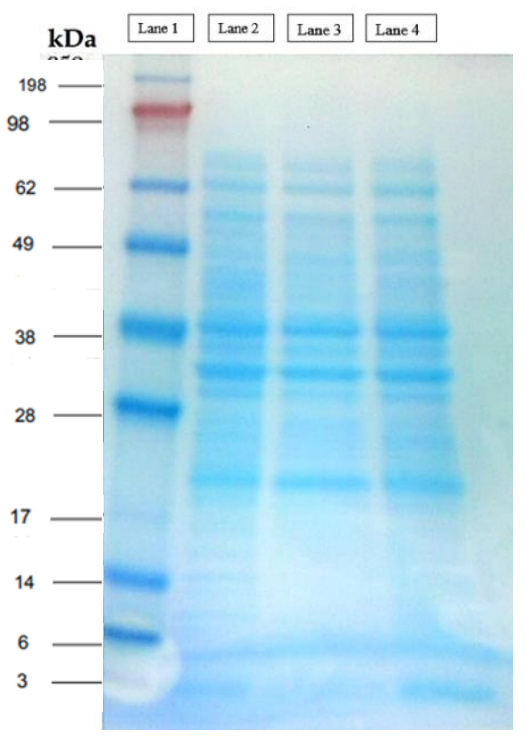

SDS page containing protein extract of CtrA expression strains containing the pRARE plasmid.

An orange arrow shows 26-kDa, with little apparent difference in the induced and uninduced band size.

Lane 1: Seeblue ${ }^{\circledR}$ Plus2.

Lane 2: un-induced sample.

Lane 3: 24 hour, $18^{\circ} \mathrm{C}$ incubation.

Lane 4: 3 hour, $37^{\circ} \mathrm{C}$ incubation.

The addition of the pRARE plasmid did not seem to increase the expression of CtrA, this was disappointing but not unexpected since pRARE does not always improve protein expression.

\subsubsection{2 pET28a(+)-ctrA codon optimised.}

Another attempted solution to the low level of CtrA expression was to construct an expression plasmid using a gBlock E. coli codon-optimised ctrA gene (produced by IDTDNA). This improves translation by replacing the rare codons for $E$. coli found in the $B$. quintana wildtype ctrA gene with codons commonly used by E. coli. The optimised sequence is shown in Appendix 4.

The codon optimised $c t r A$ gene was ligated into the pET28a(+) plasmid and electroporated into

DH5 $\alpha$ E. coli. The bacteria were incubated overnight on selective plates containing kanamycin 
before colonies were collected for digestion screening using BamHI and NdeI restriction enzymes (Figure 21).

Figure 21. codon optimized $\operatorname{ctr} A$ insert screen.

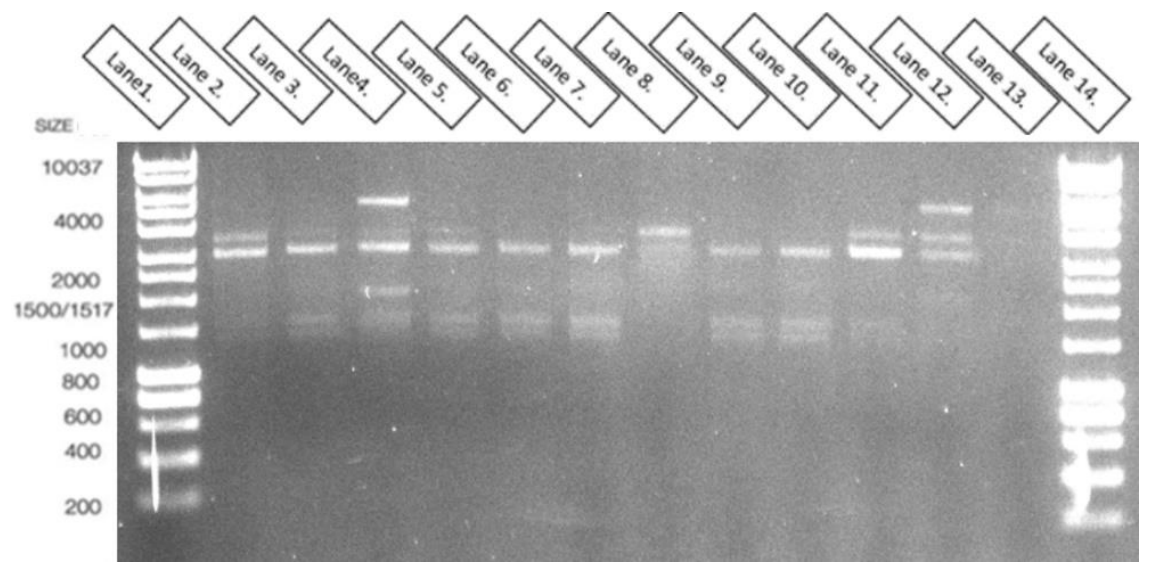

This gel contains pET28a(+)-ctrA plasmids following their isolation and digestion with, BamHI and NdeI restriction enzymes.

No $\operatorname{ctr} A$ sized bands were present, showing it was not inserted.

Lane 1 and 14: Hyperladder.

Lane 2-13: pET28a(+)-ctrA codon optimised colonies 1-12.

Figure 21 shows some interesting features. None of the lanes show a band at $700 \mathrm{bp}$, the expected size for the ctrA gene insert, suggesting it was not successfully integrated. Furthermore only the plasmids of colonies 3 and 11 have a band approximately the size of the empty pET28a(+) plasmid at $5.3 \mathrm{kbp}$, and all lanes show multiple other unexpected bands that do not correlate to any expected feature of the plasmid. This was a concerning result, when a plasmid produces a toxic product it provides a selection pressure to remove the gene or prevent its expression through mutations in the start codon. This results in a plasmid missing the gene, and potentially other parts of the plasmid while maintaining the antibiotic resistance provided by the plasmid.

To downregulate basal levels of CtrA expression during cloning, in case it did exhibit toxicity to the E. coli host, filtered glucose was added to the LB broth and selective plates, to activate 
catabolite repression of the IPTG-inducible gene. This time only three colonies grew overnight. When these were screened, however, all were negative for the ctrA insert. The plates were incubated for another night, since even lowered protein expression may slow the bacterial growth. The following morning there were many small colonies; 24 were collected and screened using colony PCR to amplify the $\operatorname{ctrA}$ insert (Figure 22).

\section{Figure 22. Small colony PCR gel.}

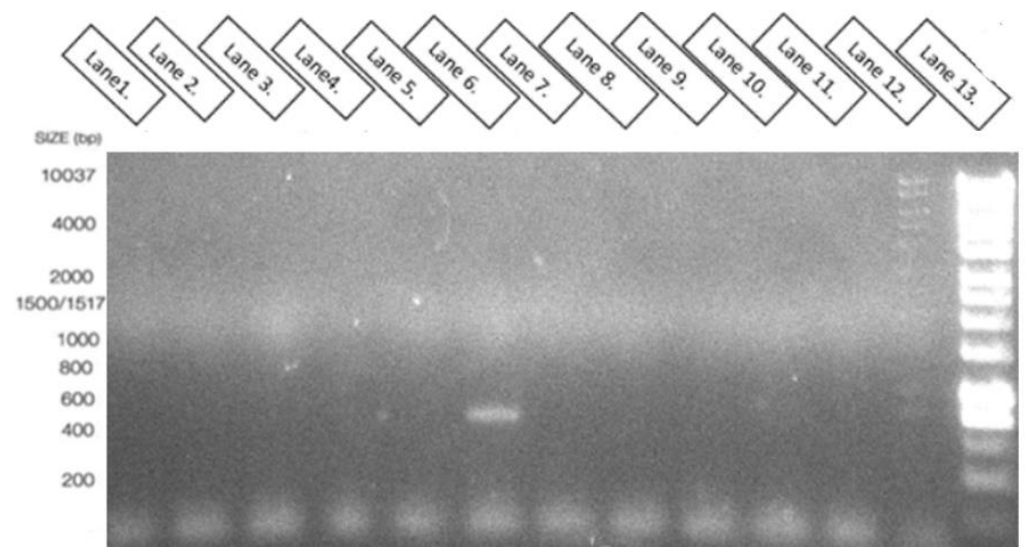

This gel shows the amplified PCR products from plasmids isolated from small colonies. A single ctrA sized insert is present in lane 6, all other lanes are empty.

Lane 1-12: small colony 13-24 PCR products.

Lane 13: Hyperladder.

This gel (Figure 22) shows that many of the bacteria did not contain plasmids with the ctrA insert present. This was not unexpected as none of the first set of screened colonies contained the correct plasmids. In addition, the extra day of incubation clearly allowed for bacteria with only a small level of resistance to the antibiotics to grow, meaning that some of the colonies likely did not contain a plasmid. However, colony 18 did have an amplified product the size of the ctrA insert. This colony along with a few other potential colonies were cultured and screened by restriction digest (Figure 23). 
Figure 23. Small colony 18 plasmid digest.

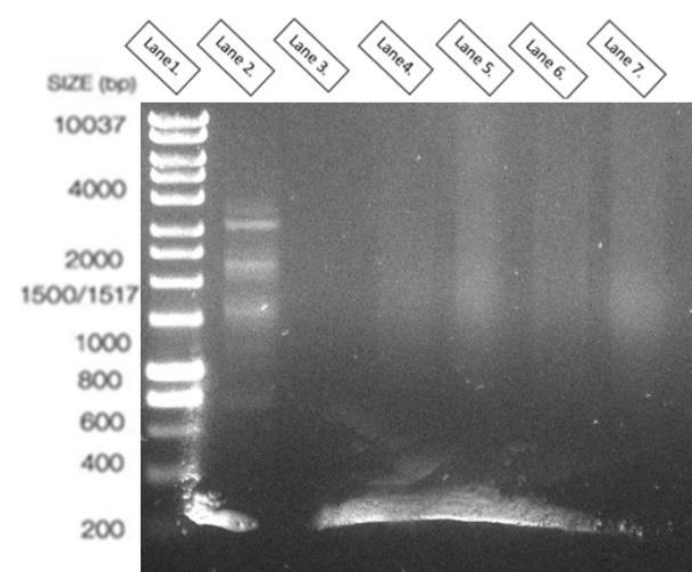

BamHI and NdeI restriction screen of potential pET28a(+)-ctrA codon optimised plasmids.

Lane 1 Hyperladder,

Lane 2: Small colony 18 plasmid digest.

Lane 3-7: Other potential colonies plasmid digest.

Figure 23 shows that while small colony 18 may contain the ctrA insert the rest of the plasmid is unrecognisable, so was unusable for further experiments. There was also very little in the lanes of the other colonies tested, revealing that they did not contain any plasmid. This was a disappointing result. We concluded that the codon-optimised B. quintana CtrA regulator exhibited some toxicity to E. coli. Even though E. coli, belonging to the gamma-proteobacteria, lacks a CtrA homologue, the regulator may have interfered with normal cell processes by binding to sites on the E. coli chromosome. The next step would be to try an expression system for the production of toxic products, in order to express the CtrA protein at a level at which it could be purified in usable quantities for EMSA. 


\section{Discussion.}

When beginning this project very little was known of the role and function of CtrA in B. quintana. Through this research we have made preliminary characterisations of the activity of CtrA in $B$. quintana and provided a foundation for further investigation of its role in the cell cycle and virulence in B. quintana.

\subsection{Key findings.}

\subsubsection{Regulator homology and gene expression.}

The $\operatorname{ctr} A$ gene is highly conserved through the alpha-proteobacteria class, so it was not surprising that $B$. quintana $\mathrm{CtrA}$ shares a high sequence identity with its $C$. crescentus homologue. Of the master cell cycle regulators, CtrA and SciP showed the highest percentage identity between $B$. quintana and $C$. crescentus. The $81 \%$ identity at the amino acid level suggests they are both transcription factors and likely bind similar motifs. Because of this we expected B. quintana and C. crescentus to share the same CtrA DNA binding motifs. The least conserved protein was ChpT with an identity of $28 \%$ suggesting its role in the cell diverged from that seen in C. crescentus, although this cannot be determined from its amino acid sequence alone. We also showed that under our incubation conditions chpT expression could not be detected, although expression of $\operatorname{ctr} A$ was clearly detected. This was unexpected due to the close functional relationship of these proteins in C. crescentus. This also suggests the role of ChpT might have diverged in B. quintana from that seen in $C$. crescentus. We also found that $\operatorname{ctr} A, s c i P$, and $\operatorname{chp} T$ are encoded together in a small locus on the $B$. quintana chromosome, as was also observed in B. bacilliformis. C. crescentus does 
not show this same organisation at this locus ${ }^{[91]}$, demonstrating B. quintana's close relatedness to B. bacilliformis and its more distant relationship to $C$. crescentus.

\subsubsection{Binding motifs.}

As a result of our search for CtrA DNA binding motifs in the genome of B. quintana str. Toulouse, we found that there were 21 genes with promoter regions containing at least one TTAACCAT binding motif; no copies of the TTAAN 7 TTAAC motif were detected anywhere throughout the genome. Only 21 directly-regulated genes is much fewer than the at least 95 genes directly regulated in C. crescentus $^{[62]}$, although there could be other CtrA-regulated genes in B. quintana that we did not identify in our bioinformatics search. Another explanation is that in C. crescentus CtrA regulates the expression of flagellum and pilin associated genes ${ }^{[93]}$, all of which are completely lacking in B. quintana, which is non motile and non piliated. It is also possible that the TTAAN $_{7}$ TTAAC binding motif has a modified sequence in B. quintana. In B. abortus the full motif is TTAACNNNNNGTTAAC, and binding motif variation was also described in $S$. meliloti ${ }^{[94]}$ and $R$. prowazekii ${ }^{[92,95]}$. This highlights a limitation of our screening method. By strictly searching for the TTAAN 7 TTAAC binding motif, we would not find slight variations of it, which may have occurred in $B$. quintana. This may explain why genes we thought were likely to be regulated by $\mathrm{Ctr}$, such as sciP, were not found in the DNA binding motif search. The final potential reason that there are fewer binding motifs in the $B$. quintana genome compared to $C$. crescentus, is that there are simply fewer genes regulated by B. quintana $\mathrm{CtrA}$. This is supported by data collected to study the diversity of the cell cycle regulation machinery in alphaproteobacteria ${ }^{[92]}$. 


\subsection{3 $\beta$-galactosidase activity assays.}

The $\beta$-galactosidase activity assays demonstrated some interesting interactions between $\mathrm{Ctr} A$ and the promoters of interest. As expected CtrA was able to induce significantly higher $\beta$-galactosidase production than that measured in the uninduced sample when interacting with the ftsE promoter. As FtsE is involved in the Z-ring, which facilitates formation of the septum and cell division, ${ }^{[1]}$ and $\mathrm{CtrA}$ is known to promote cell division in other alpha-proteobacteria, this is not a surprising result. We also found that CtrA had an inhibitory effect on the promoters of hemS and $h b p C$. This was a more surprising result, we had expected that these promoters would have been upregulated since bacterial cell division has been thought to occur during transmission in the digestive system of the arthropod vector ${ }^{[5,96]}$. However, the regulation of hemS and $h b p C$ likely have multiple contributing factors other than $\mathrm{Ctr} \mathrm{A}^{[97]}$. Because they are involved in heme metabolism and protect against toxic levels of heme, the iron regulatory systems likely contribute to their regulation, meaning this is likely a complex system requiring more research to fully understand. There was no statistically significant difference between the CtrA-induced and -uninduced ctrA promoter samples, but because we did not find a binding motif in the ctrA regulatory region, this was not an entirely unexpected result. However, we had suspected there may have been binding motifs in the ctrA promoter missed by our screen, but our $\beta$-galactosidase activity assay results did not support this.

\subsubsection{EMSA.}

Through the attempted expression of high levels of CtrA using a codon optimised ctrA gene, we began to suspect that $\mathrm{Ctr} A$ could be toxic to $E$. coli when expressed at high levels. In any case, we were able to induce the CtrA protein in an E. coli host, but not at levels high enough to successfully 
purify the protein and look for in vitro protein-DNA interactions. This could be due to a few factors, including inappropriate binding of CtrA to the chromosome and the formation of toxic protein aggregates at high concentrations. Future research into B. quintana CtrA will require this issue to be resolved, perhaps through the use of a protein expression method that enables cloning of the gene while suppressing even basal levels of expression.

\subsection{Future directions.}

\subsubsection{RT-qPCR gene expression assays.}

Further valuable data could be collected by expanding the gene expression assays carried out in this thesis. This could be used to detect the expression of $\operatorname{chpT,} c c k A$ as well as the other master regulatory genes not studied in this research. In particular, given the evidence that $c h p T$ is not expressed in $B$. quintana, it would be a good idea to look into the expression and activity of the other regulators of CtrA activation, i.e., DivJ, DivK, and PleC. Another important experiment that would provide a deeper understanding of the role of CtrA in B. quintana would be to use RT-qPCR to test gene expression of key regulators in B. quintana over the course of an infection. A human cell line could be infected with $B$. quintana, and the expression of $\operatorname{ctr} A$ and other genes could be measured throughout the course of infection using RT-qPCR. This could be also done while exposing the bacteria to a variety of conditions mimicking the diverse environment $B$. quintana encounters, such as the bloodstream of its human host and the louse digestive tract. These tests could be carried out in specialised media, or animal infection models such as the rhesus macaque. This will shed light on how the gene expression of $B$. quintana modulates over its life cycle, as well as how it relates to the regulation of environmentally regulated genes. 


\subsubsection{Expression and purification of CtrA.}

A significant part of continuing research into B. quintana $\mathrm{CtrA}$ is to achieve the expression and purification of the CtrA protein. While we were unable to express B. quintana $\mathrm{Ctr} A$ at high concentrations in E. coli, the expression could be optimised further, for instance addressing the idea that it could be a toxic protein. There are multiple ways to achieve this, such as in vitro synthesis kits like the Retic Lysate IVTTM Kit (ThermoFisher Scientific), the used of an expression system using a bacteria other than E. coli, e.g, Streptomyces lividans, along with other methods

${ }^{[98]}$. The purification of CtrA would allow for the EMSA experiments planned for this thesis, and many others, to be carried out. This could lend support to the other findings of this research, by demonstrating direct binding. Purified CtrA could also be used in ChIP Seq, as described below.

\subsubsection{ChIP Seq.}

ChIP Seq has been widely used to identify genome-wide DNA binding sites, for CtrA and other regulatory proteins ${ }^{[99]}$. A major advantage of this method is that it does not require any a priori knowledge of the sequence of the binding motif to yield results, in contrast to the motif search used in this project. In our case, ChIP Seq would be carried out by combining ectopically expressed and purified B. quintana $\mathrm{CtrA}$ with $300 \mathrm{bp}$ DNA fragments produced from the entire $B$. quintana genome. After the CtrA protein binds with its specific motifs on the DNA fragments, the DNAprotein complexes are cross linked, and B. quintana CtrA-specific antibodies are added. These antibodies are then used to immunoprecipitate the protein and cross-linked DNA. Sequencing of the DNA fragments allows for the identification of the CtrA binding sites throughout the genome. This means that binding motifs which are not identical to those of $C$. crescentus can be detected, remedying a major limitation of this project, as well as revealing binding sites that are outside of 
the promoter regions of genes. This was used in research of the S. meliloti CtrA homologue and revealed genes under direct CtrA regulation ${ }^{[99]}$. The same ChIP Seq study of S. meliloti showed that the $S$. meliloti chromosomal origin of replication, oriT, did not contain the five CtrA binding motifs found in the $C$. crescentus chromosomal origin of replication ${ }^{[99]}$. While searching for the CtrA DNA-binding motif in B. quintana, we were also looking for evidence that CtrA binds the B. quintana origin of replication but did not find any instance of multiple adjacent CtrA binding motifs correlating to the oriT. ChIP Seq would determine if these sites are absent or missed by our initial screen.

\subsubsection{Conditional mutant and transcriptome sequencing.}

Valuable insight into the role of $\mathrm{CtrA}$ in $B$. quintana could be gained through the generation of a conditional CtrA mutant, where CtrA is produced normally except under specific conditions, e.g. when it is only expressed in the presence of IPTG. This method has been used on other members of the alpha-proteobacteria class resulting in the development of an elongated cell phenotype as well as changes in the composition of the outer membrane when CtrA is depleted ${ }^{[84]}$. Performing this experiment in B. quintana would demonstrate whether CtrA has the same function in cell division as in other alpha-proteobacteria. Our research suggests that some similarities are likely, due to the CtrA interaction with the $f t s E$ promoter, but there are also clearly differences in the function of CtrA in B. quintana. The generation of a conditional mutant would also demonstrate if, as expected, ctrA is essential in B. quintana.

A conditional mutant could also be used to demonstrate changes in the transcriptome of CtrA depleted bacteria compared to wild type using global gene expression analysis, such as microarray 
or RNA-seq. This would reveal the genes regulated both directly and indirectly by CtrA, as well as whether that regulation was positive or negative depending on how the level of expression changes during CtrA depletion.

This experiment, along with ChIP-Seq, would demonstrate whether CtrA regulation for each gene was positive or negative, but also would show which genes are regulated directly and which are regulated indirectly. These techniques have been used to characterise the activity of $\mathrm{CtrA}$ in $S$. meliloti $^{[99]}$. These methods could be used to achieving an overall goal of understanding how $B$. quintana controls its post erythrocyte invasion replication halt at eight bacteria. This would involve measuring gene transcription, protein levels, and degree of CtrA. Also, the optimisation of a model infection of B. quintana and human erythrocytes. The monitoring of the bacteria intracellular activity through a combination of transcriptional assays and measuring protein and phosphorylation levels.

\subsubsection{SciP investigation.}

To expand our knowledge of the cellular regulation of B. quintana it is also necessary to study the role of the other master regulatory genes. The transcription factor SciP is an interesting candidate for further study. The SciP amino acid sequence maintains a high identity of $81 \%$ between $B$. quintana and $C$. crescentus, despite regulating many flagellum and pilin associated genes in $C$. crescentus, which are absent in B. quintana. It is also active in C. crescentus swarmer cells which don't undergo cell division. This raises some intriguing questions, including whether the quiescence in the $C$. crescentus swarmer cells is somehow equivalent to the post erythrocyte invasion G1 phase quiescence seen in B. quintana. Furthermore, because B. quintana lacks 
flagellum and pilin, which genes are regulated by SciP? Conditional mutants, microarray or RNAseq, and ChIP Seq are all techniques that could be used to answer this question. DivJ, DivK, and PleC homologues in B. quintana could also be studied in future work using these techniques.

\subsection{Concluding remarks.}

B. quintana is an important re-emerging global pathogen regaining prominence due its opportunistic pathogenesis ${ }^{[17]}$. It is the causative agent of both acute infections, such as trench fever, and chronic infections, which can result in long-standing bacteraemia, bacillary angiomatosis, and endocarditis, where there is an inflammation of the heart valves. In general, $B$. quintana and related species require further research to gain a deeper understanding of these important re-emerging pathogens.

This research represents the first characterisation of CtrA in B. quintana. Research into CtrA in other members of the alpha-proteobacteria class has shown it is an essential regulator of the cell cycle and virulence. B. quintana must tightly regulate its rate of growth throughout its infection to avoid immune detection and to facilitate transmission to new hosts. Because of this, the role of CtrA in B. quintana was an enticing subject of study, with the potential to reveal critical discoveries into the cell regulation and the nature of the stealth pathogenesis of B. quintana.

This thesis has identified 21 genes potentially directly regulated by $\mathrm{Ctr} A$ in B. quintana. Of these the promoter regions of $f t s E$, hemS, and $h b p C$ were demonstrated to be regulated by CtrA in a $\beta$ galactosidase activity assay. CtrA demonstrated a positive regulation of the ftsE promoter, likely 
stimulating the production of the FtsE cell division protein in vivo. It also exhibited an inhibitory effect on both hemS and $h b p C$. While the purification of sufficient levels of CtrA for protein-DNA interaction studies was not achieved in this project, the use of specialised toxic protein expression methods will allow its purification in future.

Expanding the understanding of the role CtrA plays in the regulation of the cell cycle and virulence will provide additional insight into the pathogenesis of B. quintana. Future work could expose how B. quintana fine tunes its regulation, for example how it coordinates its crucial halt of replication while in its intracellular erythrocyte niche. Gaining greater understanding of the cell cycle control provided by $\mathrm{CtrA}$ in $B$. quintana might lead to improved prevention, new methods of diagnosis, and novel targeted treatments for B. quintana. 


\section{Bibliography.}

1. Corbin, B.D., Y. Wang, T.K. Beuria and W. Margolin, Interaction between cell division proteins FtsE and FtsZ. J Bacteriol, 2007. 189(8): p. 3026-35.

2. Chomel, B.B. and R.W. Kasten, Bartonellosis, an increasingly recognized zoonosis. J Appl Microbiol, 2010. 109(3): p. 743-50.

3. Breitschwerdt, E.B. and D.L. Kordick, Bartonella infection in animals: carriership, reservoir potential, pathogenicity, and zoonotic potential for human infection. Clin Microbiol Rev, 2000. 13(3): p. 428-38.

4. Chomel, B.B., R.W. Kasten, K. Floyd-Hawkins, B. Chi, K. Yamamoto, J. Roberts-Wilson, et al., Experimental transmission of Bartonella henselae by the cat flea. J Clin Microbiol, 1996. 34(8): p. 1952-6.

5. Fournier, P.E., M.F. Minnick, H. Lepidi, E. Salvo and D. Raoult, Experimental model of human body louse infection using green fluorescent protein-expressing Bartonella quintana. Infect Immun, 2001. 69(3): p. 1876-9.

6. Chomel, B.B., H.J. Boulouis, S. Maruyama and E.B. Breitschwerdt, Bartonella spp. in pets and effect on human health. Emerg Infect Dis, 2006. 12(3): p. 389-94.

7. G J Olsen, D J Lane, S J Giovannoni, a. N R Pace and D.A. Stahl, Microbial Ecology and Evolution: A Ribosomal RNA Approach. Annual Review of Microbiology, 1986. 40(1): p. 337-365.

8. Regnery, R.L., B.E. Anderson, J.E. Clarridge, 3rd, M.C. Rodriguez-Barradas, D.C. Jones and J.H. Carr, Characterization of a novel Rochalimaea species, $R$. henselae sp. nov., isolated from blood of a febrile, human immunodeficiency virus-positive patient. J Clin Microbiol, 1992. 30(2): p. 26574.

9. Welch, D.F., D.A. Pickett, L.N. Slater, A.G. Steigerwalt and D.J. Brenner, Rochalimaea henselae sp. nov., a cause of septicemia, bacillary angiomatosis, and parenchymal bacillary peliosis. J Clin Microbiol, 1992. 30(2): p. 275-80.

10. Dangman, B.C., B.A. Albanese, M.A. Kacica, M.L. Lepow and M.T. Wallach, Cat scratch disease in two children presenting with fever of unknown origin: imaging features and association with a new causative agent, Rochalimaea henselae. Pediatrics, 1995. 95(5): p. 767-71.

11. Schulein, R., A. Seubert, C. Gille, C. Lanz, Y. Hansmann, Y. Piemont, et al., Invasion and persistent intracellular colonization of erythrocytes. A unique parasitic strategy of the emerging pathogen Bartonella. J Exp Med, 2001. 193(9): p. 1077-86.

12. Muller, A., M. Reiter, A.M. Schotta, H. Stockinger and G. Stanek, Detection of Bartonella spp. in Ixodes ricinus ticks and Bartonella seroprevalence in human populations. Ticks Tick Borne Dis, 2016. 7(5): p. 763-767.

13. Dzupova, O., S. Pekova, N. Sojkova, R. Feuereisl and J. Benes, Infective endocarditis due to Bartonella quintana: a severe disease and underdiagnosed etiology. Folia Microbiol (Praha), 2013. 58(6): p. 491-4.

14. Graham, J.H.P., A NOTE ON A RELAPSING FEBRILE ILLNESS OF UNKNOWN ORIGIN. The Lancet. 186(4804): p. 703-704.

15. Strong, R.P., Trench fever; report of commission, Medical Research Committee, American Red Cross;: American National Red Cross. Medical Research Committee, 1918.

16. Harms, A. and C. Dehio, Intruders below the radar: molecular pathogenesis of Bartonella spp. Clin Microbiol Rev, 2012. 25(1): p. 42-78.

17. Schmidt, H.-U., T. Kaliebe, J. Poppinger, C. Bühler and A. Sander, Isolation ofBartonella quintana from an HIV-positive patient with bacillary angiomatosis. European Journal of Clinical Microbiology and Infectious Diseases, 1996. 15(9): p. 736-741. 
18. Maurin, M., R. Birtles and D. Raoult, Current knowledge of Bartonella species. Eur J Clin Microbiol Infect Dis, 1997. 16(7): p. 487-506.

19. Maurin, M. and D. Raoult, Bartonella (Rochalimaea) quintana infections. Clin Microbiol Rev, 1996. 9(3): p. 273-92.

20. Debre, R., M. Lamy, M.L. Jammet, L. Costil and P. Mozziconacci, La maladie des griffes de chat. Sem Hop, 1950. 26(40): p. 1895-1904.

21. Greer, W.E. and C.S. Keefer, Cat-scratch fever; a disease entity. N Engl J Med, 1951. 244(15): p. 545-8.

22. Slater, L.N., D.F. Welch, D. Hensel and D.W. Coody, A newly recognized fastidious gram-negative pathogen as a cause of fever and bacteremia. N Engl J Med, 1990. 323(23): p. 1587-93.

23. Koehler, J.E., M.A. Sanchez, S. Tye, C.S. Garrido-Rowland, F.M. Chen, T. Maurer, et al., Prevalence of Bartonella infection among human immunodeficiency virus-infected patients with fever. Clin Infect Dis, 2003. 37(4): p. 559-66.

24. Pons, I., I. Sanfeliu, M.M. Nogueras, M. Sala, M. Cervantes, M.J. Amengual, et al., Seroprevalence of Bartonella spp. infection in HIV patients in Catalonia, Spain. BMC Infect Dis, 2008. 8: p. 58.

25. Karem, K.L., C.D. Paddock and R.L. Regnery, Bartonella henselae, B. quintana, and B. bacilliformis: historical pathogens of emerging significance. Microbes Infect, 2000. 2(10): $p$. 1193-205.

26. Alsmark, C.M., A.C. Frank, E.O. Karlberg, B.A. Legault, D.H. Ardell, B. Canback, et al., The louseborne human pathogen Bartonella quintana is a genomic derivative of the zoonotic agent Bartonella henselae. Proc Natl Acad Sci U S A, 2004. 101(26): p. 9716-21.

27. Maguina, C., P.J. Garcia, E. Gotuzzo, L. Cordero and D.H. Spach, Bartonellosis (Carrion's disease) in the modern era. Clin Infect Dis, 2001. 33(6): p. 772-9.

28. Maguina, C., H. Guerra and P. Ventosilla, Bartonellosis. Clin Dermatol, 2009. 27(3): p. 271-80.

29. Saenz, H.L., P. Engel, M.C. Stoeckli, C. Lanz, G. Raddatz, M. Vayssier-Taussat, et al., Genomic analysis of Bartonella identifies type IV secretion systems as host adaptability factors. Nat Genet, 2007. 39(12): p. 1469-76.

30. Raoult, D., O. Dutour, L. Houhamdi, R. Jankauskas, P.E. Fournier, Y. Ardagna, et al., Evidence for louse-transmitted diseases in soldiers of Napoleon's Grand Army in Vilnius. J Infect Dis, 2006. 193(1): p. 112-20.

31. Drancourt, M., L. Tran-Hung, J. Courtin, H. Lumley and D. Raoult, Bartonella quintana in a 4000year-old human tooth. J Infect Dis, 2005. 191(4): p. 607-11.

32. Atenstaedt, R.L., Trench fever: the British medical response in the Great War. J R Soc Med, 2006. 99(11): p. 564-8.

33. Byam, W. and L. Lloyd, Trench Fever: Its Epidemiology and Endemiology. Proc R Soc Med, 1920. 13(Sect Epidemiol State Med): p. 1-27.

34. Hotez, P.J., Neglected infections of poverty in the United States of America. PLoS Negl Trop Dis, 2008. 2(6): p. e256.

35. Jackson, L.A., D.H. Spach, D.A. Kippen, N.K. Sugg, R.L. Regnery, M.H. Sayers, et al., Seroprevalence to Bartonella quintana among patients at a community clinic in downtown Seattle. J Infect Dis, 1996. 173(4): p. 1023-6.

36. Brouqui, P., B. Lascola, V. Roux and D. Raoult, Chronic Bartonella quintana bacteremia in homeless patients. N Engl J Med, 1999. 340(3): p. 184-9.

37. Nelson, C.A., S. Saha and P.S. Mead, Cat-Scratch Disease in the United States, 2005-2013. Emerg Infect Dis, 2016. 22(10): p. 1741-6.

38. Brouqui, P., A. Stein, H.T. Dupont, P. Gallian, S. Badiaga, J.M. Rolain, et al., Ectoparasitism and vector-borne diseases in 930 homeless people from Marseilles. Medicine (Baltimore), 2005. 84(1): p. 61-8. 
39. La Scola, B. and D. Raoult, Culture of Bartonella quintana and Bartonella henselae from human samples: a 5-year experience (1993 to 1998). J Clin Microbiol, 1999. 37(6): p. 1899-905.

40. Fenollar, F. and D. Raoult, Molecular genetic methods for the diagnosis of fastidious microorganisms. APMIS, 2004. 112(11-12): p. 785-807.

41. Breitschwerdt, E.B., R.G. Maggi, B. Sigmon and W.L. Nicholson, Isolation of Bartonella quintana from a woman and a cat following putative bite transmission. J Clin Microbiol, 2007. 45(1): p. 270-2.

42. Higgins, J.A., S. Radulovic, D.C. Jaworski and A.F. Azad, Acquisition of the cat scratch disease agent Bartonella henselae by cat fleas (Siphonaptera:Pulicidae). J Med Entomol, 1996. 33(3): p. 490-5.

43. Dehio, C., U. Sauder and R. Hiestand, Isolation of Bartonella schoenbuchensis from Lipoptena cervi, a blood-sucking arthropod causing deer ked dermatitis. J Clin Microbiol, 2004. 42(11): p. 5320-3.

44. Battisti, J.M., P.G. Lawyer and M.F. Minnick, Colonization of Lutzomyia verrucarum and Lutzomyia longipalpis Sand Flies (Diptera: Psychodidae) by Bartonella bacilliformis, the Etiologic Agent of Carrion's Disease. PLoS Negl Trop Dis, 2015. 9(10): p. e0004128.

45. Koesling, J., T. Aebischer, C. Falch, R. Schulein and C. Dehio, Cutting edge: antibody-mediated cessation of hemotropic infection by the intraerythrocytic mouse pathogen Bartonella grahamii. J Immunol, 2001. 167(1): p. 11-4.

46. Hong, J., Y. Li, X. Hua, Y. Bai, C. Wang, C. Zhu, et al., Lymphatic Circulation Disseminates Bartonella Infection Into Bloodstream. J Infect Dis, 2017. 215(2): p. 303-311.

47. Chomel, B.B., H.J. Boulouis, E.B. Breitschwerdt, R.W. Kasten, M. Vayssier-Taussat, R.J. Birtles, et al., Ecological fitness and strategies of adaptation of Bartonella species to their hosts and vectors. Vet Res, 2009. 40(2): p. 29.

48. Chiaraviglio, L., S. Duong, D.A. Brown, R.J. Birtles and J.E. Kirby, An immunocompromised murine model of chronic Bartonella infection. Am J Pathol, 2010. 176(6): p. 2753-63.

49. Dehio, C., Bartonella interactions with endothelial cells and erythrocytes. Trends Microbiol, 2001. 9(6): p. 279-85.

50. Merrell, D.S. and S. Falkow, Frontal and stealth attack strategies in microbial pathogenesis. Nature, 2004. 430(6996): p. 250-6.

51. Capo, C., N. Amirayan-Chevillard, P. Brouqui, D. Raoult and J.L. Mege, Bartonella quintana bacteremia and overproduction of interleukin-10: model of bacterial persistence in homeless people. J Infect Dis, 2003. 187(5): p. 837-44.

52. Liu, M., Y. Ferrandez, E. Bouhsira, M. Monteil, M. Franc, H.J. Boulouis, et al., Heme binding proteins of Bartonella henselae are required when undergoing oxidative stress during cell and flea invasion. PLoS One, 2012. 7(10): p. e48408.

53. Liu, M., H.J. Boulouis and F. Biville, Heme degrading protein HemS is involved in oxidative stress response of Bartonella henselae. PLoS One, 2012. 7(5): p. e37630.

54. Sander, A., S. Kretzer, W. Bredt, K. Oberle and S. Bereswill, Hemin-dependent growth and hemin binding of Bartonella henselae. FEMS Microbiol Lett, 2000. 189(1): p. 55-9.

55. Roden, J.A., D.H. Wells, B.B. Chomel, R.W. Kasten and J.E. Koehler, Hemin binding protein C is found in outer membrane vesicles and protects Bartonella henselae against toxic concentrations of hemin. Infect Immun, 2012. 80(3): p. 929-42.

56. Curtis, P.D. and Y.V. Brun, Getting in the loop: regulation of development in Caulobacter crescentus. Microbiol Mol Biol Rev, 2010. 74(1): p. 13-41.

57. Zhou, B., J.M. Schrader, V.S. Kalogeraki, E. Abeliuk, C.B. Dinh, J.Q. Pham, et al., The global regulatory architecture of transcription during the Caulobacter cell cycle. PLoS Genet, 2015. 11(1): p. e1004831. 
58. Laub, M.T., H.H. McAdams, T. Feldblyum, C.M. Fraser and L. Shapiro, Global analysis of the genetic network controlling a bacterial cell cycle. Science, 2000. 290(5499): p. 2144-8.

59. McAdams, H.H. and L. Shapiro, The architecture and conservation pattern of whole-cell control circuitry. J Mol Biol, 2011. 409(1): p. 28-35.

60. Quon, K.C., B. Yang, I.J. Domian, L. Shapiro and G.T. Marczynski, Negative control of bacterial DNA replication by a cell cycle regulatory protein that binds at the chromosome origin. Proc Natl Acad Sci U S A, 1998. 95(1): p. 120-5.

61. Laub, M.T., S.L. Chen, L. Shapiro and H.H. McAdams, Genes directly controlled by CtrA, a master regulator of the Caulobacter cell cycle. Proc Natl Acad Sci U S A, 2002. 99(7): p. 4632-7.

62. Iniesta, A.A., P.T. McGrath, A. Reisenauer, H.H. McAdams and L. Shapiro, A phospho-signaling pathway controls the localization and activity of a protease complex critical for bacterial cell cycle progression. Proc Natl Acad Sci U S A, 2006. 103(29): p. 10935-40.

63. Quon, K.C., G.T. Marczynski and L. Shapiro, Cell cycle control by an essential bacterial twocomponent signal transduction protein. Cell, 1996. 84(1): p. 83-93.

64. Jacobs, C., N. Ausmees, S.J. Cordwell, L. Shapiro and M.T. Laub, Functions of the CckA histidine kinase in Caulobacter cell cycle control. Mol Microbiol, 2003. 47(5): p. 1279-90.

65. Jacobs, C., I.J. Domian, J.R. Maddock and L. Shapiro, Cell cycle-dependent polar localization of an essential bacterial histidine kinase that controls DNA replication and cell division. Cell, 1999.

97(1): p. 111-20.

66. Biondi, E.G., S.J. Reisinger, J.M. Skerker, M. Arif, B.S. Perchuk, K.R. Ryan, et al., Regulation of the bacterial cell cycle by an integrated genetic circuit. Nature, 2006. 444(7121): p. 899-904.

67. Smith, S.C., K.K. Joshi, J.J. Zik, K. Trinh, A. Kamajaya, P. Chien, et al., Cell cycle-dependent adaptor complex for ClpXP-mediated proteolysis directly integrates phosphorylation and second messenger signals. Proc Natl Acad Sci U S A, 2014. 111(39): p. 14229-34.

68. Hecht, G.B., T. Lane, N. Ohta, J.M. Sommer and A. Newton, An essential single domain response regulator required for normal cell division and differentiation in Caulobacter crescentus. EMBO J, 1995. 14(16): p. 3915-24.

69. Jacobs-Wagner, C., Regulatory proteins with a sense of direction: cell cycle signalling network in Caulobacter. Mol Microbiol, 2004. 51(1): p. 7-13.

70. Angelastro, P.S., O. Sliusarenko and C. Jacobs-Wagner, Polar localization of the CckA histidine kinase and cell cycle periodicity of the essential master regulator CtrA in Caulobacter crescentus. J Bacteriol, 2010. 192(2): p. 539-52.

71. Wheeler, R.T. and L. Shapiro, Differential localization of two histidine kinases controlling bacterial cell differentiation. Mol Cell, 1999. 4(5): p. 683-94.

72. Tsokos, C.G., B.S. Perchuk and M.T. Laub, A dynamic complex of signaling proteins uses polar localization to regulate cell-fate asymmetry in Caulobacter crescentus. Dev Cell, 2011. 20(3): p. 329-41.

73. Holtzendorff, J., D. Hung, P. Brende, A. Reisenauer, P.H. Viollier, H.H. McAdams, et al., Oscillating global regulators control the genetic circuit driving a bacterial cell cycle. Science, 2004. 304(5673): p. 983-7.

74. McAdams, H.H. and L. Shapiro, A bacterial cell-cycle regulatory network operating in time and space. Science, 2003. 301(5641): p. 1874-7.

75. Holtzendorff, J., J. Reinhardt and P.H. Viollier, Cell cycle control by oscillating regulatory proteins in Caulobacter crescentus. Bioessays, 2006. 28(4): p. 355-61.

76. Hottes, A.K., L. Shapiro and H.H. McAdams, DnaA coordinates replication initiation and cell cycle transcription in Caulobacter crescentus. Mol Microbiol, 2005. 58(5): p. 1340-53.

77. Dumler, J.S., A.F. Barbet, C.P. Bekker, G.A. Dasch, G.H. Palmer, S.C. Ray, et al., Reorganization of genera in the families Rickettsiaceae and Anaplasmataceae in the order Rickettsiales: unification 
of some species of Ehrlichia with Anaplasma, Cowdria with Ehrlichia and Ehrlichia with

Neorickettsia, descriptions of six new species combinations and designation of Ehrlichia equi and 'HGE agent' as subjective synonyms of Ehrlichia phagocytophila. Int J Syst Evol Microbiol, 2001. 51(Pt 6): p. 2145-65.

78. Christine E. Seidman, K.S., Jen Sheen, and Timm Jessen., Current Protocols in Molecular Biology (1997)

1997.

79. Zhang, J.Z., V.L. Popov, S. Gao, D.H. Walker and X.J. Yu, The developmental cycle of Ehrlichia chaffeensis in vertebrate cells. Cell Microbiol, 2007. 9(3): p. 610-8.

80. Thomas, S., V.L. Popov and D.H. Walker, Exit mechanisms of the intracellular bacterium Ehrlichia. PLoS One, 2010. 5(12): p. e15775.

81. Cheng, Z., K. Miura, V.L. Popov, Y. Kumagai and Y. Rikihisa, Insights into the CtrA regulon in development of stress resistance in obligatory intracellular pathogen Ehrlichia chaffeensis. Mol Microbiol, 2011. 82(5): p. 1217-34.

82. Moreno E., M.I., The Genus Brucella. The Prokaryotes, ed. F.S. n: Dworkin M., Rosenberg E., Schleifer KH., Stackebrandt E. (eds). 2006: Springer, New York, NY.

83. Francis, N., K. Poncin, A. Fioravanti, V. Vassen, K. Willemart, T.A. Ong, et al., CtrA controls cell division and outer membrane composition of the pathogen Brucella abortus. Mol Microbiol, 2017. 103(5): p. 780-797.

84. Deghelt, M., C. Mullier, J.F. Sternon, N. Francis, G. Laloux, D. Dotreppe, et al., G1-arrested newborn cells are the predominant infectious form of the pathogen Brucella abortus. Nat Commun, 2014. 5: p. 4366.

85. Chang, A.C. and S.N. Cohen, Construction and characterization of amplifiable multicopy DNA cloning vehicles derived from the P15A cryptic miniplasmid. J Bacteriol, 1978. 134(3): p. 1141-56.

86. Rose, R.E., The nucleotide sequence of pACYC184. Nucleic Acids Res, 1988. 16(1): p. 355.

87. Prosser, G.A., J.N. Copp, A.M. Mowday, C.P. Guise, S.P. Syddall, E.M. Williams, et al., Creation and screening of a multi-family bacterial oxidoreductase library to discover novel nitroreductases that efficiently activate the bioreductive prodrugs CB1954 and PR-104A. Biochem Pharmacol, 2013. 85(8): p. 1091-103.

88. Zhang, P., B.B. Chomel, M.K. Schau, J.S. Goo, S. Droz, K.L. Kelminson, et al., A family of variably expressed outer-membrane proteins (Vomp) mediates adhesion and autoaggregation in Bartonella quintana. Proc Natl Acad Sci U S A, 2004. 101(37): p. 13630-5.

89. Lund, A.H., M. Duch and F.S. Pedersen, Increased cloning efficiency by temperature-cycle ligation. Nucleic Acids Res, 1996. 24(4): p. 800-1.

90. Prosser, G., Discovery and Optimisation of Bacterial Nitroreductases for Use in Anti-cancer Gene Therapy. 2011, Victoria Universety of Wellington. p. 97-99.

91. Gora, K.G., C.G. Tsokos, Y.E. Chen, B.S. Srinivasan, B.S. Perchuk and M.T. Laub, A cell-typespecific protein-protein interaction modulates transcriptional activity of a master regulator in Caulobacter crescentus. Mol Cell, 2010. 39(3): p. 455-67.

92. Brilli, M., M. Fondi, R. Fani, A. Mengoni, L. Ferri, M. Bazzicalupo, et al., The diversity and evolution of cell cycle regulation in alpha-proteobacteria: a comparative genomic analysis. BMC Syst Biol, 2010. 4: p. 52.

93. Boyd, C.H. and J.W. Gober, Temporal regulation of genes encoding the flagellar proximal rod in Caulobacter crescentus. J Bacteriol, 2001. 183(2): p. 725-35.

94. Hansen, F.G., B.B. Christensen and T. Atlung, Sequence characteristics required for cooperative binding and efficient in vivo titration of the replication initiator protein DnaA in E. coli. J Mol Biol, 2007. 367(4): p. 942-52. 
95. Pellegrini, M., E.M. Marcotte, M.J. Thompson, D. Eisenberg and T.O. Yeates, Assigning protein functions by comparative genome analysis: protein phylogenetic profiles. Proc Natl Acad Sci U S A, 1999. 96(8): p. 4285-8.

96. Billeter, S.A., P.P. Diniz, J.M. Battisti, U.G. Munderloh, E.B. Breitschwerdt and M.G. Levy, Infection and replication of Bartonella species within a tick cell line. Exp Appl Acarol, 2009. 49(3): p. 193-208.

97. Battisti, J.M., L.S. Smitherman, K.N. Sappington, N.L. Parrow, R. Raghavan and M.F. Minnick, Transcriptional regulation of the heme binding protein gene family of Bartonella quintana is accomplished by a novel promoter element and iron response regulator. Infect Immun, 2007. 75(9): p. 4373-85.

98. Saida, F., M. Uzan, B. Odaert and F. Bontems, Expression of highly toxic genes in E. coli: special strategies and genetic tools. Curr Protein Pept Sci, 2006. 7(1): p. 47-56.

99. Pini, F., N.J. De Nisco, L. Ferri, J. Penterman, A. Fioravanti, M. Brilli, et al., Cell Cycle Control by the Master Regulator CtrA in Sinorhizobium meliloti. PLoS Genet, 2015. 11(5): p. e1005232. 


\section{Appendix.}

\section{Appendix 1. CtrA amino acid alignment.}

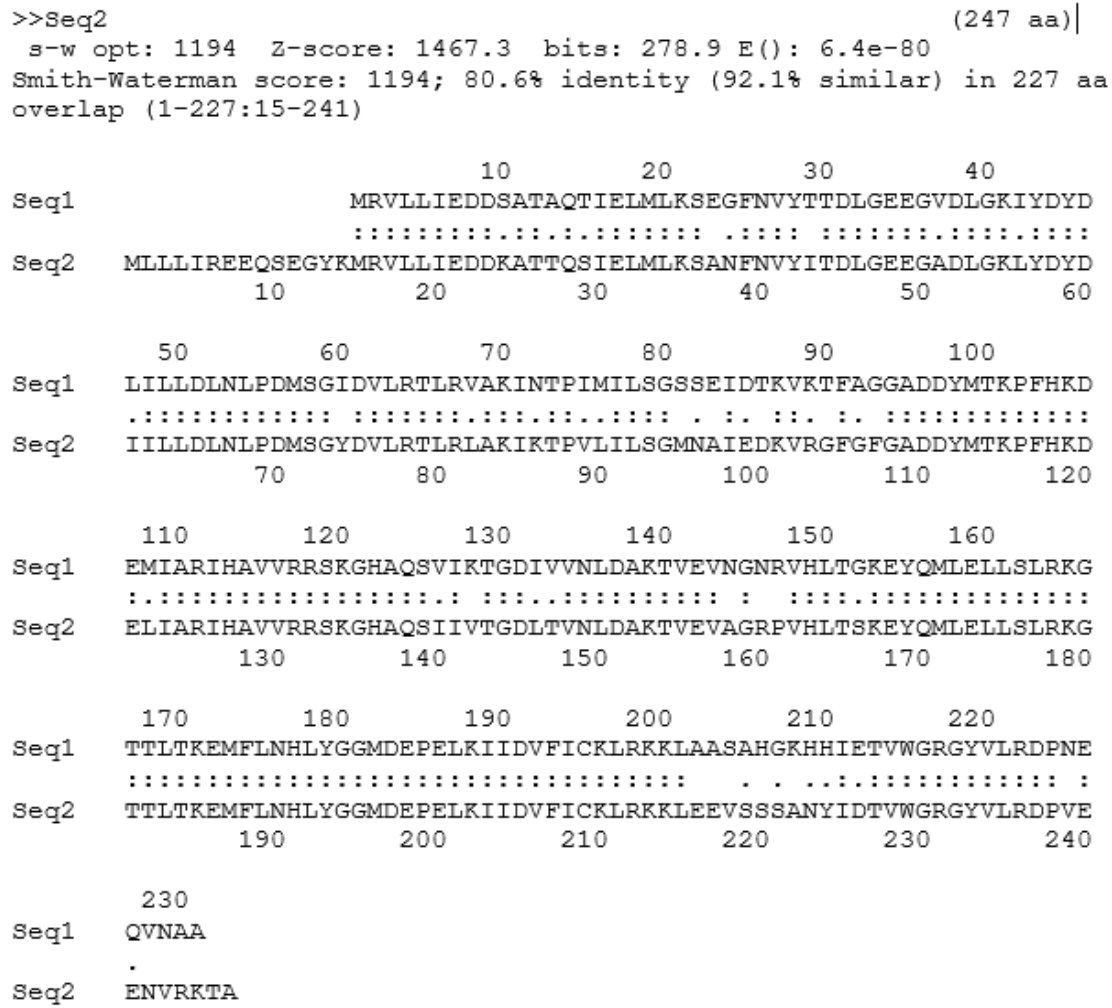

\section{CtrA DNA binding site amino acid alignment.}

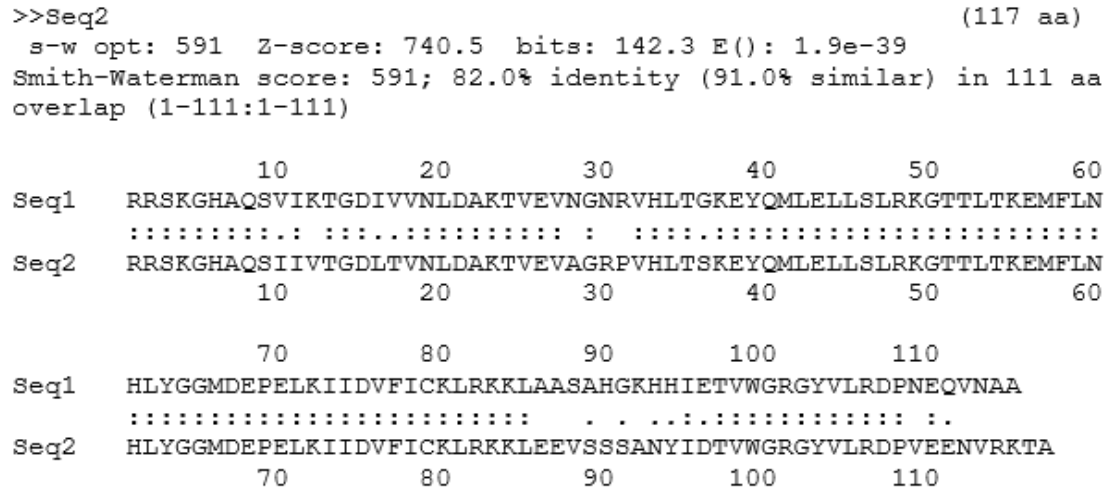

Seq1 - C. crescentus $\mathrm{CtrA}$ sequence.

Seq2 - B. quintana CtrA sequence.
Seq1 - C. crescentus CtrA DNA binding domain sequence.

Seq2 - B. quintana CtrA DNA binding domain sequence. 


\section{Appendix 2. ctrA insert sequence.}

ctrA insert sequence, forward reaction.

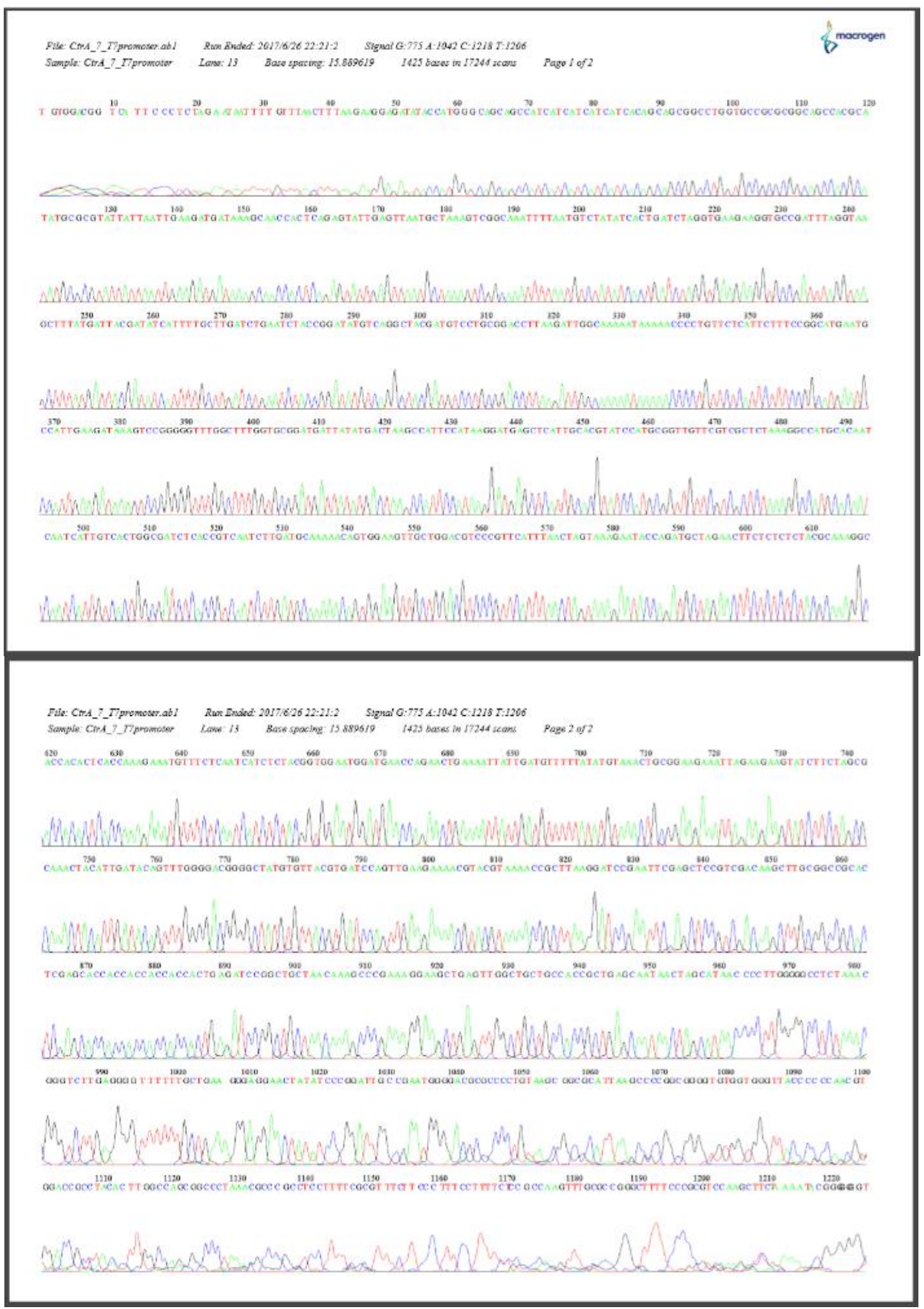


ctrA insert sequence, reverse reaction.

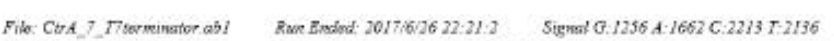

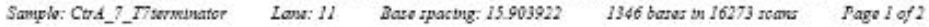

mocrogen

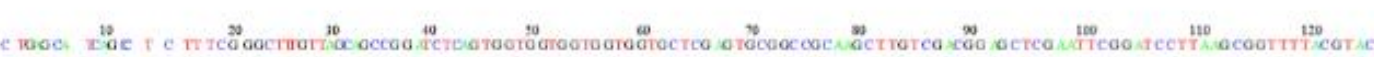

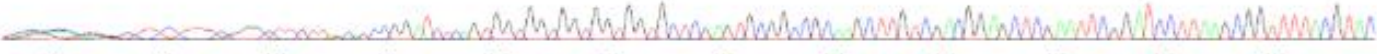

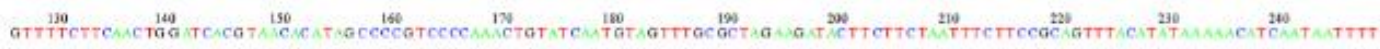

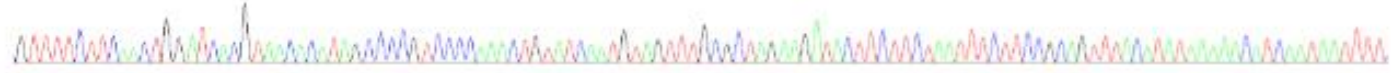

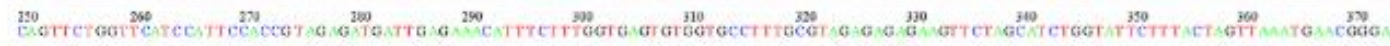

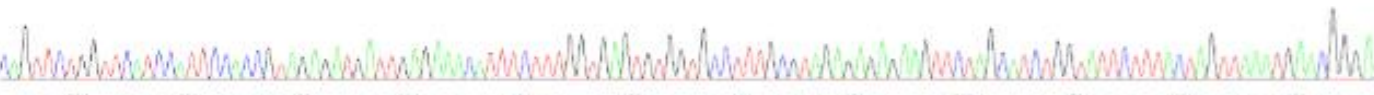

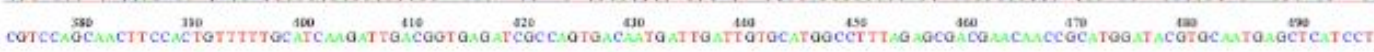

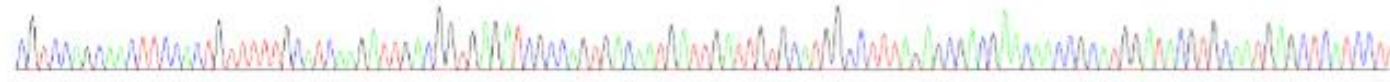
T.50.

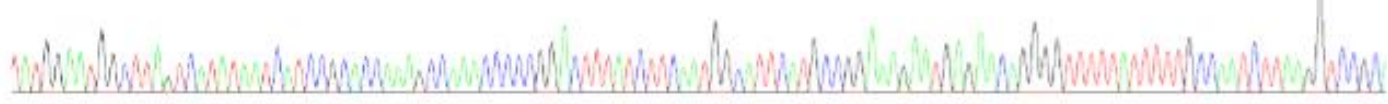

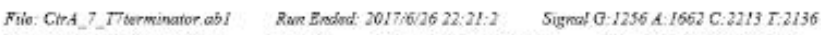

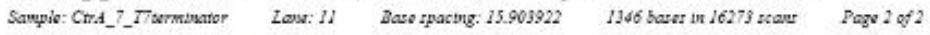

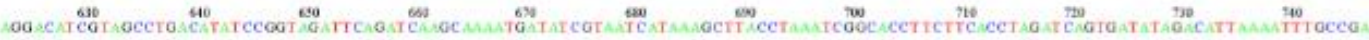

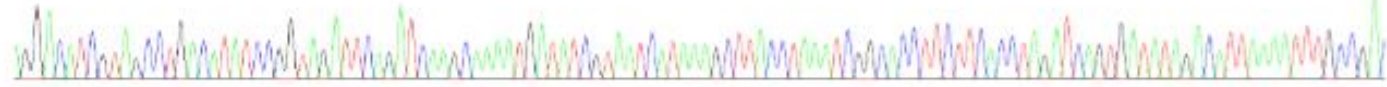

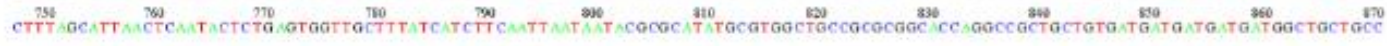

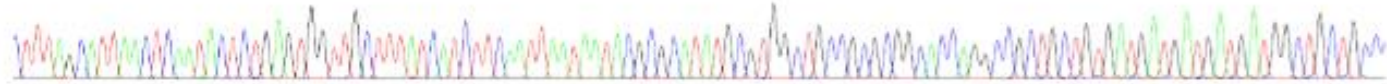

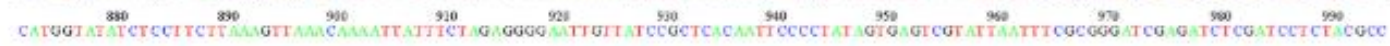

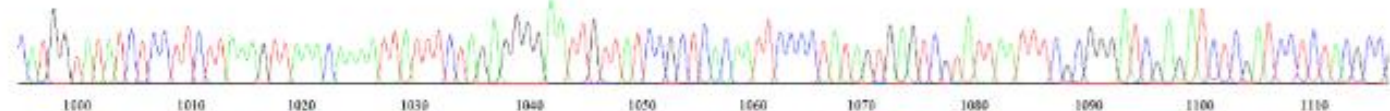

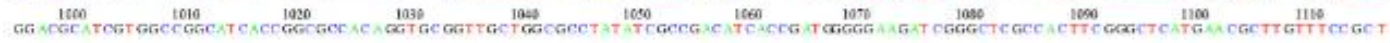

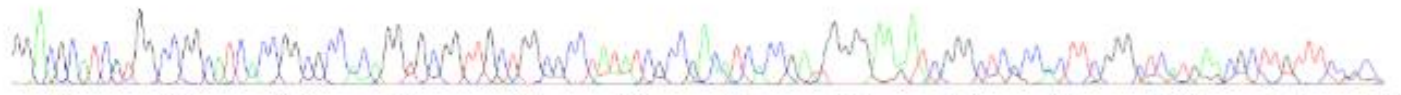

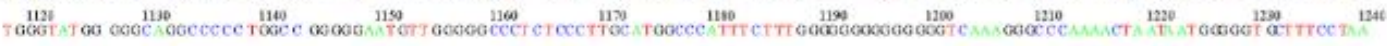

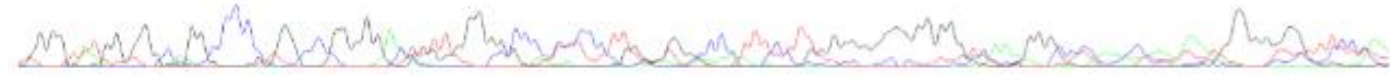




\section{Appendix 3. lac Z insert sequence.}

lacZ insert, forward sequence.

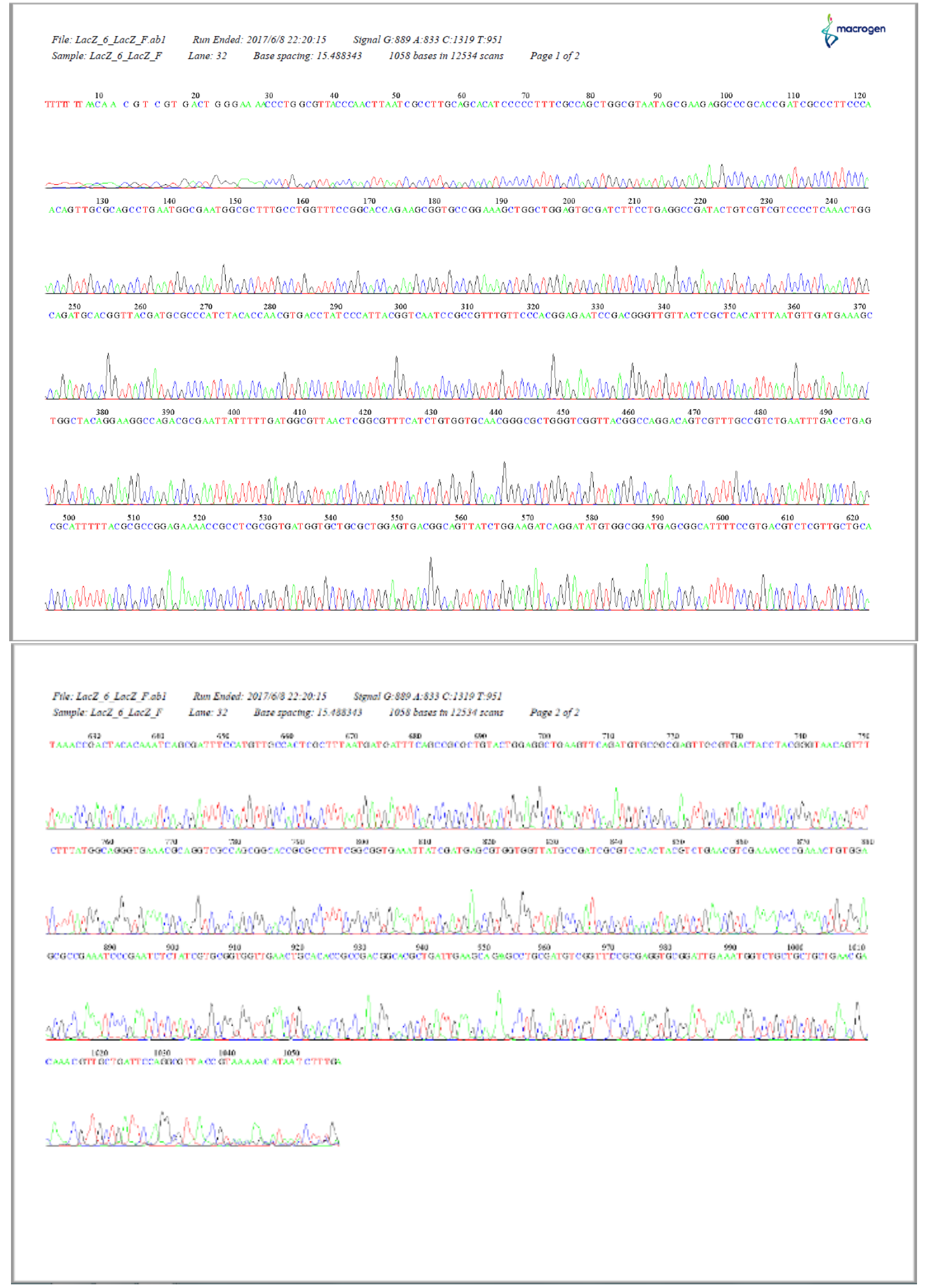




\section{lacZ insert, reverse sequence.}

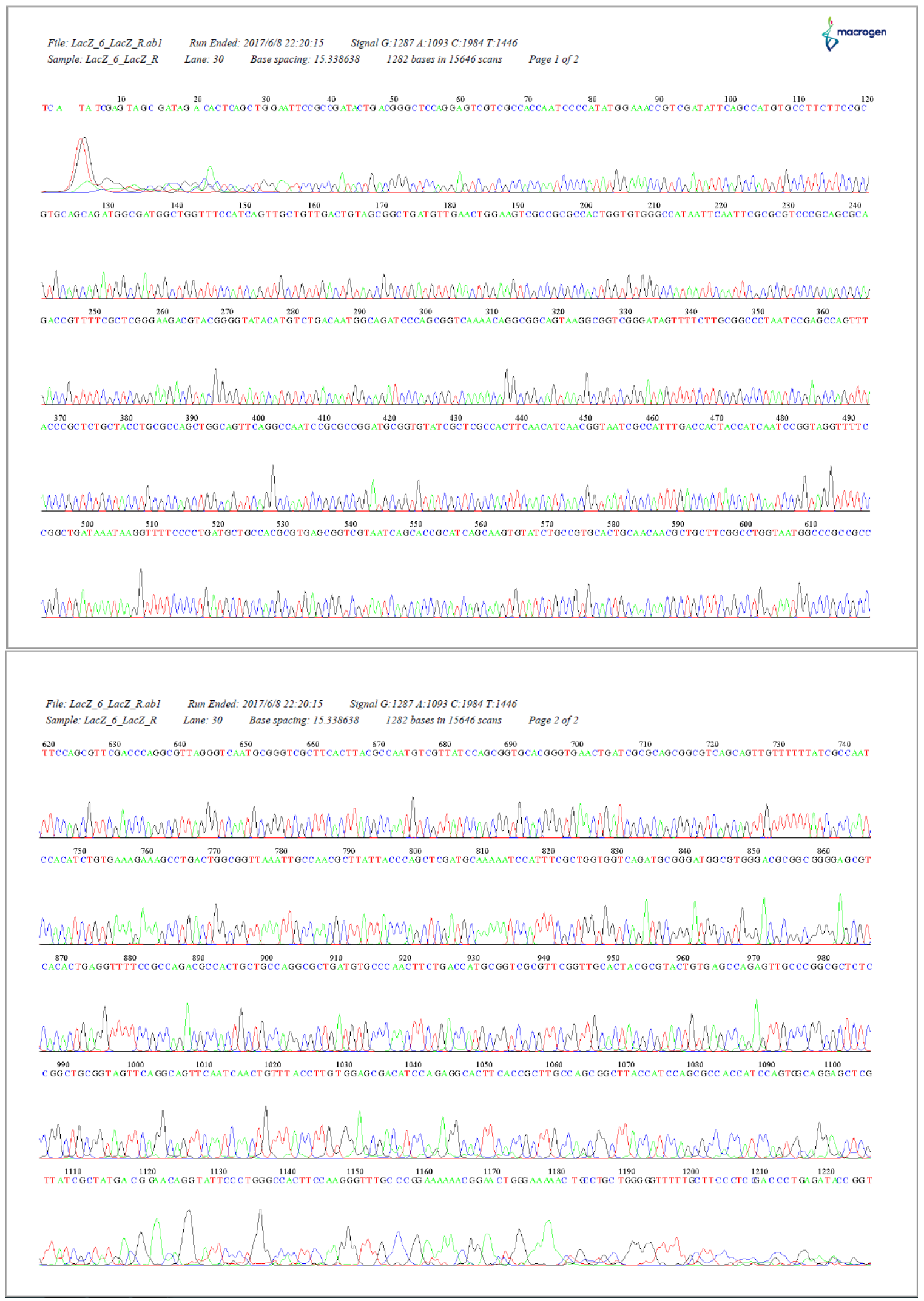


Appendix 4. codon-optimised CtrA sequence.

Bq_CtrA_codon optimised

GCGCATATGCGTGTATTGTTAATTGAAGACGACAAGGCTACCACGCAGTCGATCGA GCTGATGTTAAAGTCCGCAAACTTCAACGTCTACATCACTGATTTAGGCGAGGAAGG CGCCGATCTTGGGAAATTATATGATTATGACATTATTCTGCTTGACCTGAACTTGCCG GATATGTCTGGGTATGACGTTCTGCGCACGTTACGCTTGGCTAAAATTAAAACCCCT GTGCTGATCTTGAGCGGGATGAACGCTATCGAAGATAAAGTTCGTGGGTTTGGTTTT GGAGCCGACGATTACATGACTAAGCCATTTCACAAGGATGAGTTGATCGCTCGTATT CACGCGGTGGTTCGTCGTAGCAAAGGCCACGCTCAAAGCATCATTGTTACCGGCGA CCTTACAGTTAACTTAGACGCGAAGACAGTGGAGGTCGCTGGTCGTCCAGTGCACCT TACGAGTAAGGAATACCAAATGTTAGAGTTGCTGAGTTTACGCAAGGGGACTACGC TGACAAAAGAAATGTTTCTGAACCATCTGTACGGTGGTATGGACGAACCCGAACTTA AAATCATTGACGTTTTTATTTGTAAGTTACGCAAGAAACTGGAAGAAGTCAGTTCCT CTGCAAACTACATCGACACAGTGTGGGGCCGTGGTTACGTCCTTCGCGATCCAGTTG AAGAAAACGTGCGCAAGACAGCCTAAGGATCCGCG 